\title{
Phylogenetic relationships among atheriniform fishes (Teleostei: Atherinomorpha)
}

\author{
B.S. DYER
}

Fish Division, Museum of Zoology and Department of Biology, University of Michigan, Ann Arbor, Michigan 48109-1079, U.S.A.

AND

\section{B. GHERNOFF}

Department of Zoology, Field Museum of Natural History, Roosevelt Road at Lake Shore Drive, Chicago, Illinois 60605-2496, U.S.A.

We present evidence from adult and larval morphology for the monophyly and relationships of Atheriniformes, using other atherinomorphs, mugilids and acanthomorph fishes as outgroups. Atheriniformes is diagnosed by ten characters (larval: short preanal length, single mid-dorsal row of melanophores; adult: vomerine ventral face concave, long Al muscle tendon to lacrimal, two anterior infraorbital bones, pelvic-rib ligament, pelvic medial plate not extended to anterior end, and second dorsal-fin spine flexible). We recognize six families within the order, the hierarchical relationships among which are: (Atherinopsidae (Notocheiridae (Melanotaeniidae (Atherionidae (Phallostethidae, Atherinidae))))). Other major conclusions include: (l) Atherinopsidae (Menidiinae, Atherinopsinae) is diagnosed by 20 characters (e.g. ethmomaxillary ligament attached to palatine dorsal process, ventral postcleithrum with two dorsal rami); (2) Melanotaeniidae (Bedotiinae (Melanotaeniinae (Telmatherinini, Pseudomugilini)) is diagnosed by six characters (e.g. absence of second dorsal-fin spine, sexual dimorphism in body colour and median-fin development, greater body depth); (3) Dentatherina is in Phallostethidae; (4) Atherinidae (Atherinomorinae (Craterocephalinae, Atherininae)) is diagnosed by three characters (lacrimal notch, ventral postcleithrum between first and second pleural ribs, pelvic ventral spine); (5) Atherinidae and Phallostethidae form the Atherinoidea clade diagnosed by seven characters (e.g. interopercle dorsal process absent, dorsal wings of urohyal absent, ventral postcleithrum laminar, pelvic medial plate extended to anterior end, presence of anal plate). Bedotia, Rheocles, and melanotaeniines are shown to be derived within atheriniforms rather than the plesiomorphic sister groups to a paraphyletic 'atherinoid' group. We also demonstrate that groups traditionally placed in Atherinidae (Menidiinae, Atherininae, Atherioninae, etc.) comprise a paraphyletic assemblage.

01996 The Linnean Society of London

ADDITIONAL KEY WORDS: - Atheriniformes - phylogenetic relationships - classification morphology - Old World silversides - atherinidae - Atherinomorpha - multistate characters.

\section{CONTENTS}

Introduction . . . . . . . . . . . . . . . . . . . . . . . . . 2

History of relationships $\quad . \quad$. . . . . . . . . . . . . . . . . . . . . . . . . 2 


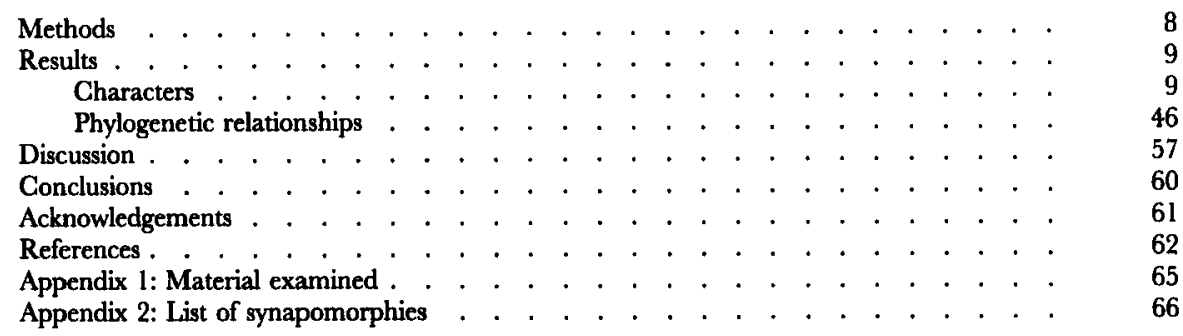

\section{INTRODUCTION}

Fishes of the order Atheriniformes are antipolar, mostly circumtropical in distribution, though present also in temperate regions of the New World. Atheriniforms are mostly surface dwellers, living in marine inshore, estuarine, or freshwater habitats; only a few species occupy offshore pelagic environments. Most marine species are silvery, usually small, and occur in large schools. Strictly freshwater groups occur in Australasia, Madagascar, and the Americas, and their species are more variable in size, colour, and shape. Atheriniforms are found in rivers and lakes of all types, from coastal lagoons to altitudes over $4000 \mathrm{~m}$. Atheriniforms are mostly elongate, with adult sizes ranging from $25 \mathrm{~mm}$ standard length (SL) to over $500 \mathrm{~mm}$ SL. Their coloration ranges from translucent to brightly-coloured, sexually-dimorphic body markings. Most species have a conspicuous silvery broad lateral stripe and are counter shaded over a silvery background.

The family composition of Atheriniformes varies significantly according to author, from two (Eschmeyer, 1990) to ten families (Saeed et al., 1994) depending on the taxa regarded as subfamilies of Atherinidae. Rosen \& Parenti (1981) standardized the nomenclature by recognizing six families together called Division I, a group they considered to be non-monophyletic. Eight families, 47 genera, and 285 species comprise the Atheriniformes according to Nelson (1994). Despite its recognition as a group since Jordan \& Hubbs' (1919) monograph, a list of features vaguely defining the group has marred previous attempts to establish relationships within the 'atherinoids'. In general, Atherinidae has been a group comprised of taxa lacking externally distinctive features of body shape, coloration, fin development, or copulatory organs that characterize other atheriniform groups. Atherinid taxa range from two subfamilies (12 genera; Saeed et al., 1994) to nine subfamilies (45 genera; Eschmeyer, 1990).

Our purpose is to investigate the phylogenetic relationships among atheriniform fishes. The outcome of this analysis is a taxonomy based on shared derived traits (synapomorphies). These groups are classified hierarchically as natural (monophyletic) taxa reflecting phylogenetic relationships. The taxonomic history relevant to our new conclusions is presented below.

\section{HISTORY OF RELATTONSHIPS}

A systematic study at this level of generality results in taxonomic rearrangements and nomenclatorial changes that need to be treated consistently throughout the paper. To avoid possible confusion between former and new usage, taxa will be 
named herein according to the nomenclatorial changes presented in Table 1, except when direct quotes are made.

History of the classification of atheriniform fishes is shown in Figure 1. Atheriniformes was created by Rosen (1964) for a group of fishes that included groups commonly known as halfbeaks, killifishes, and silversides and their allies. This assemblage was renamed Atherinomorpha in Greenwood et al. (1966) and later proposed as sister group to Percomorpha (Rosen, 1973). Rosen \& Parenti (1981) diagnosed Atherinomorpha more precisely as well as the sister-group relationship between Cyprinodontiformes (killifishes) and Beloniformes (halfbeaks, needlefishes, sauries, and flyingfishes), a group they named Division II (Fig. 2A), a group hereafter called Cyprinodontea. Rosen \& Parenti (1981) also removed adrianichthyoids (ricefishes and allies) from cyprinodontiforms and placed them in Beloniformes. Rosen \& Parenti (1981:13) also reviewed the long history of definitions for atheriniform fishes (see Fig. 1: Rosen, 1964) and concluded that "..... there has been a great deal of uncertainty about exactly what it takes to be an 'atherinoid' fish". Unable to diagnose atheriniforms, they named the assemblage of six families (Atherinidae, Bedotiidae, Isonidae, Melanotaeniidae, Telmatherinidae and Phallostethidae) Division I atherinomorphs (Fig. 1), and treated them as a paraphyletic outgroup of cyprinodontiforms plus beloniforms (Fig. 2A).

A detailed review and taxonomic history for Atherinomorpha was presented by Parenti (1993). Stiassny (1990) proposed that Mugilidae is the sister group to Atherinomorpha, based on pharyngeal jaw musculature and neural arch anatomy. An atheriniform - mugilid relationship was first postulated by Starks (1899) and later by Gosline (1962, 1963), but in the context of Percesoces. Stiassny's (1990) mugilid - atherinomorph hypothesis is supported with additional features in Stiassny (1993). Recently, Atherinomorpha was proposed as part of an enlarged Percomorpha when grouped together with mugilids, Elassoma, gasterosteiforms, and synbranchiforms into a group called Smegmamorpha by Johnson \& Patterson (1993).

In previous studies of atheriniform or atherinomorph fishes, bedotiines and melanotaeniines have been noted to share some 'percoid-like' features with 'generalized' acanthomorphs, such as morphology of the premaxilla and rostral cartilage, strong median and pelvic fin spines, the separation and underlying pterygiophore structure between the dorsal fins, and the placement of the pelvic fins Jordan \& Hubbs, 1919; Rosen, 1964; Rosen \& Parenti, 1981; Parenti, 1984, 1989, 1993; Chernoff, 1986; Stiassny, 1990). These taxa were, thus, assumed to be plesiomorphic atherinomorphs in comparison with other Division I 'atherinoids' and highly derived cyprinodontiforms and beloniforms. The concept of bedotiines and melanotaeniines as plesiomorphous atheriniforms was made explicit when Stiassny (1990: fig. 2) depicted them as sequential outgroups to the remaining atherinomorphs (Fig. 2B) based upon Rosen \& Parenti (1981) and Parenti (1984). Stiassny (1990:15) also suggested that "...Rheocles seems to exemplify the most generalized atherinomorph condition." In her analysis, the remaining atheriniforms were more closely related to Cyprinodontea than to bedotiines or melanotaeniines, i.e. atheriniforms comprised a paraphyletic group (Fig. 2B).

A different set of relationships is proposed by Saeed et al. (1994), in which atherinopsids plus notocheirids is the sister group to Atherines (Fig. 2C). This hypothesis also presents atheriniforms as a paraphyletic assemblage, with the Old 
TABLE 1. Sequenced classification of Atheriniformes. New taxonomic categories are highlighted in bold. Order of genera is alphabetical unless noted (*=included genera are phylogenetically sequenced).

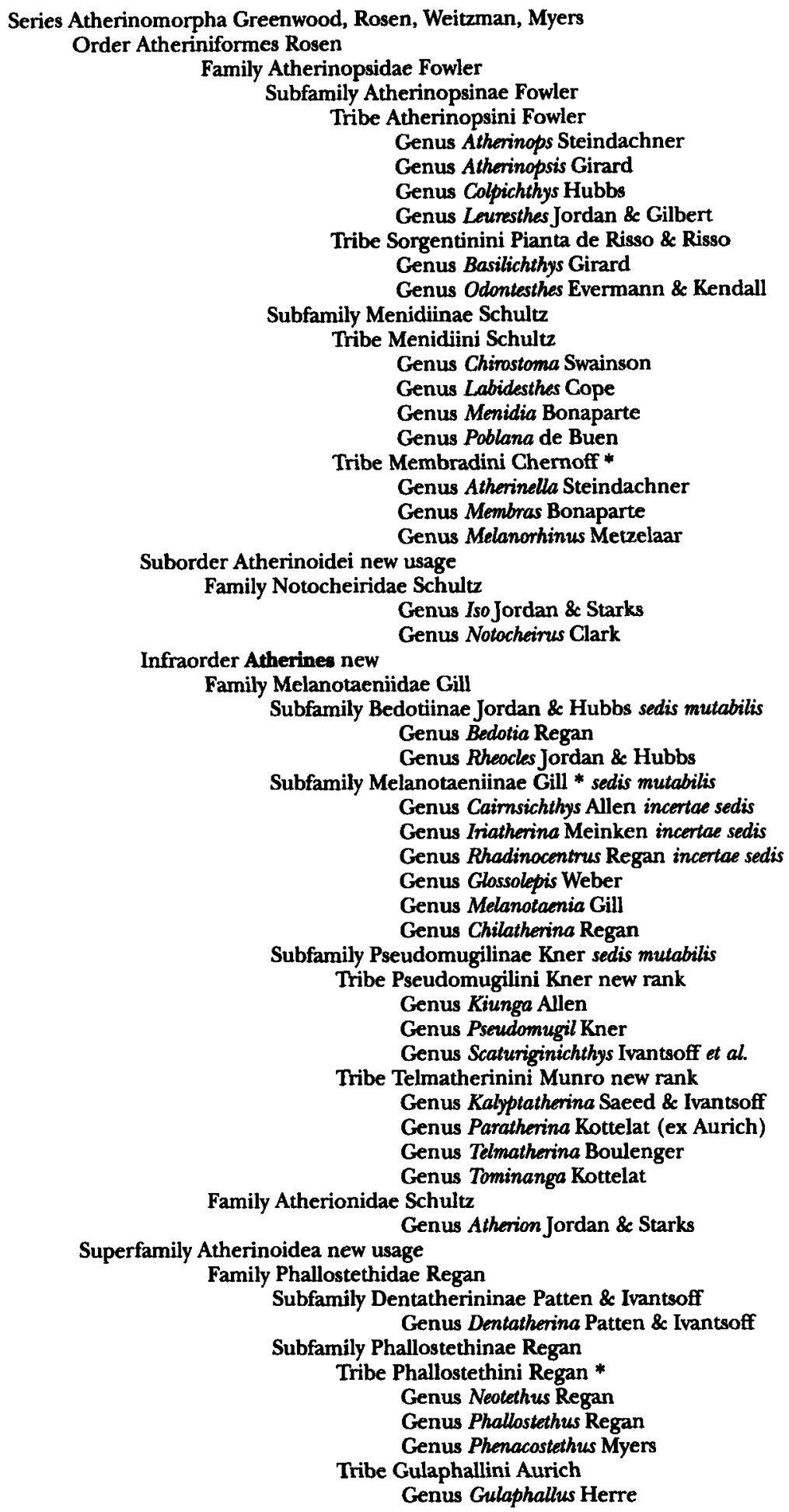

Subfamily Pseudomugilinae Kner sedis mutabilis

Tribe Pseudomugilini Kner new rank

Genus Kiunga Allen

Genus Pseudomugil Kner

Genus Scaturiginichthys Ivantsoff et al.

Tribe Telmatherinini Munro new rank Genus Kalyptatherina Saeed \& Ivantsoff

Genus Paratherina Kottelat (ex Aurich)

Family Atherionidae Schultz

Genus Telmatherina Boulenger

Genus Tominanga Kottelat

Superfamily Atherinoidea new usage

Genus Atherion Jordan \& Starks

Family Phallostethidae Regan

Subfamily Dentatherininae Patten \& Ivantsoff Genus Dentatherina Patten \& Ivantsoff

Subfamily Phallostethinae Regan

Tribe Phallostethini Regan*

Genus Neotethus Regan

Genus Phallostethus Regan

Genus Phenacostethus Myers

Tribe Gulaphallini Aurich

Genus Gulaphallus Herre 
TABLE 1. (continued)

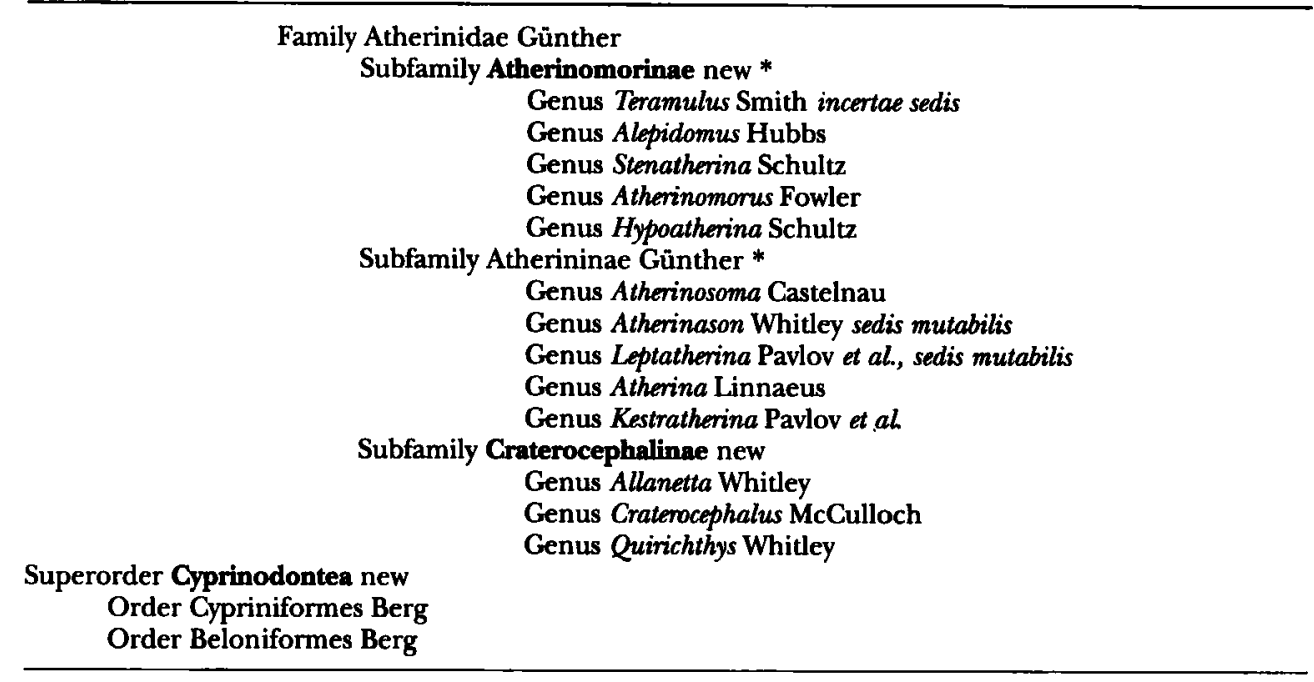

World atherinoideins more closely related to Cyprinodontea than to atherinopsids (Fig. 2C).

White, Lavenberg \& McGowen (1984) supported atheriniform monophyly with two larval features and proposed using the ordinal term Atheriniformes for Division I of Rosen \& Parenti (1981). These two larval features remain unchallenged as hypotheses of homology, despite the occurrence of these characters in other taxa as mentioned by White et al. (1984) and alternative, albeit less parsimonious, interpretations by Parenti (1993). Parenti (1984, 1989, 1993) could not confirm a monophyletic Atheriniformes and discussed possible conflicting evidence from adult morphology.

A number of systematic revisions of particular atheriniform groups have been published in the past decade. Atheriniforms have been traditionally regarded as containing New World and Old World assemblages. The phylogenetic interrelationships of New World silversides (sensu Chernoff, 1986), Atherinopsinae (White, 1985) and Menidiinae (Chernoff, 1986), were investigated and proposed as each others' closest relatives. These New World subfamilies were first proposed as sister groups in an unpublished study of atherinids and selected atheriniforms (Patten, 1978). Patten's results, though not cladistic, are similar to our phlyogenetic results.

Phylogenetic studies of Old World atheriniforms include Melanotaeniinae (Allen, 1980), Phallostethinae (Parenti, 1984, 1986, 1989), and Rheocles (Stiassny, 1990; Stiassny \& Reinthal, 1992). Relationships of two groups of freshwater atheriniforms from the Australia-New Guinea-Sulawesi region have been particularly controversial. Pseudomugilins have often been considered closely related to and hence classified within Melanotaeniiae (e.g. Jordan \& Hubbs, 1919; Schultz, 1948; Parenti, 1984; Nelson, 1984). Pseudomugil was proposed as sister group to other melanotaeniines by Allen (1980), but was later removed into its own family together with Kiunga (Saeed, Ivantsoff \& Allen, 1989). Telmatherina has been more problematic and classified within 'Melanotaeniidae' (e.g. Jordan \& Hubbs, 1919; Rosen, 1964), within 'Pseudomugilidae' (Eschmeyer, 1990; Saeed \& Ivantsoff, 1991), within Atherinidae exclusive of melanotaeniines and pseudomugilins (e.g. Nelson, 1984), or in its own 


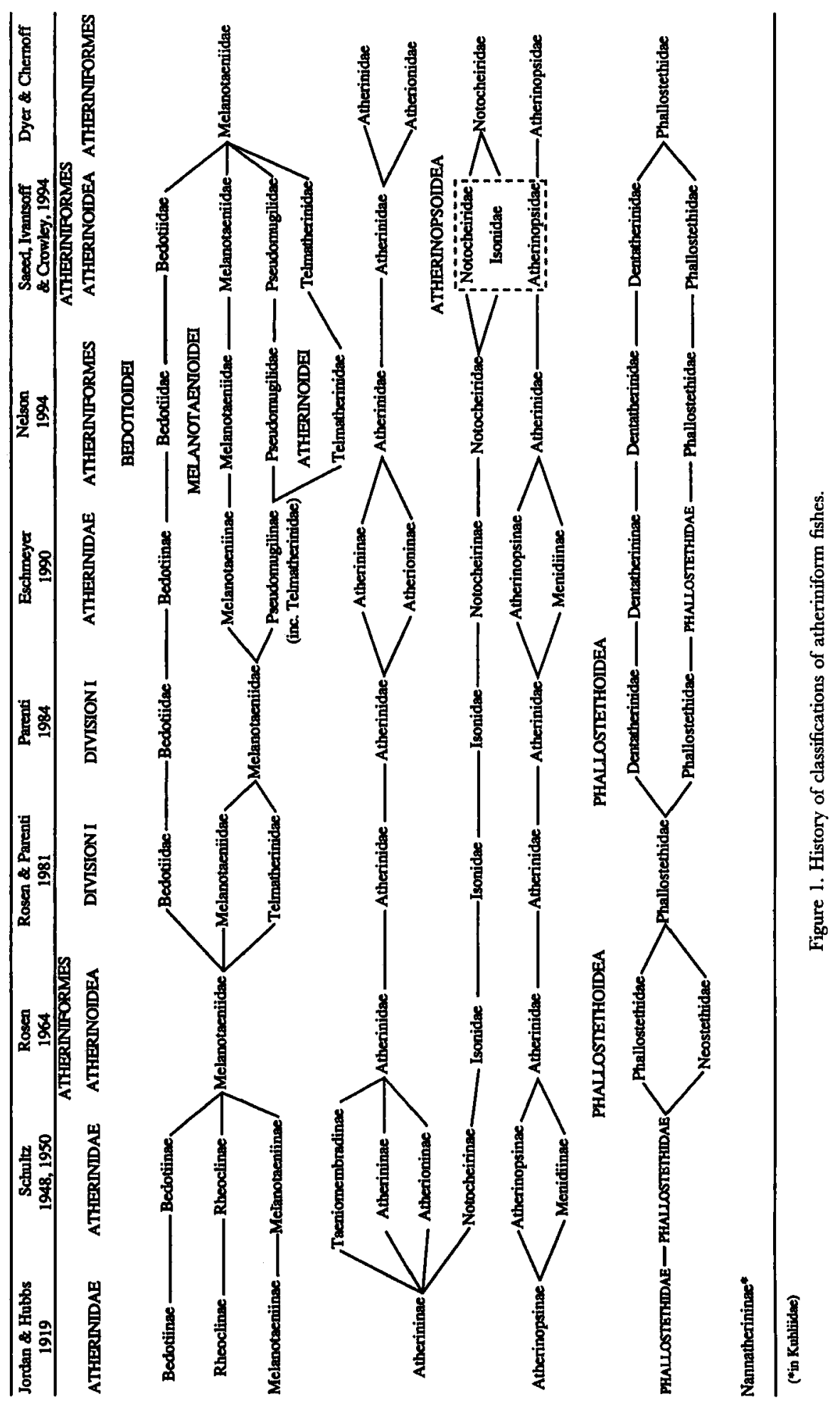


family (e.g. Munro, 1958, 1967; Rosen \& Parenti, 1981; Kottelat, 1990, 1991; Saeed \& Ivantsoff, 1991; Nelson, 1994).

Non-phylogenetic studies have significantly increased our knowledge of atheriniform morphology and species diversity, such as in Pseudomugilini (Saeed et al., 1989), Telmatherinini (Kottelat, 1990a, 1991), Notocheiridae (Said, 1983), and various genera and species of atherinids (Ivantsoff, 1978; Ivantsoff, Crowley \& Allen, 1987; Ivantsoff \& Kottelat, 1988; Pavlov et al., 1988; Crowley \& Ivantsoff, 1988, 1990 a,b,
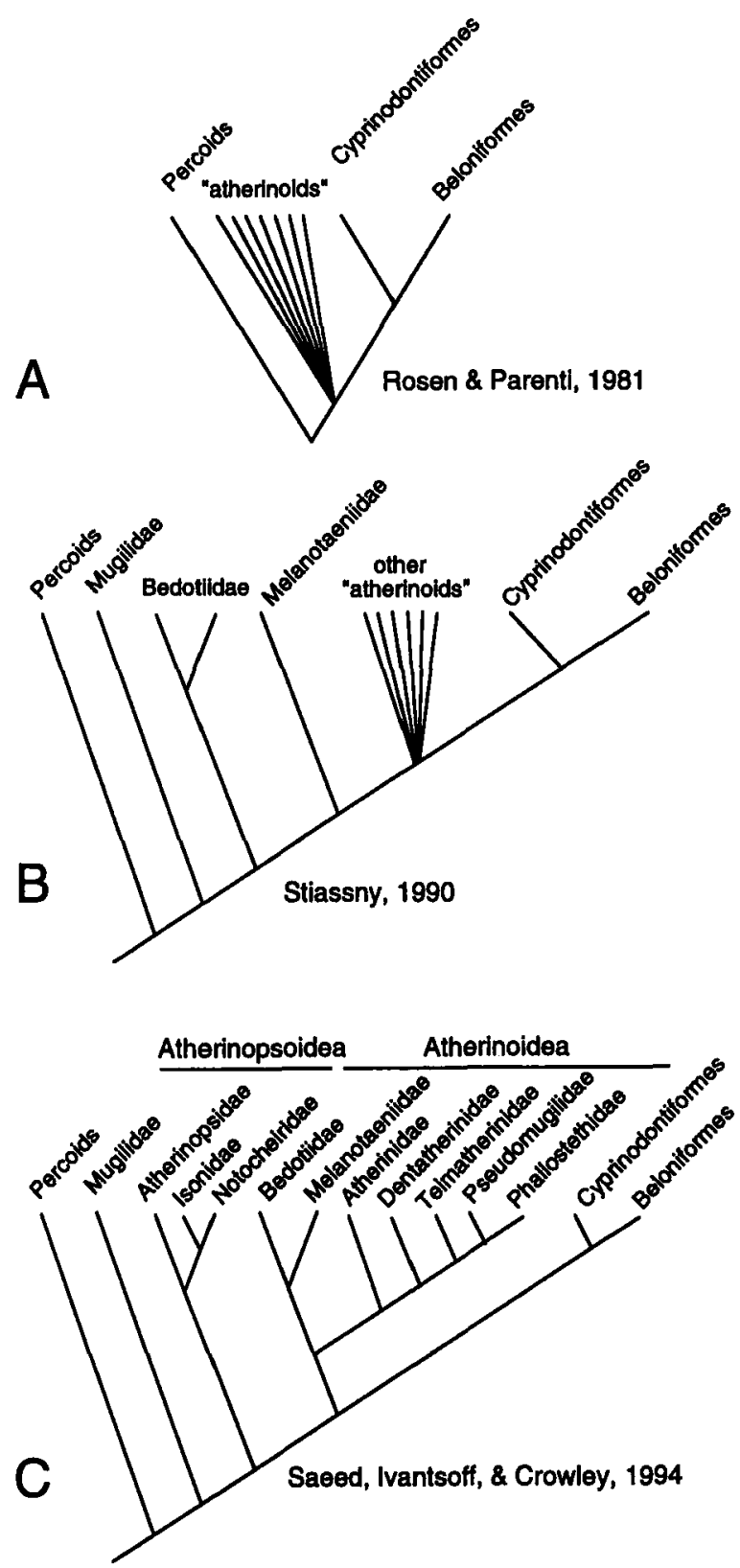

Figure 2. Interrelationships of atheriniform fishes; A, from Rosen \& Parenti (1981); B, Stiassny (1990); C, Saced $t$ al. (1994). 
1992; Crowley, 1990 a,b; Crowley, Ivantsoff \& Allen, 1991; Ivantsoff \& Crowley, 1991). Judgements about interrelationships in those studies, however, are phenetically based on unpolarized discrete characters or genetic distances.

Some controversy exists regarding the relationship of Dentatherina merceri Patten \& Ivantsoff (1983), which was first placed in a monotypic subfamily of Atherinidae (Fig. 1). Parenti (1984) proposed Dentatherina as sister to phallostethines and grouped these taxa in 'Phallostethoidea' (Fig. 1). Ivantsoff, Said \& Williams (1987) disputed the homologous nature of some characters used by Parenti (1984) based on histological evidence and morpho-functional arguments. Ivantsoff et al. (1987) also stressed that Dentatherina shared more characters with atherinids than with phallostethines. Parenti (1989:248) defended her claims of homology and capped the argument with "..., additional characters are needed to refute the proposal of a phallostethid Dentatherina sister group."

\section{METHODS}

Specimens dissected and examined in this study - listed in Appendix 1 - were either preserved in alcohol or cleared and stained for bone and cartilage following the technique of Taylor \& Van Dyke (1985). The dissection procedure of clearedand-stained specimens follows that of Weitzman (1974), except the branchial basket is removed prior to the suspensorium. Figures were all produced in a computer graphics program after originals were either drawn from a stereomicroscope with an attached camera lucida or scanned from an acknowledged source.

Characters were polarized by multiple-outgroup comparison (Farris, 1982; Clark \& Curran, 1986). Mugilidae and Cyprinodontea are considered as the minimum two taxa necessary for character polarization (Maddison, Donoghue \& Maddison, 1984). The selected atheriniform outgroups are species that represent major lineages within beloniforms, cyprinodontiforms, mugilids, percoids and percopsiforms (Appendix 1).

The information was compiled into a data matrix (Table 2) of 31 taxa and 83 characters. Each character is sequentially numbered in Table 2 based on its position on the body. The data were analysed cladistically using HENNIG86, version 1.5, of Farris (1988) and PAUP, version 3.1.1 (Swofford, 1993), with outgroup rooting and the exact search procedure. We coded all character states as integers, restricting the use of ' 0 ' for the plesiomorphic state, the '?' for missing data or for taxa with three or more states. We use '-' for non-applicable coding. Taxa that exhibit two states are coded with both states in Table 2. Characters 77, 80-83 represent a long list of traits extracted from the literature that are diagnostic of the taxa they support. Characters $77,80,81,82, \& 83$ were assigned a weight of five, four, five, six, and four, respectively, which represent the number of character states for which they are proxies. Distribution of characters on the cladogram(s) was analysed with PAUP version 3.1.1 (Swofford, 1993) and MacClade version 3.01 (Maddison \& Maddison, 1992), and with D3, version 2.1.0, of P.A. Buckup, for trees generated with HENNIG86 (Farris, 1988). Diagnostic features are listed in the legends of Figures 3-6 and a summary list of all characters is given in Appendix 2.

We analysed seven multistate characters (Chs, $2,3,18,59,64,66,68)$ as nonadditive, i.e. without a pre-determined transformation series, and 15 multistate characters (Chs 6, 7, 17, 22-24, 31, 33, 37, 40, 47, 48, 54, 60, 71) as additive. These 
15 multistate characters were ordered considering the derived states as nested within the more plesiomorphic states (Lipscomb, 1992:51). An additive multistate character is an internested set of synapomorphies, such that the derived state is inclusive of the plesiomorphic state(s) and it reflects exactly the information in additive binary coding. Hence, the criterion of inclusiveness used for ordering multistate characters is equivalent to ordering multistate characters for the ontogenetic method, i.e. the more derived states must also exhibit the less derived traits.

Characters and their states that uniquely or unambiguously support a particular node in all equally parsimonious trees are considered as diagnostic at that level of generality. These derived features only are considered as diagnostic of the clades they support, even if the characters are reversed or independently evolved in other groups. Characters described are only those traits that are phlyogenetically informative or that require some degree of discussion because of their historical importance in the taxonomy of the group.

\section{RESULTS}

Three equally most parsimonious trees were found (Length $=288$ steps, $\mathrm{CI}=0.55, \mathrm{RI}=0.79$ ). All trees share the same fully resolved topology of interrelations among major atheriniform taxa as depicted in Figure 3. Although some relationships among several genera of atherinines remain equivocal (Fig. 4), relationships among melanotaeniids (Fig. 5) and phallostethids (Fig. 6) are fully resolved.

We recognize six families and 49 genera within Atheriniformes (Table 1). The classification proposed in Table 1 is designed to fully reflect the interrelationships among taxa in Figures 3-6 and minimize, in a generally acceptable manner, the number of new categories.

\section{Characters}

The characters are grouped into traditional anatomical units, and ordered within these groups from anterior to posterior, dorsal to ventral. This ordering provides the numerical sequence for the characters given in Table 2. The citations that follow most character headings indicate the original source or pertinent discussion for that character. The relatively primitive and derived states, their distribution and variability across taxa are described for each character. At the end of each character description, in parenthesis, is the description of character states as coded in the data matrix, and the consistency and retention indices (CI, RI) for that character. When both indices have equal values only one figure is shown. Characters analysed as nonadditive are denoted with ' $n$-add'.

\section{Neurocranium and associated sensory canal bones}

1. Vomer ventral face curvature. The lateral condyles of the vomer are level with the median ventral line in outgroups and the ventral face of the vomer is flat. In all atheriniforms examined, the vomer is arched ventrally such that the lateral condyles are ventral relative to the median ventral line. This ventral arch of the vomer results 


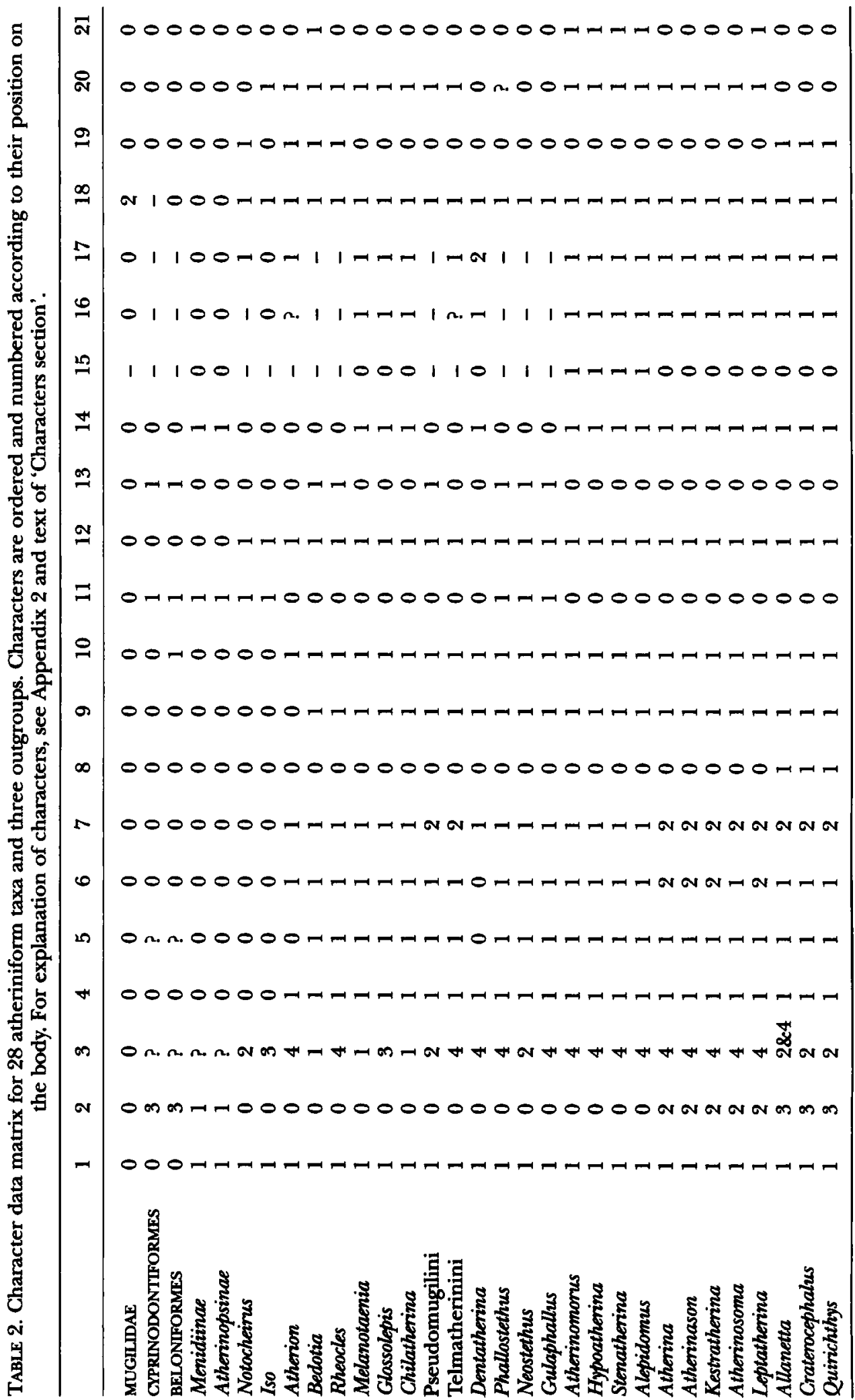




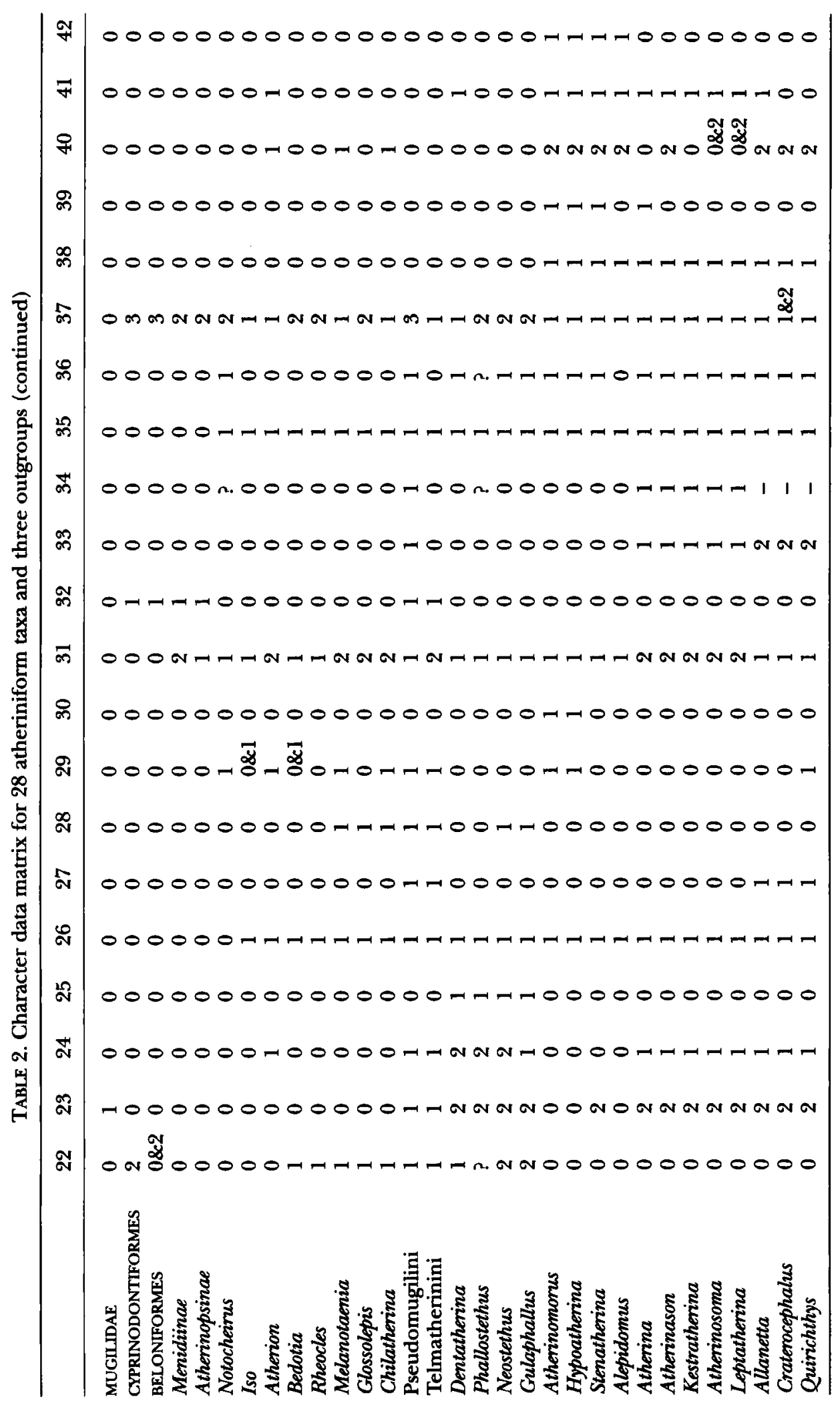




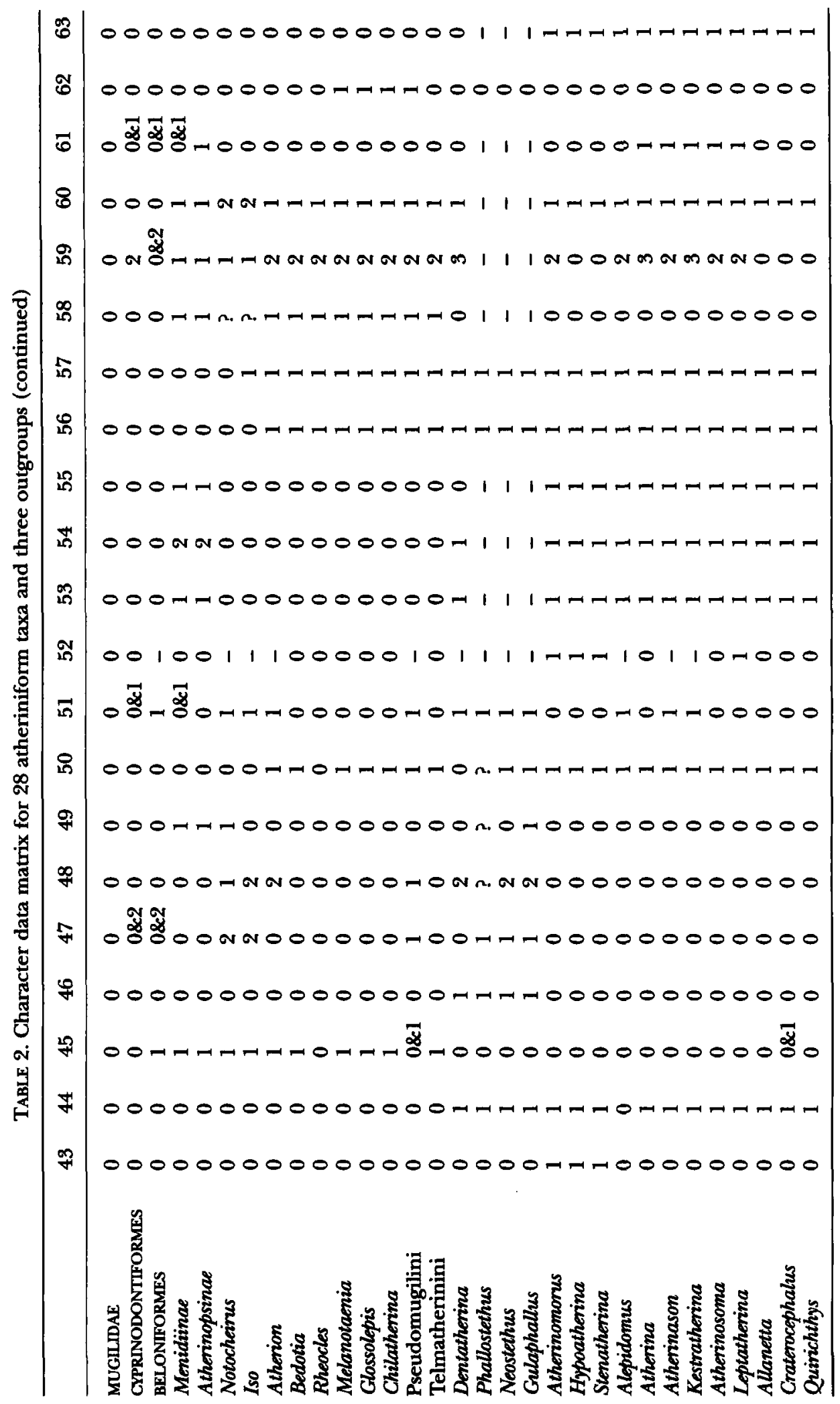


$\infty 0000000000000000-10000000000000$ வ $000-100000000000000000000000000$

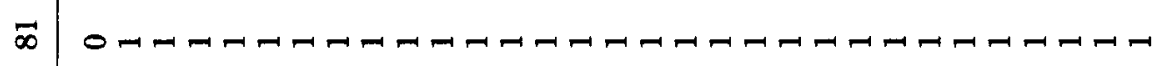
$\$ 00000-1000000000000000000000000$ R

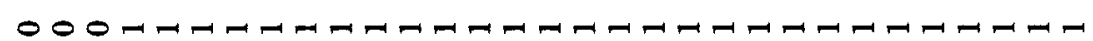

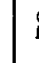

I $0000000000000000-1-1000000000000$ (1)

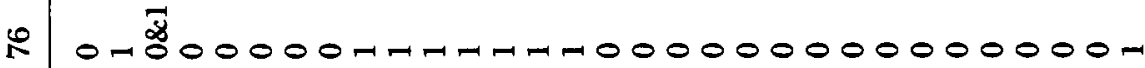

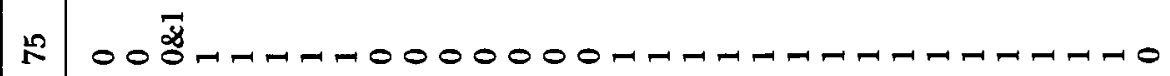
I $00 \stackrel{\overline{8}}{\bar{\theta}}$

m $000000000000000-\pi-1000000000000$ N $00000-0-00000000000000000000000$

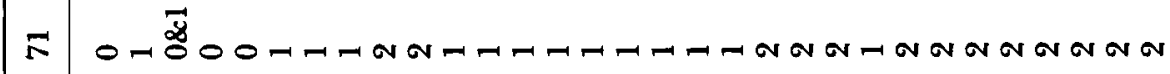
이임 $000000000000 \pi-00000-00000000$ $8000-1000 n-H A-1-0000000000000000$

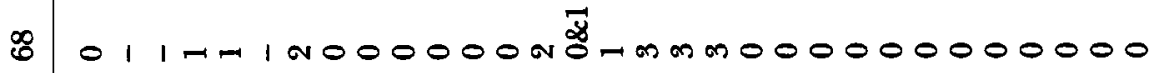
\$ O-m00000m-1000000000000000000000

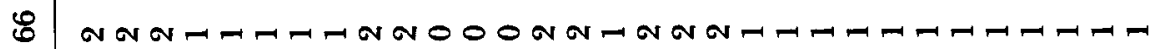

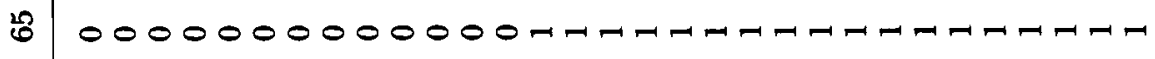

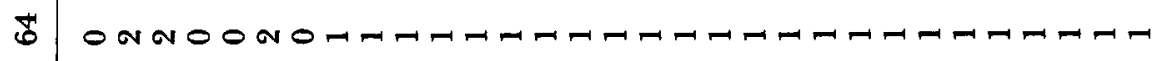
| 


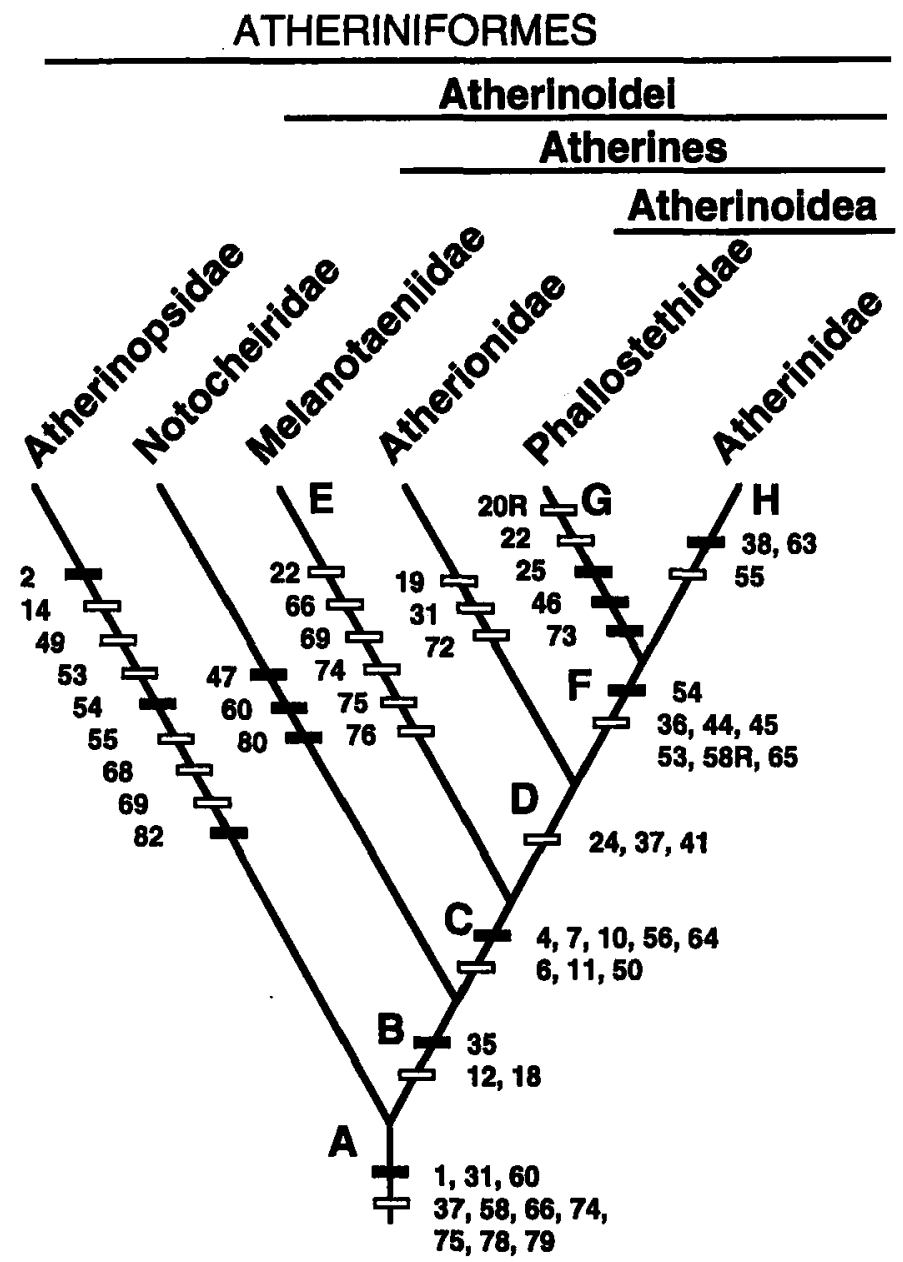

Figure 3. Interrelationships of atherininiform taxa. Diagnostic characters are unambiguously derived at that node. Unique characters are indicated opposite black bars and homoplasious characters are opposite white bars. Characters are numbered according to their location on body as in Table 2. The statistics for the tree including all taxa shown in Figs 3-5 are: length $=288$, the consistency index $=0.55$, and the retention index $=0.79 . A$, Atheriniformes: Ch. 1: ventral face of vomer concave; Ch. 31: Al lacrimal tendon long to sub-nasal shelf; Ch. 37: two anterior infraorbital bones; Ch. 58: pelvic medial plate not extended to anterior tip; Ch. 60: pelvic-rib ligament present; Ch. 66: second-dorsal fin spine flexible; Ch. 74: body depth less than 20\% SL; Ch. 75: lateral band present; Ch. 78: larval pigmentation pattern; Ch. 79: larval preanal length. Atherinopsidae. Ch. 2; ethmomaxillary ligament attached to palatine dorsal process; Ch. 14: posttemporal canal present; $\mathrm{Ch}$. 49: pectoral-fin spur absent; Ch. 53: ventral postcleithrum laminar; $\mathrm{Ch}$. 54: ventral postcleithrum with two dorsal rami; $\mathrm{Ch}$. 55: ventral postcleithrum between first and second pleural ribs; $\mathrm{Ch}$. 68 : interdorsals without ventral shaft; $\mathrm{Ch}$. 69: $\geq 3$ pleural ribs posterior to first anal pterygiophore; Ch. 82: premaxillae, oral ligaments, sphenotic process, etc. $B$, Atherinoidei: Ch. 12: epioccipital wings absent; Ch. 18: basisphenoid articulated with prootic only; Ch. 35: palatine dorsal process absent. Notocheiridae. Ch. 47: supracleithrum absent; $C h$. 60: pelvic-rib ligament elongated; $C h$. 80: pectoral and pelvic girdles, abdominal keel, etc. $C$, Atherines: Ch. 4: rostrum depression; Ch. 6: nasal bone in orbit rim; Ch. 7: nasal ventromedial ligament to lateral ethmoid; Ch. 10: parietals absent; $\mathrm{Ch}$. 11 : intercalars present; $\mathrm{Ch}$. 50: distal radials of pectoral girdle ossified; Ch. 56: scapular foramen shared with coracoid; Ch. 64: posterior basal pterygiophore of anal and second dorsal fins cartilaginous or ossified with medial plate. E, Melanotaeniidae. Ch. 22: posterior myodome restricted to prootic; Ch. 66: absence of second dorsal-fin spine; Ch. 69: $\geq 3$ pleural ribs posterior to first anal pterygiophore; Ch. 74: body depth greater than 20\% SL; Ch. 75: lateral band reduced or absent; Ch. 76: sexual dimorphism in body coloration and median fin development. $D$, Atherionidae-Atherinoidea clade: Ch. 24: hyalinecartilage submaxially meniscus; $\mathrm{Ch}$. 37; three anterior infraorbital bones: $\mathrm{Ch}$. 41 : posterodorsal border of opercle above articulation axis of suspensorium. Atherionidae: $\mathrm{Ch}$. 19: parasphenoid ventral ridge extended posteriorly; $\mathrm{Ch}$. 31: Al mandibular tendon present; Ch. 72: presence of odontodes. $F$, Atherinoidea: $C h$. 36: palatine ventral process absent; Ch. 44: absence of interopercle dorsal process; Ch. 45: absence of urohyal posterodorsal processes; Ch. 53: ventral postcleithrum laminar; Ch. 54: ventral postcleithrum with dorsal ramus; Ch. 58: pelvic medial plate extended 
in a concave ventral face in transverse section (Fig. 7$).(0=$ vomer ventral face flat; $1=$ vomer ventral face concave; 1.00 )

2. Ethmomaxillary ligament (Patten, 1978; Chernoff, 1986). The plesiomorphic atherinomorph condition found in Atherinoidei and aplocheiloids (except Epiplatys) is that of a thick ligament attached anteriorly to the dorsal process of the maxillary head and posteroventrally to the medial part of the ethmoid region. The posterior

ATHERINIDAE

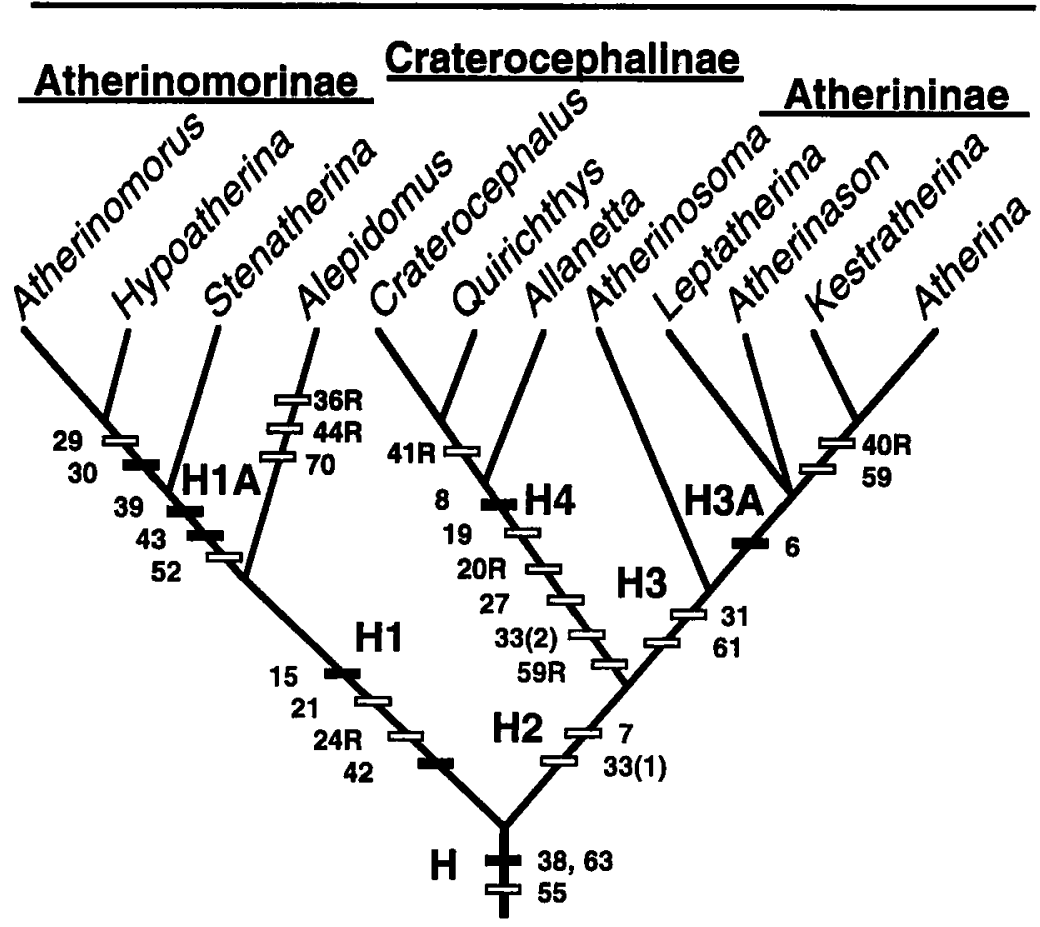

Figure 4. Interrelationships of atherinid genera. See Figure 3 for explanation of characters and tree statistics. $(-)=$ minus $(+)=$ plus. $H$, Atherinidae: Ch. 38: lacrimal notch; Ch. 55: ventral postcleithrum between first and second pleural ribs; Ch. 63: pelvic ventral spine present. H1, Atherinomorinae: $\mathrm{Ch}$. 15: posttemporal sensory canal oriented along dorsal arm of posttemporal; Ch. 21: parasphenoid fossa with ventral fenestra; Ch. 24: fibrocartilage submaxillary meniscus; Ch. 42: hyomandibular foramen present. Alepidomus: Ch. 36: palatine ventral process present; Ch. 44 dorsal process of interopercle present; $\mathrm{Ch}$. 70: ossified PU2vt. HIA, Atherinomorinae ( - ) Alepidomus clade: Ch. 39: infraorbital two with notch in sensory canal; Ch. 43: preopercular notch of sensory canal present; Ch. 52: dorsal postcleithrum elongated. Atherinomorus (+) Hypoatherina: Ch. 29: teeth on external surface of premaxilla; $\mathrm{Ch}$. 30: villiform patch of teeth on jaws. H2, Atherininae-Cratercephalinae clade: Ch. 7: nasal ventromedial ligament to palatine; Ch. 33: palatine anterior process directed dorsally. H3, Atherininae: Ch. 31: Al mandibular tendon present; Ch. 61: pelvic process attached to pleural rib six to eight. $H 3 A$, Atherininae $(-)$ Atherinosoma clade. Ch. 6: nasal not in orbit rim, middle as narrow as posterior border. Atherina (+) Kestratherina: Ch. 40: preopercularanterior infraorbital connection absent; Ch. 59: pelvic dorsolateral process oriented posterodorsally. $H 4$. Craterocephalinae: Ch. 8: nasal ventromedial process present; Ch. 19: parasphenoid ventral ridge extended posteriorly; Ch. 20: parasphenoid fossa absent; Ch. 27: maxillary shaft wide proximally; Ch. 33: palatine anterior process and ligament absent; Ch. 59: pelvic dorsolateral process absent. Craterocephalus $(+)$ Quirichthys: Ch. 41: posterodorsal border of opercle below articulation axis of suspensorium with neurocranium.

to anterior end; Ch. 65: anal plate present. G, Phallostethidae: Ch. 20: parasphenoid fossa absent; Ch. 22: posterior myodome restricted to prootic; Ch. 25: paradentary cartilage present; Ch. 46: uncinate process of first epibranchial absent; Ch. 73: small sized adults ( $\leq 40 \mathrm{~mm} \mathrm{SL}$ ). $H$, Atherinidae $\mathrm{Ch}$. 38: lacrimal notch present; Ch. 55: ventral postcleithrum between first and second pleural ribs; Ch. 63: pelvic ventral spine present. 
portion of the ligament attaches either to the mesethmoid, lateral ethmoid, or ethmoid cartilage (Fig 8; Patten \& Ivantsoff, 1983: fig. 5; Saeed et al., 1989: fig. 6A; Stiassny, 1990: fig. 22). A derived condition found in Atherinopsidae is for this ligament to be attached to a dorsal process of the palatine (Fig 8A; Patten, 1978; White, 1985; Chernoff, 1986); this condition is also present and postulated to be independently derived in Percopsis.

The ethmomaxillary ligament is absent in cyprinodontoids and beloniforms, and independently so in the bedotiine species Rheocles sikorae (Sauvage) and $R$. wrightae

\section{MELANOTAENIIDAE}

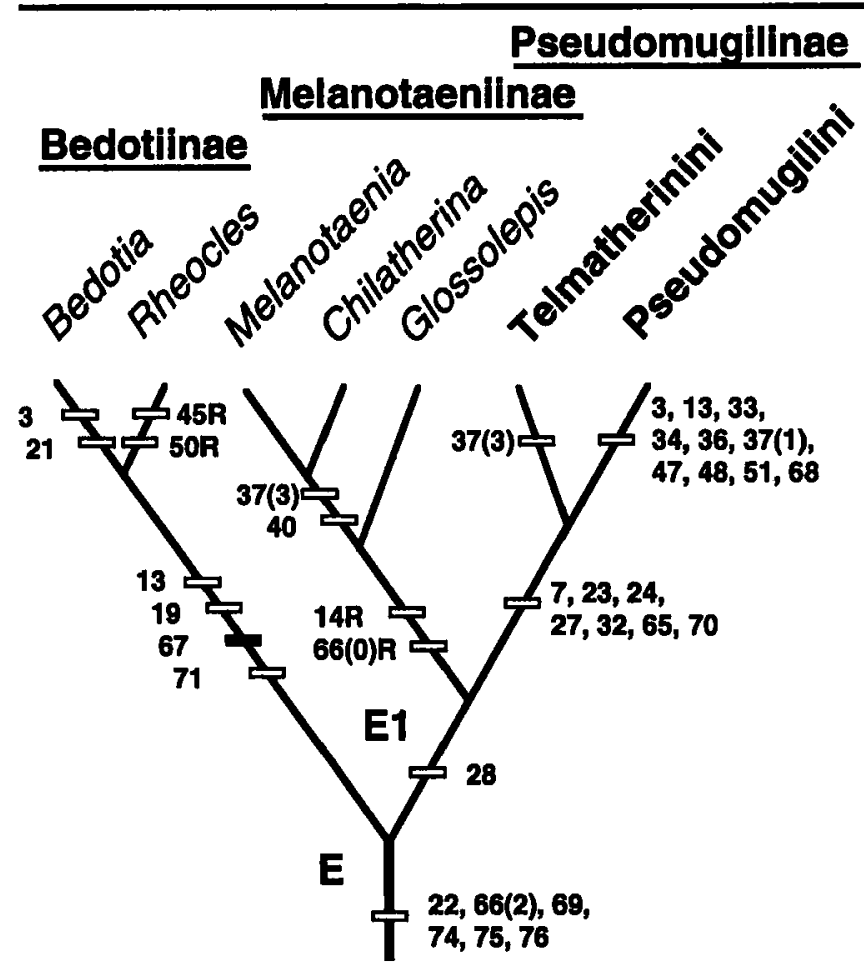

Figure 5. Interrelationships of melanotaeniid taxa. See Figure 3 for explanation of character numbers and tree statistics. $(-)=$ minus; $(+)=$ plus. $E$, Melanotaeniidac. Ch. 22: posterior myodome restricted to prootic; Ch. 66: absence of second dorsal-fin spine; Ch. 69: $\geq 3$ pleural ribs posterior to first anal pterygiophore; Ch. 74: body depth greater than $20 \% \mathrm{SL}$; Ch. 75: lateral band reduced or absent; Ch. 76: sexual dimorphism in body coloration and median fin development. Bedotïnae: Ch. 13: pterotic canal absent; Ch. 19: parasphenoid ventral ridge extended posteriorly; Ch. 67: anal-fin spine absent; Ch. 71: mandibular sensory canal enclosed. Bedotia: Ch. 3: mesethmoid in contact with all bones; Ch. 21: parasphenoid fossa with ventral fenestra. Rheocles: Ch. 45: absence of urohyal posterodorsal processes; Ch. 50: distal radials of pectoral girdle cartilaginous. E1, Melanotaeniinae-Pserudomugilinae clade: Ch. 28: distal premaxillary teeth enlarged. Melanotaeniznae. Ch. 14: posttemporal canal present; Ch. 66: second dorsal-fin spine strong. Melanotaenia (+) Chilatherina: Ch. 37: three anterior infraorbitals; Ch. 40 preopercularanterior infraorbital canals connected, semi-continuous. Pseudomugilinae. Ch. 7: nasal ventromedial ligament attached to palatine; Ch. 23: enlarged submaxillary meniscus; Ch. 24: submaxillary meniscus with hyaline-cartilage core; $\mathrm{Ch}$. 27: maxillary shaft wide proximally; $\mathrm{Ch} .32: \mathrm{Al}$ maxillary tendon to distal half of maxilla; Ch. 65: anal plate present: Ch. 70: ossified PU2vt cartilage. Pseudomugilini: Ch. 3: mesethmoid absent; Ch. 13; pterotic canal absent; Ch. 33: anterior palatine process directed dorsally; $\mathrm{Ch}$. 34: anterior palatine ligament to nasal bone; Ch. 36: palatine ventral process reduced or absent; Ch. 37: one anterior infraorbital bone (lacrimal); Ch. 47: supracleithrum disk-like; Ch. 48: cleithrum dorsal enclosure reduced; Ch. 5l: dorsal postcleithrum absent; Ch. 68: interdorsals absent. Telmatherinini: Ch. 37: three anterior infraorbitals. 
Stiassny (Stiassny, 1990; Stiassny \& Reinthal, 1992), and in craterocephalines. In Notocheirus the ethmomaxillary ligament is extremely short, the derived maxilla is very close to the ethmoid block and with limited movement. In atherinines, a uniquely long and thin ligament extends to the posterodorsal region of the lateral ethmoid (Fig. 8D). $(0=$ ethmomaxillary ligament thick with direct attachment to midethmoid region, $1=$ ligament with palatine attachment, $2=$ thin ligament to posterodorsal region of lateral ethmoid, 3 = ligament absent; $0.75,0.89$; n-add)

3. Mesethmoid Rosen and Parenti (1981:20) used a "dermal and endochrondral disklike ethmoid ossification" to diagnose Atherinomorpha. The size of the mesethmoid, its shape, composition, and which bones it contacts is quite variable within atherinomorphs (Parenti, 1981; Tigano \& Parenti, 1988; Chernoff, 1986). In Cyprinodontea, it is either absent, disk-like and contacts all bones of the ethmoid region, contacts only the lateral ethmoids and frontals, or is isolated. In Atherinopsidae the mesethmoid is either absent (De la Hoz \& Vial, 1988: fig. 2), somewhat circular and isolated (De la Hoz \& Tosti-Croce, 1981: figs 2, 4), contacts only the frontals and vomer (Fig. 8A; Starks, 1899: pl. I.2), or contacts the vomer

\section{PHALLOSTETHIDAE}

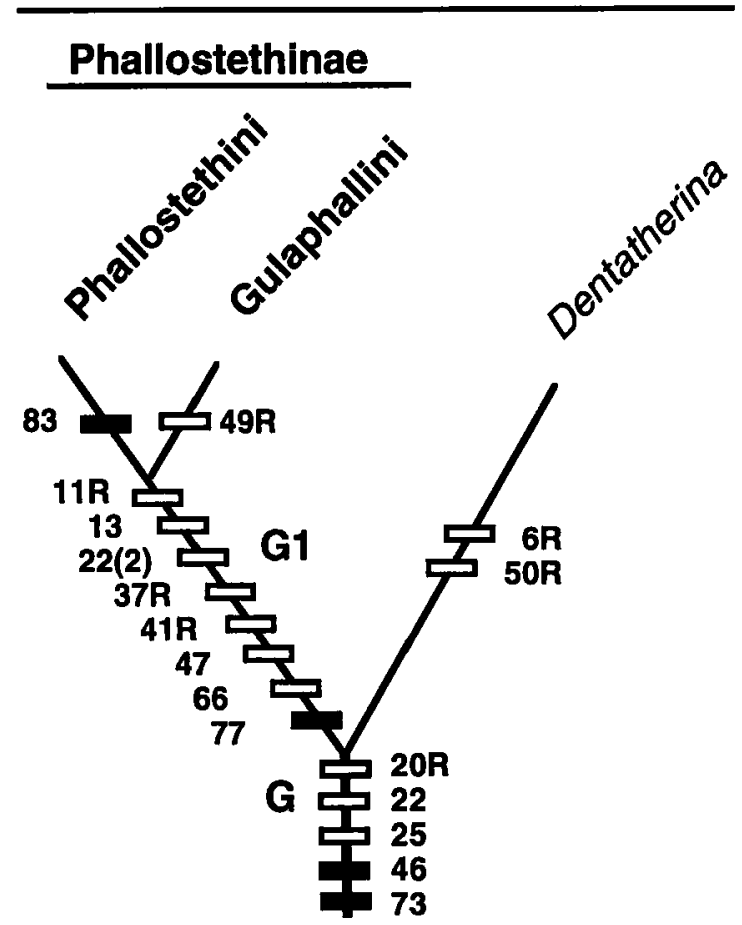

Figure 6. Interrelationships of phallostethid taxa. See Figure 3 for explanation of listed characters and tree statistics. G, Phallostethidae: Ch. 20: parasphenoid fossa absent; Ch. 22: posterior myodome restricted to prootic; Ch. 25: paradentary cartilage present; Ch. 46: uncinate process of first epibranchial absent; Ch. 73: small sized adults ( $\leq 40 \mathrm{~mm} \mathrm{SL}$ ). Dentatherina: Ch. 6: posterior end of nasal narrower than middle; $\mathrm{Ch}$. 50: pectoral distal radials cartilaginous. G1, Phallostethinae Ch. 11: intercalar absent; Ch. 13: pterotic canal absent; Ch. 22: posterior myodome absent; Ch. 37: two anterior infraorbitals; Ch. 41: posterodorsal border of opercle below articulation axis of suspensorium; Ch. 47: supracleithrum disk-like; Ch. 66: second dorsal-fin spine absent; Ch. 77: priapium. Phallostethini: Ch. 83: priapial characters (Parenti, 1989). Gulaphallini: Ch. 49: pectoral-fin spur absent. 

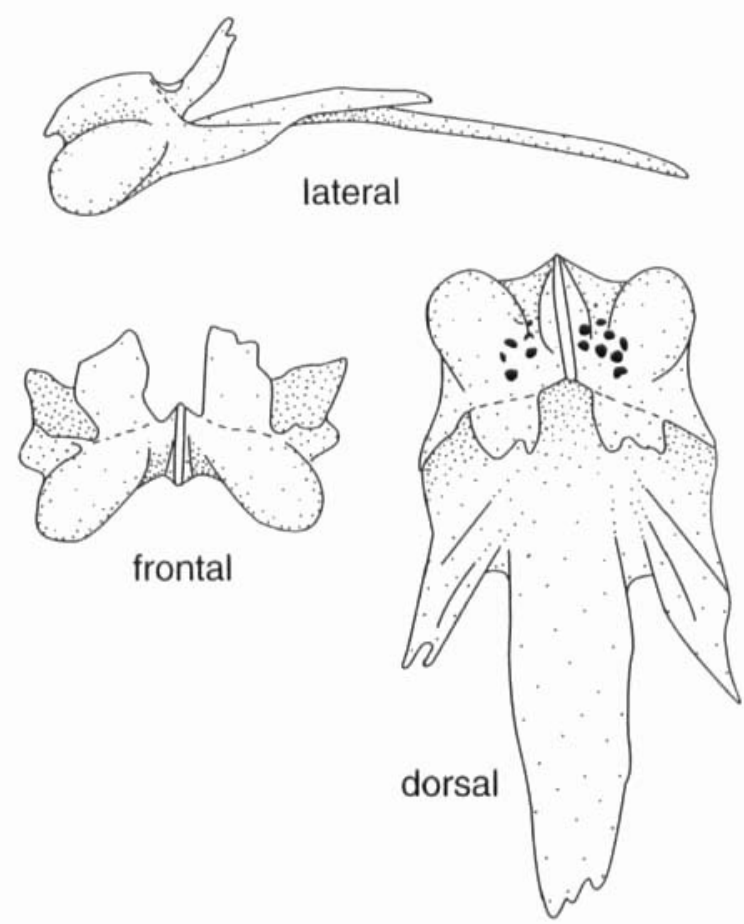

Figure 7. Vomer of Atherinops affinis (UMMZ uncat) in frontal, lateral, and dorsal view.

only (Chernoff, 1986). The plesiomorphic condition for Atherinformes cannot be hypothesized unambiguously in this analysis because many states are present in Gyprinodontea and Atherinopsidae. A sub-circular, isolated mesethmoid (Fig. 8B, D) appears to be a widespread condition within atheriniforms. The mesethmoid is absent in Notocheinus (Rosen, 1964), pseudomugilins (Saeed et al., 1989), Neostethus, and in most craterocephalines. The mesethmoid is variably present in Allanetta mugiloides McCulloch and Craterocephalus marjoriae Whitley (Crowley, 1990a: appendix 2; Crowley \& Ivantsoff, 1992). The mesethmoid is ossified in our specimens of Allanetta which, according to Patten (1978), was present in about $50 \%$ of his specimens. The mesethmoid is in contact with frontals and lateral ethmoids in Bedotia and melanotaeniines (Fig. 8C), and is in contact with the frontal only in Iso (Fig. 8E). $(0=$ mesethmoid in contact with all bones, $1=$ mesethmoid in contact with lateral ethmoids and frontals, $2=$ mesethmoid absent, $3=$ mesethmoid in contact with frontal only, $4=$ mesethmoid disk-like and isolated, ? = polymorphic; $0.50,0.38$; n-add)

4. Rostral fossa or depression (Patten, 1978). The plesiomorphic condition in atheriniforms is for the ethmoid cartilage to be thickest medially, sloping down to thinner anterior and lateral regions. The ethmoid region of Atherines (Fig. 3: Node $\mathrm{C}$ ) has a median depression, forming a concavity in frontal view in relation to the anterior processes of the lateral ethmoids (Fig. 11). Saeed et al. (1994) refer to this feature as absence of nasal septum. The posterior extension of this depression is variable and may be associated with the length of the ascending processes of the premaxillae. Externally, this depression or fossa is noticeable between the medial borders of the 
nasals. $(0=$ ethmoid cartilage convex medially, $1=$ ethmoid cartilage concave medially; 1.00)

5. Nasal bone and posterior naris (Patten, 1978). The plesiomorphic condition for atherinomorphs is a dorsally directed opening of the posterior naris and a convex posterolateral border of the nasal bone. Atherinopsids, notocheirids, and Atherion (Fig. 8A, E, B, respectively) have a concavity in the posterolateral border of the nasal bone opposite the posterior naris (White, 1985: fig. 6; De la Hoz \& Tosti-Croce, 1981: fig. 2). The posterolateral concavity of Atherion is in the form of a lateral notch (Fig 8B) because of a widening of the posterior border (see Ch. 6). The nasal bone of atherinids, phallostethines, and melanotaeniids is derived in that it is roughly triangular in dorsal view, the posterior naris is displaced to a lateral opening, and the lateral border is relatively straight (Fig. 8C). The nasal of Dentatherina (Patten \& Ivantsoff, 1983: fig. 5) is apparently reversed to the relatively plesiomorphic condition, similar to that in atherinopsids. $(0=$ posterolateral border of nasal bone

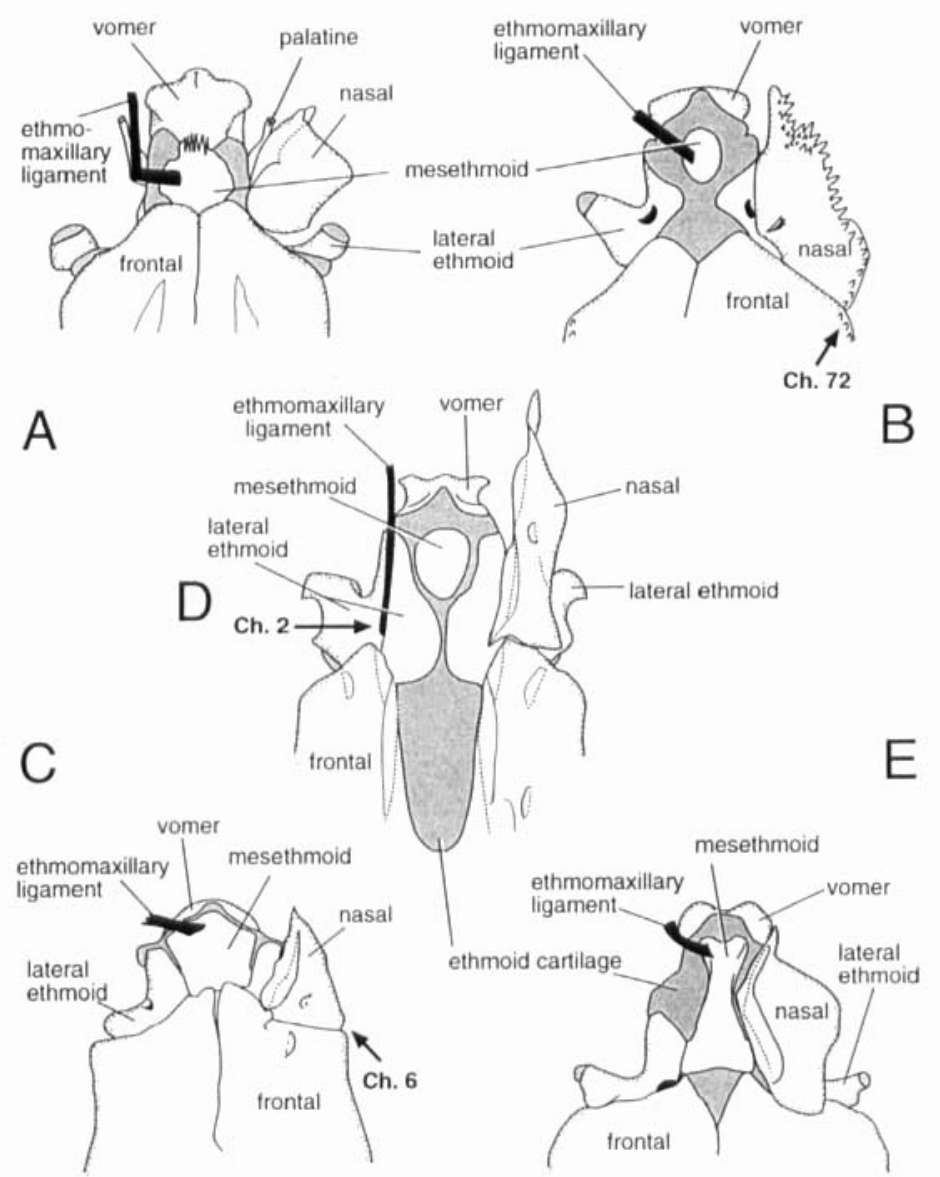

Figure 8. Dorsal view of ethmoid regions; A, Menidia: B, Atherion; C, Bedotia sp. (UMMZ 218508); D, Atherinason; E, Iso. The apparent contact between mesethmoid and lateral ethmoids in $8 \mathrm{E}$ is an effect of the dorsal view of this figure. Figures A, B, D, \& E are modified from Patten (1978). Arrows indicate Characters 2, 6, \& 72 . 
concave at dorsal opening of posterior naris, $1=$ posterolateral border of nasal slightly concave or straight, posterior naris lateral, ? = polymorphic; $0.33,0.71$ )

6. Nasal bone in orbit rim (Patten, 1978). A roughly diamond-shaped nasal bone that does not extend to the orbital rim is a plesiomorphic condition of atherinomorphs. In atherinopsids, notocheirids, and Dentatherina, the nasal bone is wider at its midlength and narrower posteriorly, clearly excluded from the orbital rim (Fig. 8A, E; Rosen, 1964: fig. 5; De la Hoz \& Tosti-Croce, 1981: fig. 2; White, 1985; fig. 6). With the exception of Dentatherina, Atherines has a derived condition of the nasal bone in which it is roughly triangular in dorsal view, being widest posteriorly, such that the posterolateral corner of the bone is included in the orbital rim (Fig. 8B, C), In Atherion, the posterolateral region of the nasal bone forms a wide portion of the orbital rim between the frontal and lacrimal (Fig. 8B). Another derived condition is found in atherines except for Atherinosoma, in which the nasal is excluded from the orbital rim and is as narrow in the middle between the nares as it is posteriorly (Fig. 8D). $(0=$ nasal not reaching orbital rim, middle of bone wider, $1=$ nasal in orbit rim, posterior border wider than middle, 2 = nasal not in orbit rim, middle as narrow as posterior border; $0.67,0.91$ )

7. Nasal ventromedial ligament (Patten, 1978). Plesiomorphically, atheriniforms lack a nasal ventromedial ligament. The nasal bone is closely attached to the frontal and lateral ethmoid by strong connective tissue, and to the maxillary head by a wide ligament. Unique to Atherines (Fig. 3: Node C) is presence of a ventral ligament connecting the medial rim of the nasal to the well developed anterior process of the lateral ethmoid (Fig. 10A). Another derived condition, seen in pseudomugilins, atherinines, and craterocephalines, is the ventral attachment of this ligament to the palatine (Figs 10B, 11). ( 0 = nasal lacking a ventromedial ligament, 1 = nasal ventromedial ligament present, attached to lateral ethmoid, $2=$ nasal ventromedial ligament present, attached to palatine; $0.67,0.94$ )

A unique condition is found in Iso where the nasal bones have a medial attachment to the enlarged mesethmoid that abuts between them (Fig. 8E).

8. Nasal ventral process (Patten, 1978). Lack of a nasal ventral process is the plesiomorphic condition in atheriniforms (Figs 10A, 11). A feature unique to craterocephalines is a ventral process of the medial border of the nasal, to which the ventromedial ligament (Ch. 7) is attached (Fig. 10B). ( $0=$ nasal bone without a ventral process, $1=$ ventral process of nasal bone present; 1.00)

A slight thickening of the medial border of the nasal bone was observed in Leptatherina, and atherinomorines except Alepidomus.

9. Frontal-lateral ethmoid contact (Patten, 1978). In atheriniform outgroups the anterior region of the frontals overlie the cartilaginous ethmoid block but, do not contact the lateral ethmoids (Fig. 9). In atherinids and melanotaeniids, the frontal and lateral ethmoid bones articulate with no intervening cartilage (Fig. 12). $(0=$ frontal not in contact with lateral ethmoid, $1=$ frontal and lateral ethmoid in contact; 0.50 , 0.88 )

10. Parietal bones (Patten, 1978). Parietals are present in atheriniform outgroups except for beloniforms and some cyprinodontoids (Parenti, 1981:423). Parietals are also present in atherinopsids (Starks, 1899; De la Hoz \& Tosti-Croce, 1981: fig. 2) and notocheirids, though reduced in Iso (Said, 1983; Saeed et al., 1994). Absence of 


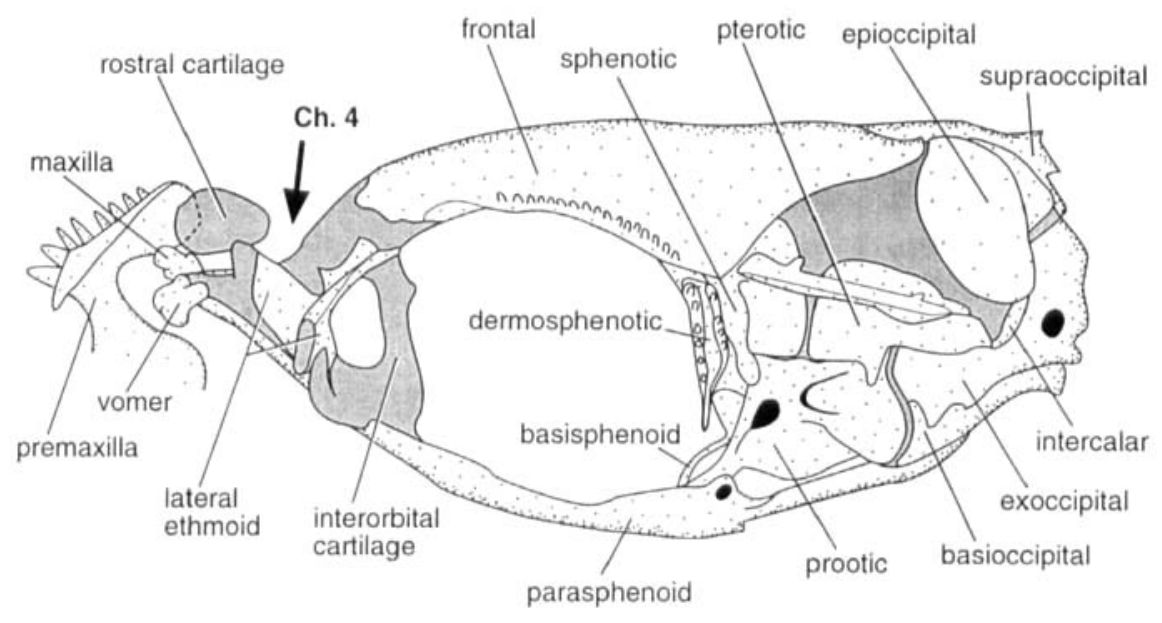

Figure 9. Atherion elymus (UMMZ 204128), lateral view of the left side of neurocranium, with rostral cartilage and internal view of right premaxilla. Arrow indicates Character 4.

parietal bones is a derived feature of Atherines (Fig. 3: Node C; Figs 9, 12, 13), $(0=$ parietals present, $1=$ parietals absent; $0.50,0.83$ )

11. Intercalar bones. Presence of intercalar bones is the generalized condition in acanthomorphs. Presence of an intercalar is considered the plesiomorphic feature relative to atherinomorphs (e.g. present in mugilids). It is, however, lacking in Cyprinodontea, atherinopsids, and notocheirids (Fig. 13A) except for Iso hawaiiensis Gosline (Said, 1983). The intercalar is present in Atherines (Fig. 3; Node C; Figs 9, 12, 13B), with the exception of phallostethines (Roberts, 1971: figs 3, 4). $(0=$ intercalar present, $1=$ intercalar lacking; $0.33,0.75)$

12. Epioccipital wing. Presence of posteriorly-widened laminar epioccipital flanges is a plesiomorphic feature of atherinomorphs and mugilids (Starks, 1899). Absence of epioccipital wings is a derived feature of Atherinoidei (Figs 9, 12, 13), though present in some species of Craterocephalus (Patten, 1978; Crowley, 1990). Epioccipital wings

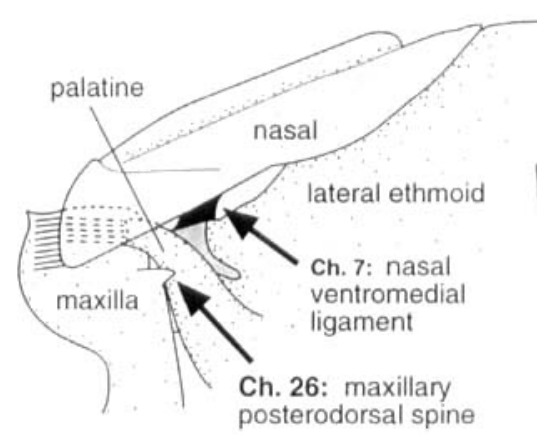

A

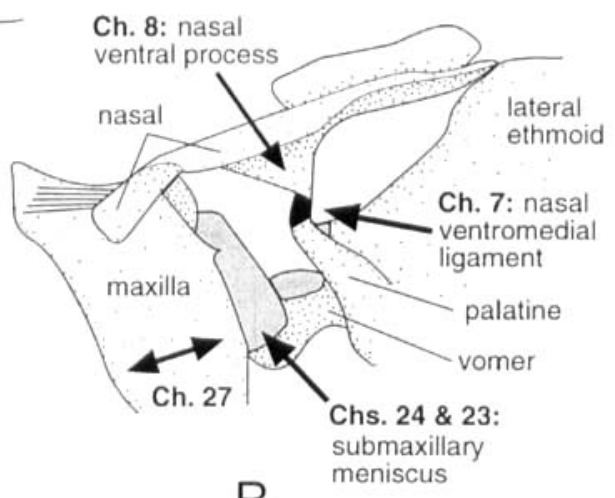

Figure 10. Schematic lateral view of ethmoid regions (modified from Patten, 1978); A, Atherinomorus ogilbyi; B, Allanella mugiloides. Arrows indicate Characters 7, 8, 23, 24, 26, \& 27. 


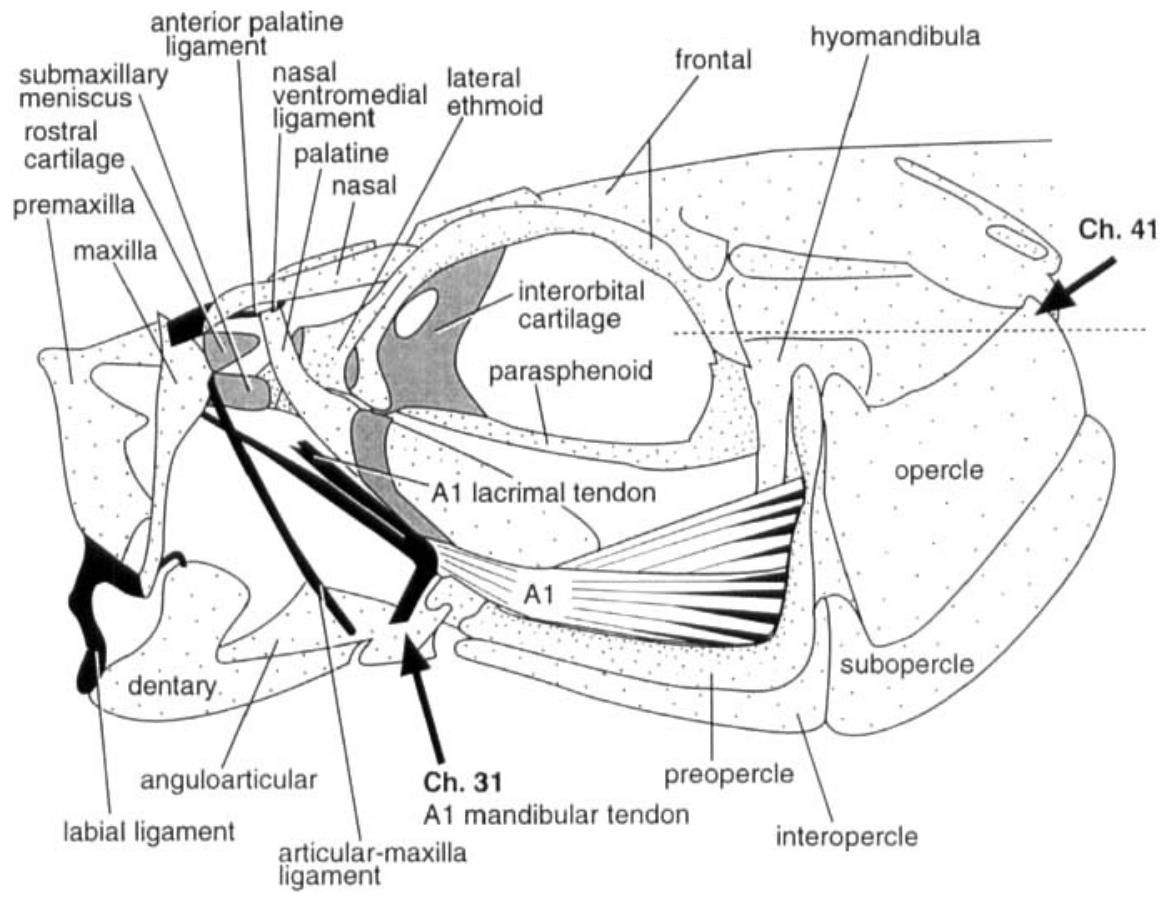

Figure 11. Leptatherina presbyteroides, schematic view of left side of head (modified from Patten, 1978). Cartilage in gray, ligaments and tendons in black, and Al muscle striped. Arrows indicate Characters 31 \& 41 .

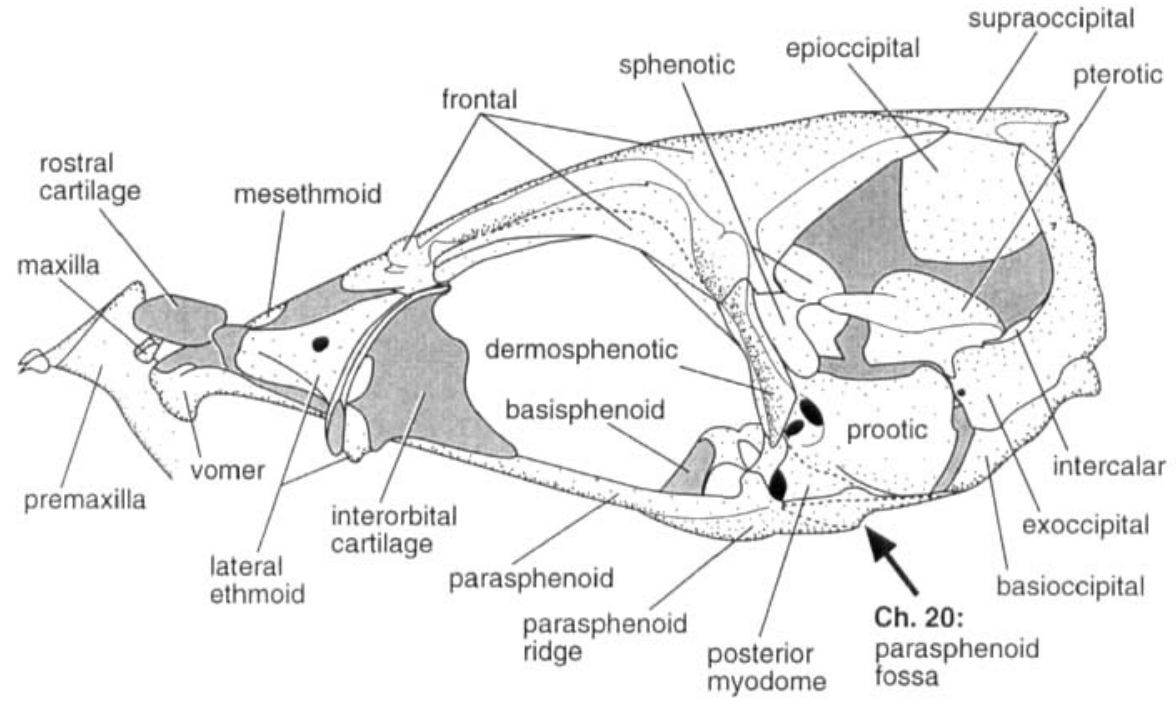

Figure 12. Rheocles alcotrensis (UMMZ 217679), lateral view of left side of neurocranium, including rostral cartilage and premaxilla. Arrow indicates Character 20. 
are reduced or absent in species of Chirostoma and Menidia colei. ( $0=$ epioccipital wings present; 1 = epiocciptal wings absent; $0.50,0.75$ )

13, 14. Temporal region sensory canals. Lateral sensory canals of the temporal region of the head are present on the pterotic, posttemporal, and as 'floating' extrascapular ossifications in atherinomorph outgroups (De la Hoz \& Tosti-Croce, 1981: fig. 2; White, 1985: fig. 13; Stiassny, 1993: fig. 7). These sensory canal ossifications are all present in atherinopsines, absent in Cyprinodontea, and present in part in menidiines, mugilids, and atherinoideins (Figs 14, 15). Mugilids, menidiines, and some atherinoideins lack a posttemporal canal. Menidiines and atherinoideins lack extrascapsular bones. Presence of pterotic and posttemporal sensory canal bones is considered as plesiomorphic and derived conditions, respectively, within atheriniforms.

The pterotic canal is present in most atherinodeins except for bedotiines, Pseudomugil, and phallostethines. (Ch. 13: $0=$ pterotic canal present, $1=$ pterotic canal absent; $0.25,0.57$ )

The posttemporal canal is lacking in most atherinoideins except for melanotaeniines, Dentatherina, and atherinids (Figs 14, 15). (Ch. 14: $0=$ posttemporal canal absent, 1 = posttemporal canal present; 0.20, 0.67)
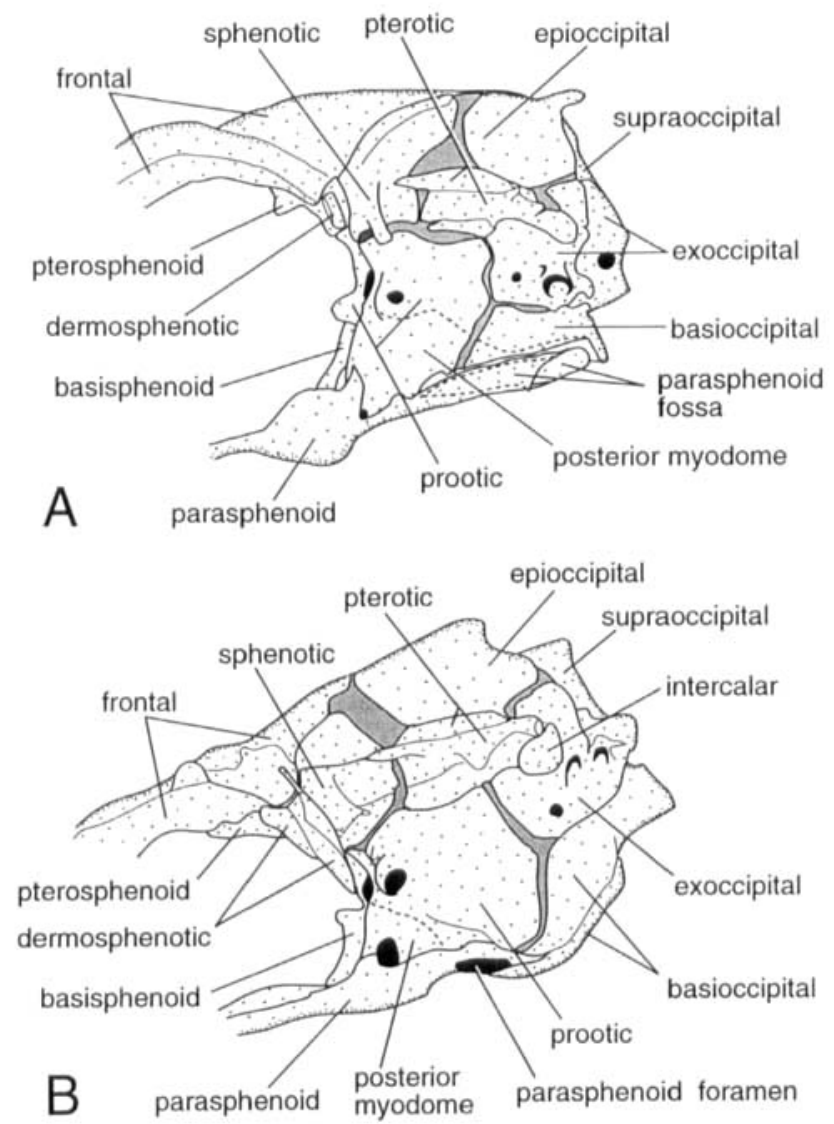

Figure 13. Lateroventral view of neurocranium; A, Iso thothophilus (UMMZ 217631); B, Bedotia sp. (UMMZ 218508). Dashed lines indicate borders of internal features. 


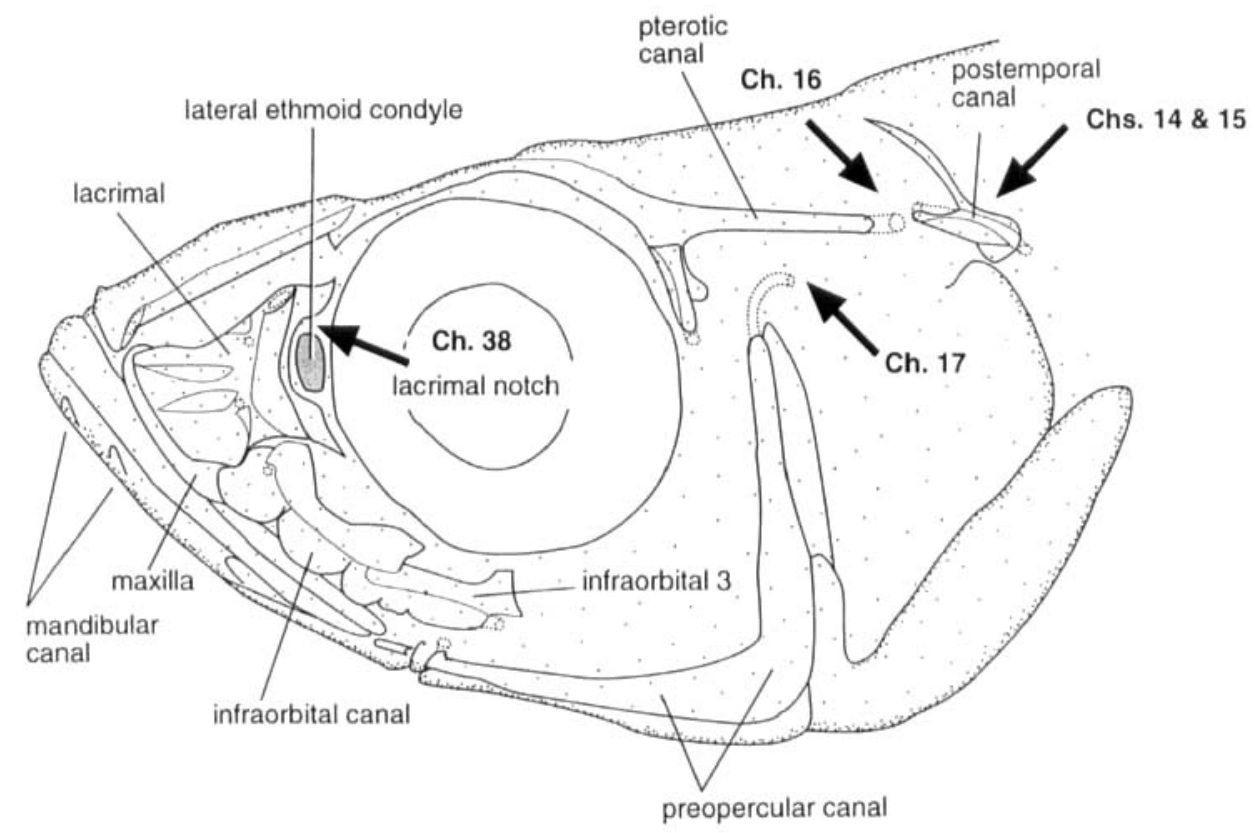

Figure 14. Atherina boyeri (UMMZ 185092), schematic view of left side of head. Dotted lines indicate lateral sensory canals and pores. Arrows indicate Characters 14, 15, 16, 17, \& 38 .

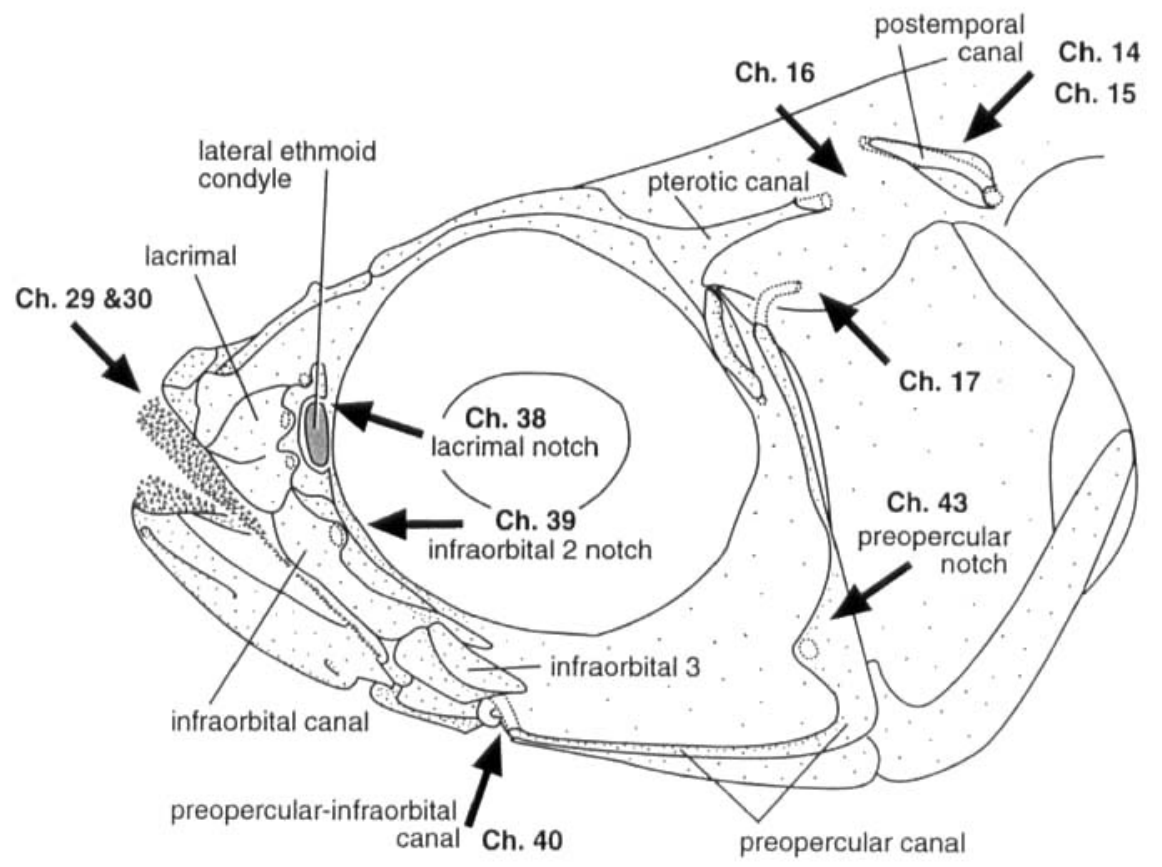

Figure 15. Atherinomonus eendrachtensis (UMMZ 196221), schematic view of left side of head. Arrows indicate Characters $14,15,16,17,29,30,38,39,40, \& 43$. 
15. Posttemporal sensory canal orientation. The plesiomorphic atheriniform condition is for the posttemporal to have a relatively short sensory canal oriented towards the pterotic sensory canal (Fig. 14). Atherinomorines have a derived condition in which the longitudinal axis of the posttemporal sensory canal is parallel to the dorsal arm of the posttemporal (that which connects to the epioccipital), forming roughly a $45^{\circ}$ angle with the pterotic canal (Fig. 15). This is evident even in the reduced condition seen in Alepidomus. ( $0=$ posttemporal canal oriented to pterotic canal, $1=$ posttemporal canal oriented along dorsal arm of posttemporal; 1.00)

16. Pterotic-posttemporal sensory canal connection. In mugilids and atherinopsids, the pterotic and posttemporal canals are connected by a continuous sensory canal tube. A derived condition is found in some atherine taxa having both pterotic and posttemporal canals, in which a sensory canal connection between them is lacking (Figs 14,15$).(0=$ pterotic and posttemporal sensory canals connected, $1=$ pterotic and posttemporal sensory canals disconnected, $-=$ non-applicable $?=$ unknown; 1.00)

17. Pterotic-preopercular sensory canal connection. In mugilids, atherinopsids, and Iso, the sensory canals of the pterotic and preopercle are connected. A derived condition of atherinoideins with a pterotic canal, with the exception of Iso, is for the dorsal end of the preopercular canal to open posterodorsally instead of connecting to the pterotic canal (Figs 14, 15). Oryzias and Dentatherina have a further derived condition in which the preopercular sensory canal is connected anterodorsally to the dermosphenotic or posterior infraorbital canal. Phallostethines lack a pterotic canal; their preopercular and dermosphenotic canals, though not continuous, have pore openings in close proximity. $(0=$ pterotic and preopercular sensory canals connected, $1=$ pterotic and preopercular sensory canals disconnected, $2=$ preopercular and dermosphenotic canals connected, $-=$ non-applicable; $0.67,0.75$ )

18. Basisphenoid-prootic-pterosphenoid articulation. In Euacanthopterygii, a generalized condition comprises the basisphenoid articulating with the prootic and pterosphenoid. The condition in mugilids differs from other outgroups in that the basisphenoid is reduced and does not articulate with the prootic or pterosphenoid. Cyprinodontiforms, adrianichthyoids, and Elassoma lack a basisphenoid. In exocoetoids, the basisphenoid is attached to the prootic and pterosphenoid, rarely to the prootic only. In atherinopsids the basisphenoid articulates with both the pterosphenoid and prootic, or with the pterosphenoid only (Starks, 1899; De la Hoz \& Vial, 1988: fig. 1). Atherinoideins share a derived feature of the basisphenoid articulating solely with the prootic (Fig. 13). $(0=$ basisphenoid articulated with pterosphenoid and prootic, 1 = basisphenoid articulated with prootic only, $2=$ basisphenoid reduced, not articulated dorsally, $-=$ non-applicable ? = polymorphic; $1.00 ; \mathrm{n}$-add)

19. Parasphenoid ventral ridge (Patten, 1978). The ventromedial ridge of the parasphenoid, when present, reaches its greatest expansion below or anterior to the opening of the posterior myodome, and extends posteriorly to about the position of the internal carotid foramen (Fig. 13A). In craterocephalines, the ventral ridge continues posteriorly to the end of the parasphenoid. The posterior extension of this ridge is also found, at different stages of development, in Notocheirus (Rosen, 1964; Said, 1983), Atherion, and bedotiines (Figs 9, 12, 13B). ( $0=$ parasphenoid ventral ridge short, 1 = parasphenoid ventral ridge extended posteriorly; $0.25,0.50$ ) 
A further derived condition of the parasphenoid is found in Notocheinus in which a blade-like process is oriented anteroventrally (Rosen, 1964: fig. 4B).

20. Parasphenoid fossa (Patten, 1978). The plesiomorphic condition for atheriniforms is for there to be no fossa in the parasphenoid bone. Presence of a cavity restricted to the posterior region of the parasphenoid is unique to Atherinoidei (Figs 12, 13A), except for Notocheirus, phallostethids, and craterocephalines, where there is no fossa. The posterior opening of this cavity resembles that of the posterior myodome (Ch. 22), but is non-homologous with that structure because of the co-occurrence of both features in Iso (Fig. 13A), thus failing the test of conjunction (Patterson, 1982). ( $0=$ non parasphenoid fossa, $1=$ presence of a fossa contained by the parasphenoid, ? = unknown; 0.25, 0.75)

21. Parasphenoid ventral fenestra. The plesiomorphic condition for atherinoideins with a parasphenoid fossa is for it to have a posterior opening only. A derived condition present in Bedotia, Leptatherina, and atherinomorines is for the parasphenoid fossa to have a ventral fenestra in addition to the posterior opening (Fig. 13B). $(0=$ parasphenoid fossa with posterior opening only, 1 = parasphenoid fossa with posterior and ventral fenestra; $0.33,0.60$ )

22. Posterior myodome (Patten, 1978). The posterior myodome is a cavity that houses the posterior extension of the external eye muscles between the floor of the braincase and the parasphenoid. The plesiomorphic atherinomorph condition is for the posterior myodome to extend beyond the prootics, ventral to the basioccipital (Fig. 13A). Melanotaeniids, Dentatherina, and the Craterocephalus stercusmuscarum speciesgroup (Patten, 1978) share a derived condition in which the posterior myodome is restricted to the prootics (Figs 12, 13B). Cyprinodontiforms, Oryzias, Horaichthys, and phallostethines share the derived condition of no posterior myodome. $(0=$ posterior myodome present under prootics and basioccipital, $1=$ posterior myodome present under prootics only, $2=$ posterior myodome absent, ? = unknown; $0.57,0.75$ )

Fawes

23. Submaxillary meniscus size. A relatively small, circular, and biconcave meniscus between the ethmoid region and the maxillary head is a plesiomorphic feature for acanthopterygian fishes (Parenti, 1984). A derived condition in atheriniforms is a greatly enlarged, sometimes barrel-shaped (taller than wide) submaxillary meniscus as present in phallostethids (Roberts, 1971: fig. 5; Patten \& Ivantsoff, 1983), Stenatherina, atherinines, and craterocephalines (Figs 10B, 11). All atherinomorines examined have the plesiomorphic condition except Stenatherina which has an independently derived and greatly enlarged meniscus. Pseudomugilines and mugilids also have the derived condition of a somewhat enlarged meniscus relative to the plesiomorphic condition present in other melanotaeniids (Saeed et al., 1989) and other outgroups, but is never taller than it is wide. $(0=$ submaxillary meniscus small, 1 = submaxillary meniscus slightly enlarged, as tall as wide, $2=$ submaxillary meniscus enlarged, taller than wide; $0.25,0.78$ )

As discussed by Pietsch (1984) and Ivantsoff et al. (1987) the size of the submaxillary meniscus is correlated with longer ascending processes of the premaxillae and is hypothesized to enhance the extent of upper jaw protrusion.

Size and composition of the submaxillary meniscus have been discussed as a single character in the literature (Parenti, 1984; Ivantsoff et al., 1987). In this study, size (Ch. 
23) and composition (Ch. 24) of the meniscus were distinguished as separate of the same structure; their independence was corroborated by derivation at different levels of generality within atheriniforms.

24. Submaxillary meniscus matrix (Parenti, 1984; Ivantsoff et al., 1987). The plesiomorphic condition for acanthomorphs (and certainly for atheriniforms) is a submaxillary meniscus of a fibro-cartilaginous matrix (Parenti, 1984). A derived condition within atheriniforms is a hyaline-cartilage submaxillary meniscus rather than a fibrocartilage meniscus (Figs 10B, 11). In Atherion, Gulaphallus, and pseudomugilines the meniscus is mostly fibrous with a hyaline-cartilage core. A further derived condition is a fully hyaline-cartilage meniscus found in atherinines, craterocephalines, and phallostethids (Roberts, 1971: fig. 5; Patten \& Ivantsoff, 1983). Unique within atheriniforms is a perichondral ossification of the hyalinecartilage submaxillary meniscus characteristic of phallostethids except for Gulaphallus. ( 0 = fibrocartilage submaxillary meniscus, $1=$ hyaline-cartilage submaxillary meniscus, 2 = hyaline-cartilage submaxillary meniscus perichondrally ossified; 0.40 , 0.81 )

Several species of the atherinopsid genus Membras, including $M$. martinica, $M$. argentea, and two undescribed species, have enlarged bony menisci, but which are not perichondral ossifications.

25. Labial ligament paradentary (Parenti, 1984; Ivantsoff et al., 1987). In atheriniforms and outgroups, the labial ligament connects the distal tips of the upper-jaw bones to the dentary. The labial ligament of Dentatherina and phallostethines is thickened anteriorly, and internally has a bone close to the dentary. This labial-ligament bone is the so-called parandentary (Parenti, 1984, 1986). The homology of these paradentary bones was questioned by Ivantsoff $e t$ al. (1987) based on histological and functional arguments. The pardentary bones in Dentherina are calcified nodules within a hyaline cartilage (Ivantsoff et al., 1987: fig. 1), whereas in phallostethines the bones are perichondral ossifications (Ivantsoff et al., 1987: fig. 2; Parenti, 1986: fig. 1). What is common to Dentatherina and phallostethines is presence of hyaline cartilage in the labial ligament, and that is our basis for assessment of homology. In this study, paradentaries are proposed to be homologous as cartilaginous structures. Paradentary bones may have developed independently through different ontogenetic pathways. We agree with Parenti (1989:248) and reject Ivantsoff et al.'s use of functional statements to determine homology as we do all a priori statements of homology in absence of a phylogenetic framework. $(0=$ no paradentary cartilage, 1 = paradentary cartilage present; 1.00 )

Calcification in the ligament between the distal tips of the maxilla and premaxilla seems to be unique to Dentatherina (Patten \& Ivantsoff, 1983: fig. 4). Beloniform species of Cypselurus and Chriodorus have cartilaginous nodules in the maxillapremaxilla ligament.

26. Maxillary posterodorsal spine (Patten, 1978). In mugilids and other outgroups the proximal region of the maxillary shaft has an anterodorsal process or spine, to which the articular-maxillary ligament is attached. In Elassoma, Lates and Morone this spine is on the antero-lateral portion of the dorsal half of the maxilla. Atherinopsids and Cyprinodontea lack a process or spine in the proximal region of the maxillary shaft, and the articular-maxillary ligament is attached lower on the maxilla (De la Hoz \& Vial, 1988: fig. 8B). Atherinoideins have a derived posterodorsal spine-like process in 


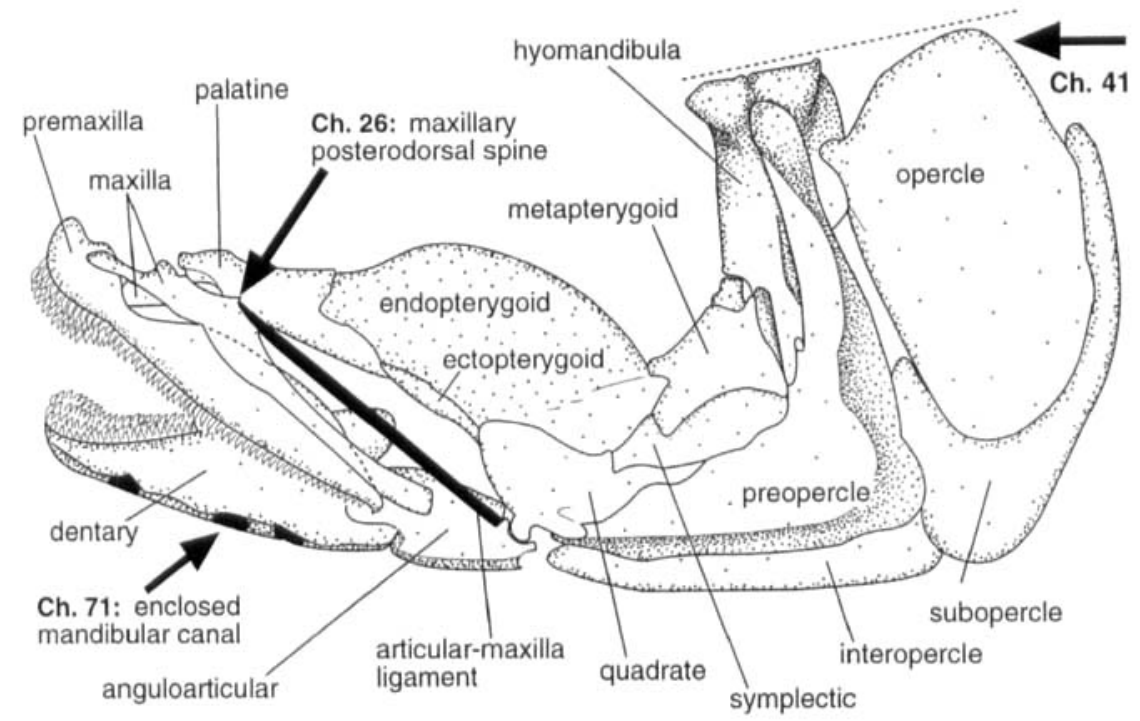

Figure 16. Lateral view of left suspensorium and jaws of Bedotia sp. (UMMZ 218508). Arrows indicate Characters $26,41, \& 71$.

the proximal region of the maxilla (Figs 10A, 16), a condition unique were it not also present in Percopsis, though independently derived in the current hypothesis (Johnson \& Patterson, 1993; but see Parenti, 1993). The posterodorsal spine is not prominent in more derived craterocephalines because the proximal region of the maxilla is broader (Ch. 27). The posterodorsal spine is absent in Pseudomugil in conjunction with absence of the articular-maxillary ligament (Saeed et al., 1989). The posterodorsal spine is present, however, in other pseudomugilines and is reduced in Telmatherina (Saeed \& Ivantsoff, 1991). The posterodorsal spine is lacking in Notocheirus (Rosen, 1964; Said, 1983) together with most all other features of the maxillary head. $(0=$ no maxillary posterodorsal spine, $1=$ maxillary posterodorsal spine present; 0.50 , 0.83)

27. Width of the proximal region of the maxillary shaf (Patten, 1978). The plesiomorphic condition in atherinomorphs is for the maxillary shaft to be narrow at its junction with the maxillary head and wider distally. Craterocephalines and pesudomugilines have at least the proximal third of the maxillary shaft expanded (Fig. 10B) and abruptly tapered distally (Patten, 1978; Ivantsoff, 1978; Crowley, 1990a; Saeed et al., 1989). $(0=$ maxillary shaft narrow proximally, $1=$ maxillary shaft expanded proximally; $0.50,0.75$ )

This character is not to be confused with the anterior shelf of the maxilla overlapping the premaxilla (Fig. 14; Alexander, 1967: fig. 3), a feature diagnostic of Atherina. The maxillary shelf is also illustrated in †Palaeoatherina rhodanica Gaudant, 1976 (Ferrandini, Ferrandini \& Gaudant, 1976), type species of the genus, but not in the other described species of †Palaeoatherina (Chedhomme \& Gaudant, 1984; Gaudant, 1989).

28. Enlarged distal premaxillary teeth. Distal premaxillary teeth of most atherinomorphs and outgroups are the same size or smaller than those near the symphysis. A derived condition characterizes several groups of atherinomorphs in which there are a 
number of enlarged teeth on the distal portion of the premaxilla that overlap the lower jaw when the mouth is closed. Taxa with the derived feature include Oryzias (Parenti, 1987), some hemirhamphids (Collette, pers. comm.), melanotaeniines (Allen, 1980), pseudomugilins (Allen, 1980; Saeed et al., 1989), telmatherins (Saeed \& Ivantsoff, 1991), Gulaphallus, and Neostethus (Roberts, 1971). $(0=$ distal premaxillary teeth equal in size or smaller than proximal teeth, $1=$ distal premaxillary teeth larger than proximal teeth; $0.33,0.67$ )

29. External premaxillary teeth. Jaw teeth on the interior face of the premaxilla and dentary is a plesiomorphic condition of atherinomorphs. Presence of teeth on the external face of the premaxilla is a derived feature of some adrianichthyoids (Rosen, 1964; Kottelat, 1990 b,c, 1991) and some atherinoideins. Teeth present on the external surface of the premaxilla are found in Notocheirus, Iso natalensis Regan (Said, 1983), Atherion (Fig. 9), some Bedotia, most melanotaeniines (Allen, 1980), pseudomugilins (Saeed et al. 1989), telmatherins (Kottelat, 1990a, 1991), Atherinomorus (Fig. 15), Hypoatherina, and Quirichthys. ( $0=$ no premaxillary teeth on external surface, $1=$ presence of premaxillary teeth on external surface, $0.38,0.38$ )

30. Villiform teeth on jawes. Jaw teeth of the outer row larger than or equal to inner rows of teeth is the plesiomorphic condition of atheriniforms. Atherinomorus and Hypoatherina have a characteristic patch of relatively fine villiform teeth of equal size on the external and internal surfaces of the premaxillae, and on a wide area at the dentary symphysis (Fig. 15). $(0=$ jaw teeth rows of unequal size, $1=$ fine villiform jaw teeth of equal size; 1.00 )

\section{Suspensorium}

31. Lacrimal and mandibular tendons of adductor mandibulae 1 muscle. The plesiomorphic condition present in mugilids and outgroups is for the adductor mandibulae 1 (Al) muscle to have anteriorly a single tendinous attachment to the maxilla. A derived condition of atheriniforms is a long tendon connecting the proximal end of the $\mathrm{Al}$ muscle tendon to the ventral surface of the sub-nasal shelf of the lacrimal (Fig. 11; Alexander, 1967b: fig. 2C; Melinkat \& Zeiske, 1979; De la Hoz \& Vial, 1988; Stiassny, 1990). Another derived condition found in menidiines, Leuresthes, Odontesthes, Atherion, melanotaeniines, Telmatherina, and atherinines, is presence of a short mandibular tendon from the proximal end of the Al muscle tendon to the mandible near its articulation with the quadrate (Fig. 11). $(0=\mathrm{Al}$ muscle with no lacrimal tendon, or a short proximal tendon to the ventral region of the lacrimal, $1=\mathrm{Al}$ muscle with a long proximal tendon to the sub-nasal shelf of the lacrimal, $2=\mathrm{Al}$ muscle with long lacrimal tendon and a short mandibular tendon; 0.33, 0.69)

32. Maxillary tendon of adductor mandibulae 1 muscle (Rosen, 1964). The plesiomorphic acanthomorph condition present also in mugilids and atherinoideins is for the adductor mandibulae (Al) muscle to insert anteriorly, via tendon, on the internal surface of the proximal region of the maxillary shaft (Fig. 11; Alexander, 1967a, 1967b: fig. 1A; Gosline, 1981). In cyprinodontiforms (Alexander, 1967b: fig. 4A), beloniforms, atherinopsids (De la Hoz \& Vial, 1988), and pseudomugilines (Saeed $e t$ al., 1989) the maxillary tendon is attached to the distal half of the maxilla (Rosen, 1964: fig. 11). $(0=\mathrm{Al}$ maxillary tendon attached to the proximal region of the shaft, $1=\mathrm{A} 1$ maxillary tendon attached to the distal half of the maxilla; $0.33,0.60$ ) 
33. Anterior palatine process (Patten, 1978). The plesiomorphic condition found in atherinomorph outgroups is for the palatine process (maxillary process of the palatine, or palatine prong) to be directed anteriorly over the proximal region of the maxillary shaft. In cyprinodontiforms and beloniforms the palatine process is directed more laterally, in some cases nearly at right angles with the body of the palatine. A derived condition is found in pseudomugilins (Saeed et al., 1989) and atherinines, in which this process is directed dorsally (Fig. 11) rather than anteriorly (Figs 10A, 16). Another derived condition is found in craterocephalines, in which the palatine process is absent altogether, replaced in some specimens by bony projections of the palatine body (Fig. 10B). $(0=$ anterior palatine process directed anteriorly, $1=$ anterior palatine process directed dorsally, $2=$ anterior palatine process absent; $0.67,0.90)$

Atherina is unique in that the palatine process is a cartilaginous element separated from the body of the palatine by a sheath of connective tissue, rather than continuous with it by cartilage or cartilage replacement bone.

34. Anterior palatine ligament (Patten, 1978). The plesiomorphic atheriniform condition is presence of a ligament between the anterior tip of the palatine process and the maxilla (Fig. 10A). Pseudomugilins and atherinines have a derived condition in which the anterior palatine ligament is connected to the anterior half of the nasal (Fig. 11). Another derived condition is absence of the anterior palatine ligament (Fig. 10B) in craterocephalines; because this condition is directly associated with absence of the palatine process (Ch. 33), however, it is coded as non-applicable in the data matrix (Table 2). $(0=$ anterior palatine ligament connected to maxilla, $1=$ anterior palatine ligament connected to nasal bone, $?=$ unknown, $-=$ non-applicable; 0.50 , 0.80 )

A derived condition is found in Iso in which the anterior palatine ligament adjoins the anterior nasal ligament to the maxilla. This feature is considered autapomorphic of Iso; we were unable to confirm this condition in Notocheirus.

35. Palatine dorsal process (White, 1985; Chernoff, 1986). A dorsal process of the palatine, located posterior to the palatine process (Ch. 33), is present in mugilids, cyprinodontoids (Parenti, 1981), and atherinopsids (White, 1985; Chernoff, 1986). The ethmomaxillary ligament (Ch. 2) is attached to this process in atherinopsids (Fig. 8A; Chernoff, 1986: fig. 4B), at times separated in two ligaments by the dorsal process. A derived condition of Atherinoidei is absence of the dorsal process (Figs 10, $11,16) .(0=$ palatine dorsal process present, $1=$ palatine dorsal process absent; 1.00)

36. Palatine ventral process (Patten, 1978). The ventral border of the palatine is keel-like anteriorly and is attached to the vomer by ventromedial ligaments (Patten, 1978: fig. $16 \mathrm{~A})$; the so-called ventral process is the anteroventral corner of the palatine body. This 'process' is greatly reduced or absent in Notocheirus (Rosen, 1964), Iso hawaiiensis Gosline and an Australian population of I. rhothophilus Ogilbyi (Said, 1983), some species of Pseudomugil (Saeed et al., 1989), phallostethids (Roberts, 1971), and atherinids (Fig. 11), except for Alepidomus. $(0=$ palatine ventral process present, 1 = palatine ventral process reduced or absent, ? = unknown; $0.25,0.79$ )

37. Number of anterior infraorbitals (Chernoff, 1986b; Parenti, 1993). Presence of an infraorbital series of five or more canal bearing bones is the plesiomorphic condition for acanthomorphs. An incomplete series of infraorbitals, composed of one posterior 
dermosphenotic bone and one to three anterior infraorbitals, characterizes atherinomorphs, Elassoma, and gasterosteiforms (Parenti, 1993; Johnson \& Patterson, 1993). Within atherinomorphs, cyprinodontiforms and beloniforms have only one anterior infraorbital bone, the lacrimal. Two anterior infraorbital bones are found in atherinopsids (Chernoff, 1986), Notocheirus (Said, 1983), bedotiines (Stiassny, 1990: fig. 12), Glossolepis, Iriatherina and Caimsichthys (Ivantsoff et al., 1987), phallostethines (Roberts, 1971: fig. 4), and six species of Craterocephalus (Crowley, 1990a). Telmatherins and melanotaeniins such as Rhadinocentrus, Melanotaenia, Chilatherina, have three anterior infraorbital bones (Chernoff, 1986; Ivantsoff et al., 1987; Stiassny, 1990; Saeed \& Ivantsoff, 1991), as do Iso, Atherion, Dentatherina, and atherinids (Figs $14,15)$. Pseudomugilins are unique among atheriniforms in having the lacrimal as the only anterior infraorbital bone (Saeed et al., 1989; Saeed \& Ivantsoff, 1991). $(0=$ more than four infraorbitals present, $1=$ three anterior infraorbital bones present, $2=$ two anterior infraorbital bones present, $3=$ one anterior infraorbital present, the lacrimal; $0.40,0.57$ )

Atherinoidein taxa with only two anterior infraorbitals have an elongate second infraorbital, a condition possibly due to fusion of infraorbitals as in Atherinosoma (Ivantsoff et al., 1987) or Craterocephalus kailolae (Ivantsoff, Crowley, \& Allen, 1987).

38. Lacrimal notch. The plesiomorphic atheriniform condition is for the lacrimal to articulate posteriorly with the cartilaginous lateral condyle of the lateral ethmoid. Atherinids share the unique feature of having a notch in the posterior margin of the lacrimal which exposes the cartilaginous articular surface of the lateral ethmoid condyle, in lateral view (Figs 14,15$)(0=$ no lacrimal notch, $1=$ lacrimal notch present; 1.00)

39. Notch in sensory canal of infraorbital two (Patten, 1978). The sensory canal of the anterior infraorbital bones is not fully enclosed by bone in Atherinoidei (see Ch. 7l). The bony posterior wall usually forms a lateral enclosure of the sensory canal, and the canal pores are directed anterolaterally. In atherinomorines except Alepidomus, the dorsal sensory canal pore of infraorbital two is more posteriorly displaced and larger, forming a noticeable notch in its posterolateral wall (Fig. 15), ventral to the articulation of infraorbital two with the lacrimal. A small notch in infraorbital two is also present in species of Atherina (Fig. 14), but our analysis shows this is independently derived because other atherinines lack this posterior pore location. ( $0=$ no notch on infraorbital two, $1=$ infraorbital two notch present; $0.50,0.67$ )

40. Preopercular-anterior infraorbital sensory canals connection (Gosline, pers. comm.) The preopercular sensory canal is either connected anteriorly with the mandibular sensory canal in atheriniform outgroups, or is disconnected as in exocoetoids, atherinopsids, and notocheirids. Presence of a connection between the sensory canal of the anterior infraorbital series and the anterior opening of the preopercular canal (Fig. 15) may be unique among telosts. The preopercular-anterior infraorbital connection, however, it is not found in all atherinoideins and is present in two conditions. Atherion, Melanotaenia and Chilatherina, share an intermediate pore between the two sensory canals. A direct connection between both sensory canals, without an intervening pore, is found in all atherinomorines and craterocephalines, and in the atherinines Atherinosoma elongata (Klunzinger), Atherinason hepsetoides (Richardson) and Leptatherina presbyteroides (Richardson). Atherina and Kestratherina have both sensory canals clearly disconnected (Fig. 14), whereas Atherinosoma microstoma (Günther) and $L$. 
wallacei (Prince, Ivantsoff, \& Potter) have pores from both canals opening in close proximity, though still disconnected. If the character state in Atherion and some melanotaeniines is considered as an intermediate condition between no connection and full connectivity between both sensory canals, as in most atherinids, this character may be ordered in such a transformation series. $0=$ preopercular and anterior infraorbital canals not connected, $1=$ preopercular and anterior infraorbital canals connected, with intermediate pore or semi-continuous, $2=$ preopercular and anterior infraorbital canals connected, without intermediate pore or fully continuous; $0.60,0.76$ )

41. Posterodorsal border of the opercle (Saeed \& Ivantsoff, 1991). The dorsal border of the opercle varies from convex to slightly concave in atherinomorphs. The plesiomorphic atheriniform condition is for the dorsal border of the opercle to be at or below a line projected from the axis of articulation between the hyomandibula and the neurocranium (Fig. 16). Atherion, Dentatherina, and atherinids exhibit a derived condition in which the posterodorsal border of the opercle is elongated dorsally above the axis of articulation of the suspensorium, making the dorsal border of the bone very concave (Fig. 11). Patten (1978; table 6) listed this feature but did not use it to diagnose any group. Patten \& Ivantsoff (1983) refer to the posterior border of the opercle in Dentatherina as steeply inclined, and Saeed \& Ivantsoff (1991) attempt to characterize Atherinidae with "...upper edge of opercle almost invariably oblique...". It seems to us this feature is better interpreted by the position of the posterodorsal tip of the opercle relative to the axis of articulation of the suspensorium. Within craterocephalines, the derived condition is found in Allanetta and Craterocephalus honoriae (Ogilbyi), and absent in Quirichthys and all other species of Craterocephalus (Patten, 1978; Crowley, 1990a). ( 0 = posterodorsal tip of opercle ventral to line of articulation axis of suspensorium, $1=$ posterodorsal tip of opercle clearly dorsal to articulation axis of suspensorium; 0.33, 0.82)

42. Foramen of hyomandibular nerve (Patten, 1978). Plesiomorphically, the hyomandibular nerve penetrates the hyomandibular dorsomedially and ventrolaterally (Fig. 17A). The hyoid and mandibular nerves branch inside the hyomandibular and exit posteriorly and laterally, respectively. A derived condition in atherinomorines is a dorsal foramen in the hyomandibula, so that the hyomandibular nerve is exposed laterally; the nerve branches lateral to the hyomandibula and only the hyoid branch is housed by bone (Fig. 17B). ( $0=$ no hyomandibular foramen, $1=$ hyomandibular foramen present; 1.00)

43. Preopercular notch. The plesiomorphic condition in atheriniforms is for the sensory canal pores of the preopercular vertical shaft to be directed posteriorly. All atherinomorines except Alepidomus, have a noticeable notch in the ventral region of the vertical shaft of the preopercle (Fig. 15). This notch marks the position of the third pore from the top which opens anterolaterally rather than posteriorly. This feature has been used previously to distinguish atherinomorine genera (Smith, 1965; Ivantsoff, 1978; Patten, 1978; Ivantsoff \& Crowley, 1991). ( $0=$ no preopercular notch, $1=$ preopercular notch present; 1.00)

44. Dorsal process of the interopercle (Patten, 1978). The dorsal border of the interopercle in atheriniforms is either strongly indented or has a dorsal process to which a short ligament from the posterior ceratohyal is attached (Patten, 1978: figs 16A, 17A). This process or indentation is absent in phallostethids and atherinids except for Alepidomus 


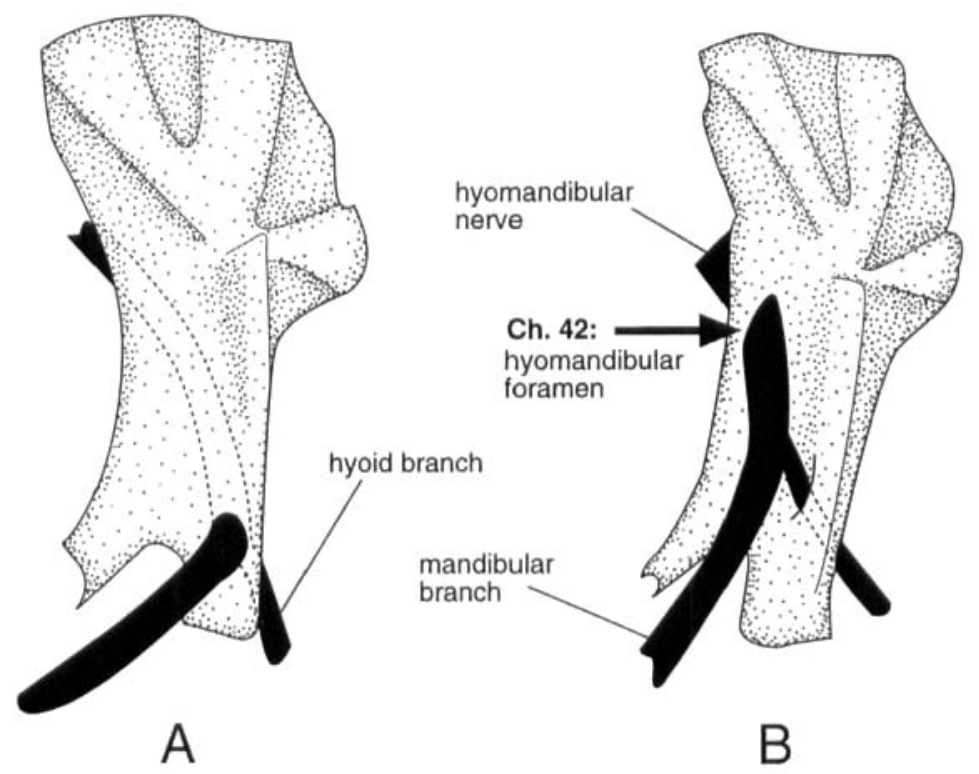

Figure 17. Lateral view of left hyomandibular bones (modified from Patten, 1978); A, Loptatherina presbyteroides; B, Atherinomorus ogilbyi. Arrow indicates Character 42.

(Patten, 1978: fig. 7A; Patten \& Ivantsoff, 1983: 338). ( $0=$ dorsal process of interopercle present, $1=$ dorsal process of interopercle absent; $0.50,0.93$ )

\section{Branchial basket}

45. Urohyal posterodorsal processes (Patten, 1978). The posterior end of the urohyal of many atheriniform fishes has a dorsally expanded shaft in the form of a keel and bilateral, posterodorsal processes perpendicular to the main body of the shaft (Fig. 18). These posterodorsal processes are absent in mugilids, cyprinodontiforms and
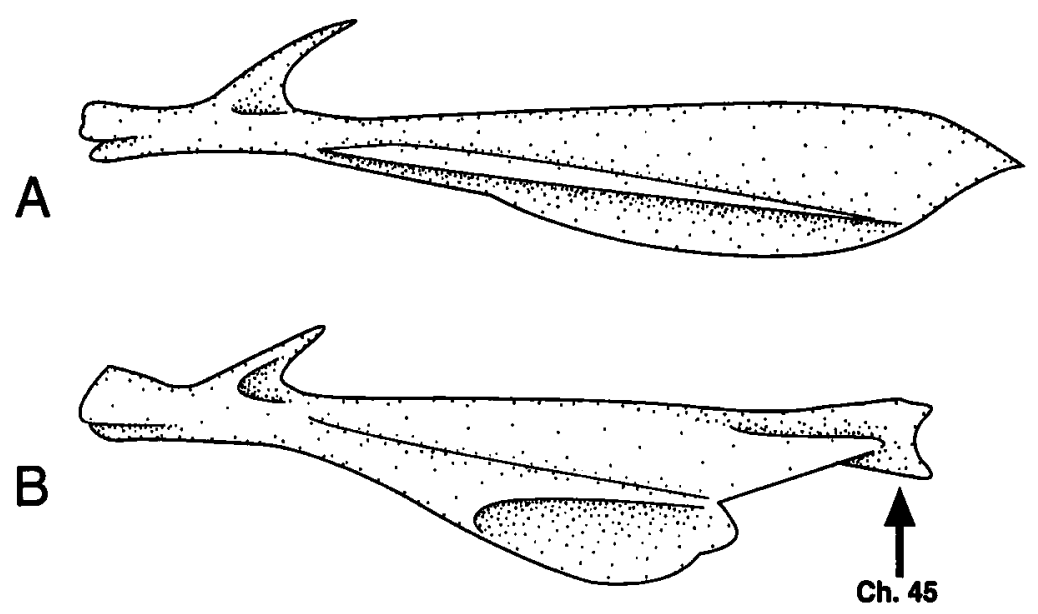

Figure 18. Lateroventral views of urohyals (modified from Patten, 1978); A, Allanetta mugiloides; B, Craterocephalus stercumuscarum. Arrow indicates Character 45. 
other outgroups. Posterodorsal processes of the urohyal are present in beloniforms, atherinopsids (Chernoff, 1986: fig. 15; termed wings), and atherinoideins. These posterodorsal processes are highly reduced or absent (Fig. 18) in atherinids and phallostethids. Exceptions are presence of posterodorsal processes in the Craterocephalus stercusmuscarum species group (Fig. 18B; Patten, 1978; Crowley, 1990b), and absence of posterodorsal processes in Rheocles (Stiassny, 1990; Stiassny \& Reinthal, 1992) and some species of Pseudomugil (Saeed et al., 1989). ( $0=$ urohyal posterodorsal processes highly reduced or absent, $1=$ urohyal posterodorsal processes present; $0.50,0.70)$

46. First epibranchial without an uncinate process. The plesiomorphic condition of atheriniforms and outgroups is for the first epibranchial to have an uncinate process to which the interarcual cartilage is attached (Rosen \& Parenti, 1981). In phallostethids this uncinate process is absent (as is the interarcual cartilage) and the first epibranchial is rod-like. (Roberts, 1971: fig. 8; Rosen \& Parenti, 1981: fig. 19). $(0=$ uncinate process of first epibranchial present, $1=$ uncinate process of first epibranchial absent; 1.00)

Phallostethids also have a greatly reduced pharyngobranchial 1, which is either a cartilaginous nodule, an ossified nodule, or absent. In Melanorhinus, pharyngobranchial 1 is absent. The first epibranchial in Dentatherina is disproportionately large.

\section{Pectoral fin and girdle}

47. Supracleithrum. Presence of a well developed supracleithrum is plesiomorphic for atheriniforms, though reduced relative to atherinomorph and mugilid outgroups (Figs 19, 20; Stiassny, 1993). A derived condition of the supracleithrum is its reduction to a small disk-like bone as found in pseudomugilins (Saeed et al., 1989) and phallostethines (Roberts, 1971: fig. 10; Ivantsoff et al., 1987). The supracleithrum is
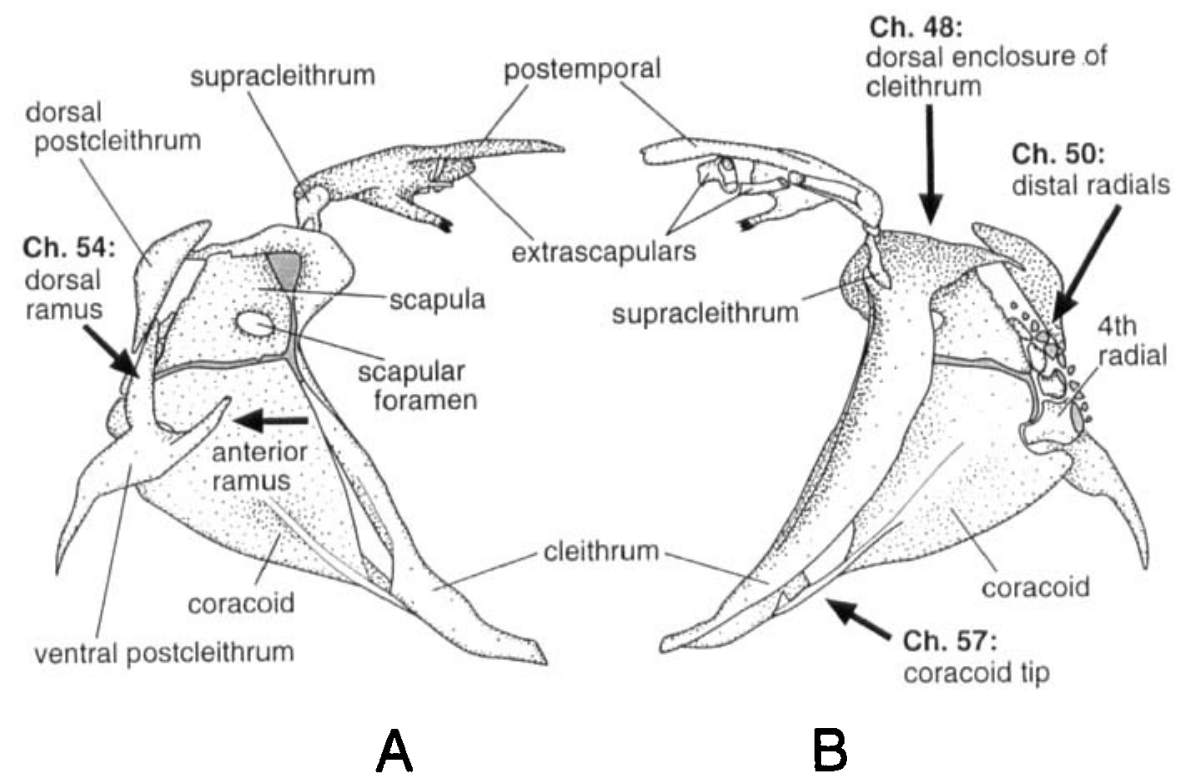

Figure 19. Left pectoral girdle of Odontesthes regia (UMMZ 218455); A, internal view; B, external view. Arrows indicate Characters 48, 50, 54 \& 57. 


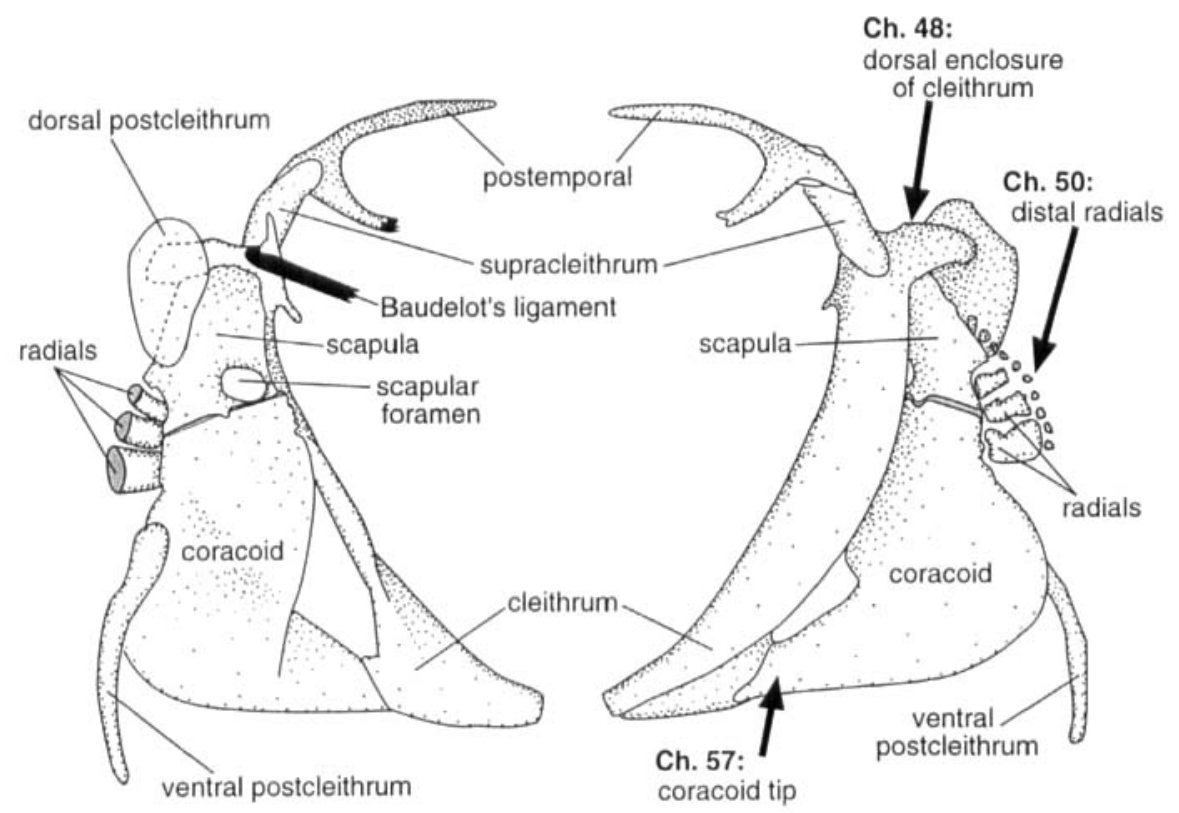

A

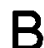

Figure 20. Left pectoral girdle of Bedotia sp. (UMMZ 218508); A, internal view; B, external view. Arrows indicate Characters $48,50, \& 57$.

absent in notocheirids (Saeed et al., 1994), adrianichthyoids (Rosen, 1964), and Old World aplocheiloids (Parenti, 1981). $(0=$ supracleithrum well developed, $1=$ supracleithrum small and disk-like, 2 = supracleithrum absent; 0.75, 0.67)

48. Dorsal enclosure of cleithrum (Allen, 1980; Stiassny, 1993). The anterior face of the cleithrum extends laterally and posteriorly to overlap and partially enclose the underlying abductor muscles of the pectoral fin. The posterolateral extension of the cleithrum decreases ventrally and is absent at the ventral mid-line. The posterolateral extension is greatest dorsally where it meets posteriorly with the medial extension of the cleithrum, forming a dorsal enclosure that projects beyond the posterior border of the scapula (Figs 19, 20; Allen, 1980: "dorsal head of cleithrum"; Stiassny, 1993: "dorsal cleithral process"). In Notocheirus (Rosen, 1964; Said, 1983) and pseudomugilins (Saeed et al., 1989), the posterior extension of the dorsal enclosure is reduced and ends anterior to the posterior border of the scapula. The dorsal enclosure is absent in Iso, Atherion, and phallostethids (Patten, 1978: figs 16C, 17C; Roberts, 1971: fig. 10; Patten \& Ivantsoff, 1983: fig. 2). (0 = cleithrum posterodorsal enclosure present, projected beyond scapula, $1=$ cleithrum posterodorsal enclosure reduced, not extended beyond scapula, 2 = cleithrum posterodorsal enclosure absent, $?=$ unknown; $0.29,0.50$ )

49. Pectoral-fin spur (Stiassny, 1993). A small first pectoral-fin spur, dorsal and proximal to the second unbranched ray, is the generalized condition in atherinomorphs and outgroups (Stiassny, 1993). Absence of this spur, either by loss of this element or by fusion with the head of the second pectoral-ray hemitrichium, is 
characteristic of Notocheirus, atherinopsids, and Gulaphallus. ( $0=$ pectoral-fin spur present, 1 = pectoral-fin spur absent, ? = unknown; 0.33)

Kottelat (1990a) listed presence of a pectoral spine in his diagnosis of Telmatherinini. The pectoral-fin spur of Telmatherina specimens examined was no different from that of other melanotaeniids, but we have yet to examine other telmatherins in order to characterize the group.

50. Ossification of the pectoral distal radials. In atheriniform outgroups, the pectoral distal radials are cartilaginous (Fig. 19B). In Atherines, the dorsal three to nine elements are ossified (Fig. 20B). The only exception we have found are cartilaginous radials in Rheocles and Dentatherina. $(0=$ pectoral distal radials cartilaginous, $1=$ pectoral distal radials ossified, ? = unknown; $0.33,0.78$ )

51. Dorsal postcleithrum. The plesiomorphic presence of a dorsal postcleithrum is found in mugilids, cyprinodontiforms (though absent in New World aplocheiloids; Parenti, 1981), atherinopsines (Fig. 19), and melanotaeniids (Fig. 20), except for pseudomugilins Saeed et al. (1989). The derived absence of a dorsal postcleithrum is found in beloniforms, some menidiines (Chernoff, 1986), notocheirids, Atherion, phallostethids, and in the atherinids Alepidomus, Atherinason, and Kestratherina. In some specimens of Alepidomus the dorsal postcleithrum is present as an extremely reduced nodule on one side only. $(0=$ dorsal postcleithrum present, $1=$ dorsal postcleithrum absent; 0.30 , 0.36 )

52. Dorsal postcleithrum shape. A well developed ovate dorsal postcleithrum is the plesiomorphic condition for atheriniforms (Fig. 20). In Leptatherina, and atherinomorines except Alepidomus, the dorsal postcleithrum is elongated ventrally and contacts the dorsal arm of the ventral postcleithrum. $(0=$ dorsal postcleithrum ovate, $1=$ dorsal postcleithrum elongated, $-=$ non-applicable; $0.50,0.67$ )

53. Ventral postcleithrum shape. A rod-shaped ventral postcleithrum connected to the anterior face of the first pleural rib is the plesiomorphic condition for atheriniforms (Fig. 20; Parenti, 1993; fig. 2; Stiassny, 1993: fig. 4A). A derived condition present in atherinopsids (Fig. 19), Dentatherina, and atherinids, is an expanded, laminar ventral postcleithrum. $(0=$ ventral postcleithrum rod-like, $1=$ ventral postcleithrum laminar, $-=$ non-applicable; $0.50,0.92$ )

The rod-like postcleithrum in atheriniforms is invariably well-separated from the dorsal postcleithrum (Fig. 20A), whereas the laminar postcleithrum is always in contact with the dorsal postcleithrum (Fig. 19A), when the latter is present.

Because of the highly modified nature of the pectoral girdle in phallostethines and the participation of some of its elements in the formation of the priapium in phallostethine males, the ventral postcleithrum is mostly absent or present just as a splint of bone (Parenti, 1989). For this reason, we have conservatively assigned a nonapplicable coding format to this and other ventral postcleithral characters (Chs 53-55).

54. Ventral postcleithrum rami. The plesiomorphic atherinomorph condition is for there to be no rami at the dorsal end of the ventral postcleithrum (Fig. 20A). Atherinids and Dentatherina have one dorsal ramus on the ventral postcleithrum, whereas in atherinopsids two rami are present, of about the same size (Fig. 19A). ( $0=$ no dorsal rami of ventral postcleithrum, $1=$ one dorsal ramus of ventral postcleithrum, 
$2=$ two dorsal rami of ventral postcliethrum, $-=$ non-applicable; $0.67,0.93$ ) (see Ch. 53 for phallostethine condition)

55. Ventral postcleithrum position. The ventral postcleithrum situated anterior to the first pleural rib is the plesiomorphic atherinomorph condition (Parenti, 1993: fig. 2; Stiassny, 1993: fig. 4A), also seen in Dentatherina. A derived condition of atherinopsids and atherinids is for the ventral postcleithrum to be located between the first and second pleural ribs. $(0=$ ventral postcleithrum anterior to first pleural rib, 1 = ventral postcleithrum between first and second pleural ribs, - = non-applicable; $0.50,0.92$ ) (see Ch. 53 for phallostethine condition)

56. Scapular foramen. The plesiomorphic condition of atheriniforms is for the scapular foramen to be fully enclosed by the scapula and clearly separated from the scapulacoracoid articulation (Fig. 19A). In Atherines, the scapular foramen is either shared with the coracoid or separated from its dorsal border by a thin splint of bone (Fig. 20A). The size of the foramen was proposed by Patten (1978) as diagnostic of atherinids and melanotaeniines. We do not include this feature in our analysis because of its variability and instead focus on the incorporation of the coracoid in its ventral border. $(0=$ scapular foramen fully enclosed in scapula, $1=$ scapular foramen shared with coracoid or separated by a thin splint of bone; 1.00)

57. Distal end of the coracoid. The ventral shaft of the coracoid articulates distally with the posteroventral region of the cleithrum. The plesiomorphic condition found in Cyprinodontea (Parenti, 1981), atherinopsids (Fig. 19; Parenti, 1981: fig, 7B), and Notocheirus (Rosen, 1964; Said, 1983) is for the distal end of the coracoid to be relatively narrow, usually with a cartilaginous tip. In Oryzias, Horaichthys, Iso and Atherines, the distal end of the coracoid is wide, non-cartilaginous, and squared by the forward extension of the anterior and posteromedial laminar wings to the articulation with the cleithrum (Fig. 20; Ivantsoff et al., 1987: fig. 6B; Saeed \& Ivantsoff, 1991: fig, 4C). $(0=$ distal end of coracoid narrow, $1=$ distal end of coracoid wide; $0.50,0.83$ )

\section{Pelvic fin and girdle}

58. Pelvic bone medial plate (Chernoff, 1986). The plesiomorphic feature of atherinomorphs is for the medial plate of the pelvic bone to be extended to the anterior end of the longitudinal shaft. In atheriniforms, the pelvic medial plate is short of the anterior end except for atherinids, phallostethids, Atherinella schultzi and $A$. marvelae, Leuresthes, and Cauque (Dyer, in press). ( $0=$ pelvic medial plate extended to anterior end; $1=$ pelvic medial plate not reaching anterior end, $-=$ non-applicable, ? = unknown; 0.50, 0.89)

Another derived condition is present in notocheirids, where the medial plate appears to be fused with the anteromedial process, forming the pelvic foramen characteristic of this group (Fig. 21A).

59. Pelvic bone dorsolateral process. Mugilids and other atherinomorph outgroups have a poorly developed or no dorsolateral process of the pelvic bone (Parenti, 1993; fig. 2; Stiassny, 1990; Fig. 13; Stiassny, 1993: figs 3, 4; Stiassny \& Moore, 1992). Beloniforms have a long and thin (Rosen, 1964: fig. 18) or sometimes expanded dorsolateral process, whereas cyprinodontiforms usually have a short and stubby process. A derived condition of atherinopsids and notocheirids is a pointed spine-like 
process (Chernoff, 1986: fig. 17; Saeed et al., 1994) which is greatly elongated in the latter group (Fig. 21A; Rosen, 1964). Atherines share with cyprinodontiforms a short and stubby process oriented slightly anterodorsally (Fig. 21C). In Dentatherina (Ivantsoff et al., 1987: fig. 6C), Atherina, and Kestratherina the dorsolateral process is oriented posterodorsally rather than anteriorly. In Hypotatherina, Stenatherina, and craterocephalines (Allen, 1980: fig. 10L; Crowley \& Ivantsoff, 1990a,b) the dorsolateral process is greatly reduced or absent. $(0=$ pelvic bone with no dorsolateral process or poorly developed, $1=$ pelvic dorsolateral process spine-like, $2=$ pelvic dorsolateral process short and stubby, oriented anterodorsally, $3=$ pelvic dorsolateral process short and stubby, oriented posterodorsally, - = non-applicable; $0.44,0.55 ; \mathrm{n}$-add)

60. Pelvic bone-pleural rib ligamentous connection (Parenti, 1993; Stiassny, 1993).The plesiomorphic condition present in mugilids and Cyprinodontea is no ligamentous connection between the pelvic girdle and a pleural rib (Parenti, 1993; Stiassny, 1993). Despite presence of a dorsolateral process of the pelvic bone in cyprindontiforms and beloniforms, there is no ligamentous connection to the pleural ribs, except
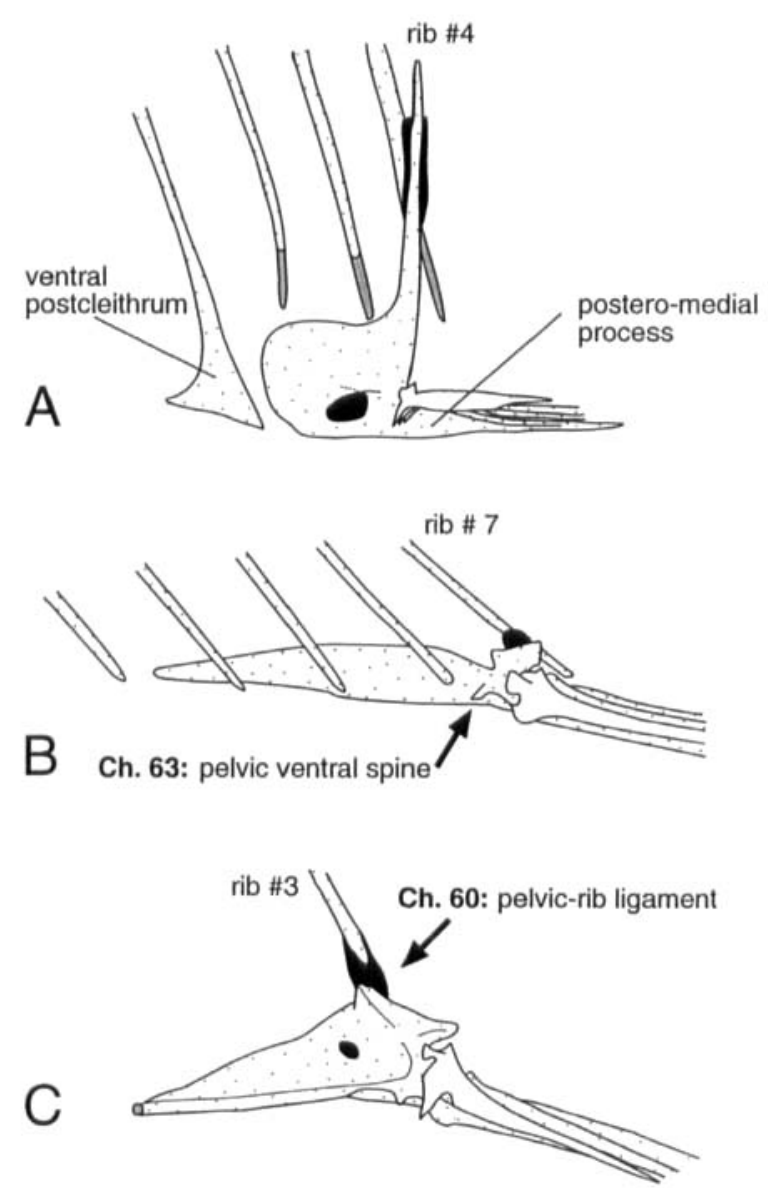

Figure 21. Left side of pelvic girdle and attachment to pleural rib; A, Lso thothophilus (UMMZ 217631); B, Leptatherina (modified from Patten, 1978); C, Atherion elymus (UMMZ 204128). Arrows indicate Characters $60 \& 63$. 
in the adrianichthyid Xenopoecilus (Parenti, 1993). The pelvic bone of mugilids has a ligamentous attachment to the tip of the ventral postcleithrum instead of a pleural rib (Parenti, 1993: fig. 2A; Stiassny, 1993: fig. 4C). In atheriniforms, there is a short and thick ligament between the distal end of a pleural rib and the dorsolateral process of the pelvic girdle (Fig. 21). In notocheirids, the pelvic dorsolateral process is elongated and attached to the pleural rib by an elongated ligament (Fig. 21A). $(0=$ no pelvicrib ligament, 1 = pelvic-rib ligament present, short and thick, $2=$ pelvic-rib ligament present, elongated, $-=$ non-applicable; 1.00)

61. Position of pelvic girdle (Patten, 1978). The pleural rib with which the dorsolateral process of the pelvic bone is associated varies among atherinomorphs. As supported by mugildis and other percoids, the plesiomorphic condition relative to atherinomorphs is the pelvic girdle anteriorly positioned and inclined away from the ventral body wall, and connecting to the pectoral girdle in percoids. The posterior displacement of the pelvic girdle and lack of dorsal inclination of the pelvic girdle axis, are derived features of Atherinomorpha (Stiassny, 1993). The position of the pelvic girdle is variable in atherinomorphs, but its derived position is posterior to the sixth pleural rib. In exocoetoids, the dorsolateral process of the pelvic girdle is opposite or posterior to the tenth pleural rib. In Oryzias and Xenopoecilus, however, the dorsolateral process is opposite the third or fourth ribs (Parenti, 1993). Cyprinodontiforms have the pelvic dorsolateral process close to ribs three and four, or close to ribs six and seven. In menidiines, the pelvic bone is attached to rib four in Melanorhinus and Menidia colei Hubbs, rib five in Poblana and Chirostoma, rib six in Membras and Atherinella, and rib seven in Labidesthes and Menidia. In atherinopsines, the pelvic bone is attached to pleural rib nine or more posteriorly. The pelvic ligament of atherinoideins attaches consistently to the third, fourth or fifth pleural ribs, except in atherinines where the attachment is to ribs six, seven and eight (Fig. 21B). $(0=$ pelvic dorsolateral process attached to anterior pleural rib, rib three through five, 1 = pelvic dorsolateral process attached to posterior pleural rib, rib six or posterior, - = non-applicable; 0.80 )

62. Membrane between the ffth pelvic-fin ray and body wall (Allen, 1980). The plesiomorphic condition is for there to be no membranous attachment of the fifth pelvic-fin ray to the body wall. Presence of such a membrane, enclosing a naked area around the anus and urogenital openings, is a derived feature of pseudomugilins and melanotaenines. This feature was proposed as diagnostic of a sister-group relationship between pseudomugilins and melanaotaeniines (Allen, 1980; Allen \& Cross, 1982), a group which included Cairnsichthys, Rhadinocentrus and Iriatherina. This membrane, however, is lacking in our specimens of Telmatherina and it was not mentioned by Kottelat (1990, 1991) or Saeed \& Ivantsoff (1991). We code this feature as absent in telmatherins, despite not knowing what conditions are present in Scaturiginichthys, Kalyptatherina, Tominanga, and Paratherina. $(0=$ no membrane between fifth pelvic-fin ray and body wall, $1=$ membrane present between fifth pelvic-fin ray and body wall; $0.50,0.67)$

A naked area around the urogenital and anus openings is also present in the Rheocles alaotrensis species group (Stiassny, 1990; Stiassny \& Reinthal, 1992), though lacking a membrane. Concurring with Stiassny (1990), we consider the naked area as independently derived in Rheocles, Pseudomugil and melanotaeniines.

63. Pelvic ventral spine. The ventral face of the pelvic bone, lateral to the longitudinal 
shaft, is a smooth surface to which the abductor muscles are attached. Unique to atherinids is a small, anteroventrally directed spine which is between the base of the dorsolateral process and the longitudinal shaft of the pelvic bone (Fig. 21B). This spine lies between and clearly separates, the abductor muscles of the pelvic spine and those of the pelvic rays. $(0=$ no pelvic ventral spine, $1=$ pelvic ventral spine present, $-=$ non-applicable; 1.00 )

\section{Median fins}

64. Posterior basal pterygiophores of second dorsal and anal fins. In mugilids and atheriniforms except Notocheirus, the posterior two-fin rays (couplet) of the second dorsal and anal fins share the posterior distal pterygiophore of the penultimate basal pterygiophore. The posterior two basal pterygiophores also share an enlarged cartilaginous plate medial to the fin-ray couplet (Fig. 22). The plesiomorphic condition is for the posterior basal pterygiophore to be reduced and separate from the penultimate basal pterygiophore (Fig. 22A), despite sharing a cartilaginous plate; this condition is found in mugilids, atherinopsids, and Iso (though very small). A derived condition found in Atherines is the posterior basal pterygiophore to be either cartilaginous (Fig. 22B) or fully ossified together with the shared medial plate (Fig. 22C), and supporting a finray couplet. Another derived condition is found in Cyprinodontea and Notocheirus in which a single ray is attached to the posterior distal pterygiophore of the median fins,
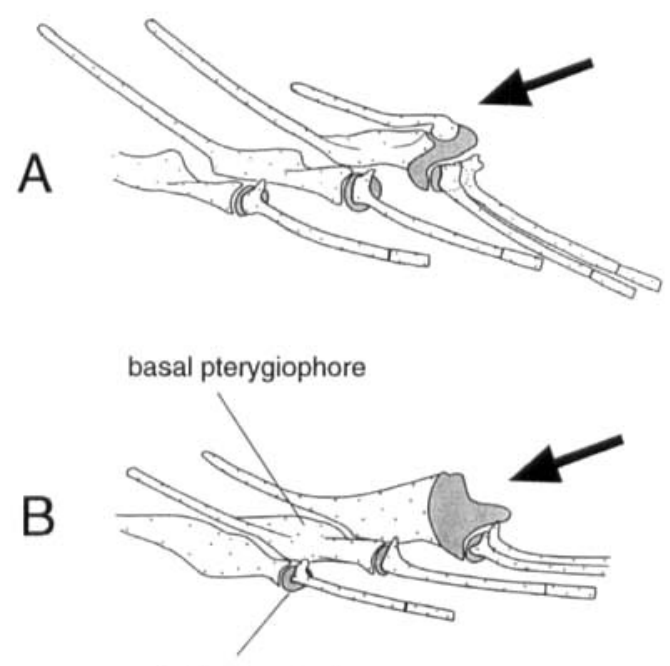

distal pterygiophore

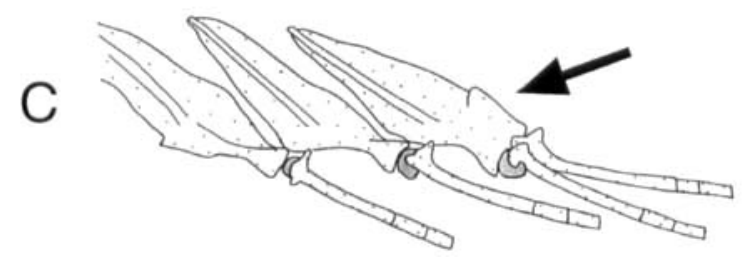

Figure 22. Posterior anal-fin pterygiophores; A, Odontesthes incisa (UMMZ 95499); B, Atherion elymus (UMMZ 204128); C, Bedotia sp. (UMMZ 218508). Arrows indicate Character 64. 
and the two posterior basal pterygiophores do not share a cartilaginous plate (Parenti, 1981: figs 69, 70). ( 0 = posterior basal pterygiophore ossification reduced, sharing a medial cartilaginous plate with the penultimate pterygiophore, and supporting a fin-ray couplet, 1 = posterior basal pterygiophore cartilaginous or ossified with the medial plate, and supporting a fin-ray couplet; $2=$ posterior basal pterygiophore fully developed, not sharing a medial plate with penultimate basal pterygiophore and no fin-ray couplet; $0.67,0.83 ; \mathrm{n}$-add)

65. Anal plate of first anal pterygiophore (Ivantsoff et al., 1987; Parenti, 1984). The plesiomorphic atheriniform condition is for the first pterygiophore of the anal fin to be slightly enlarged relative to the other pterygiophores, and support a spine and an unbranched fin ray (Fig. 23A). Unique to pseudomugilines, phallostethids, and atherinids is presence of an anteriorly expanded first anal pterygiophore in the shape of a roughly triangular plate (Fig. 23D; Ivantsoff et al., 1987: fig. 4). Reduction of this anal plate in the Craterocephalus eyresii species group is reported by Patten (1978:65) and Crowley (1990). $(0=$ no anal plate, $1=$ anal plate present; $0.50,0.92)$

We interpret the condition in melanotaeniines (Fig. 23C; Ivantsoff et al., 1987: fig. $4 \mathrm{~A})$ not as a reduced anal plate, but as a basal pterygiophore modified to support the

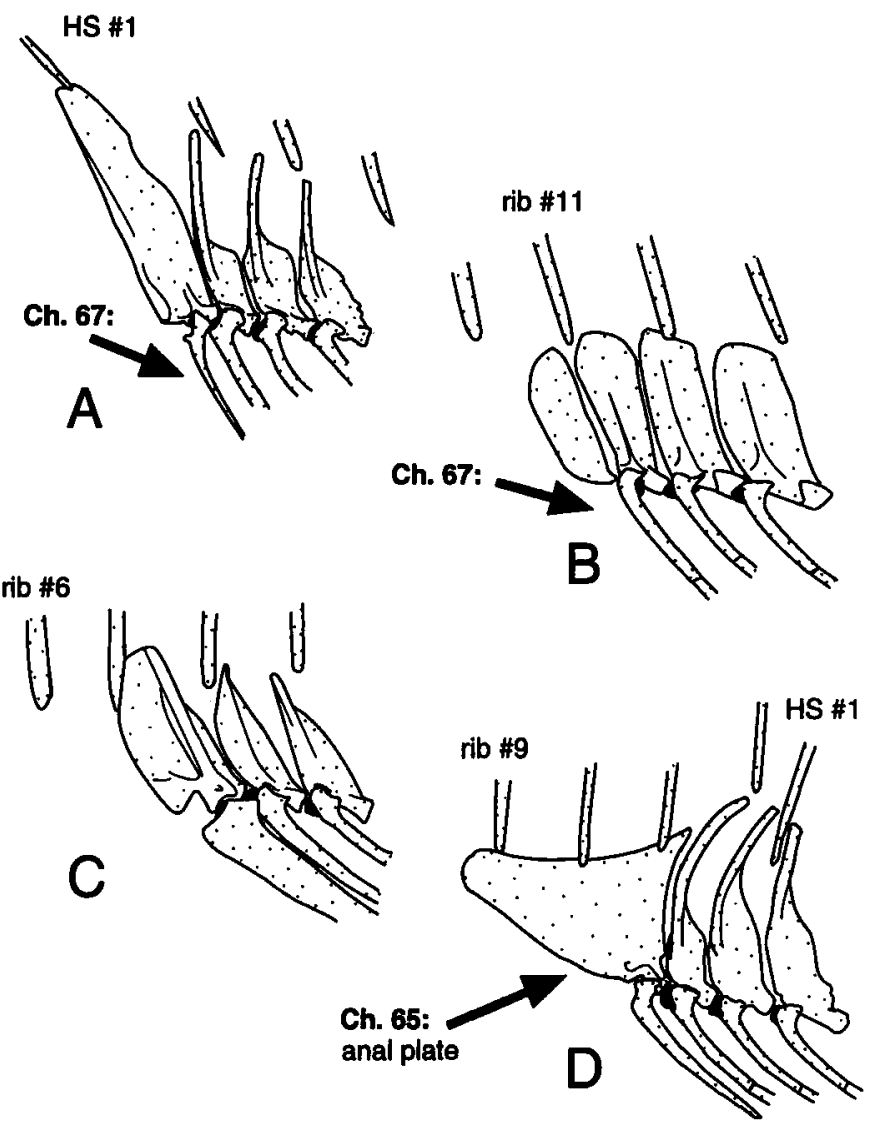

Figure 23. Anterior anal-fin pterygiophores; A, Atherion elymus (UMMZ 204128); B, Bedotia sp. (UMMZ 218508); G, Melanotaenia solata (UMMZ 203850); D, Pseudomugil signifer (UMMZ 217684). Arrows indicate Characters $65 \& 67$. 
strong anal spine ventral to the body cavity. Bedotiines have a modified first pterygiophore (Fig. 23B) different from that in melanotaeniines or Atherion (Fig. 23A).

66. Second dorsal-fin spine. Presence of a strong spine (unsegmented ray) preceding the second dorsal fin is the plesiomorphic condition found in outgroups of atherinomorphs and mugilids. The second dorsal fin of atheriniforms and mugilids is hypothesized to be homologous with the single dorsal fin possessed by cyprinodontiforms and beloniforms (Parenti, 1993: 188). With the exception of fordanella, an advanced cyprinodontiform (Parenti, 1981), Cyprinodontea lack a spine on the dorsal fin (Parenti, 1993). Mugilids lack a spine on the second dorsal fin. Most atheriniforms, possess a single flexible spine preceding the second dorsal fin (Ivantsoff et al., 1987: figs 4, 5). A second dorsal-fin spine is lacking, however, in bedotiines, pseudomugilines, and phallostethines, whereas some melanotaeniines such as Melanotaenia, Glossolepis, and Chilatherina have strong stout spines. $(0=$ second dorsal fin with strong spine, 1 = second dorsal fin with flexible spine, $2=$ second dorsal fin without spine; $0.40,0.75 ; \mathrm{n}$-add)

Allen (1980) reported Iriatherina as having a relatively weak but still strong second dorsal-fin spine, whereas Caimsichthys and Rhadinocentrus lack a spine. Saeed et al. (1994) discuss the segmentation of the anteriormost ray of the second dorsal fin in Rheocles alaotrensis and in Bedotia geayi, but did not consider it as a general feature for the group and did not discuss this feature in melanotaeniines.

Patterson (1992: fig. 2) characterized Atherinomorpha as having a single dorsal supernumerary ray. Cyprinodontea has one dorsal supernumerary ray as do mugilids, however, the first dorsal fin of atheriniforms has two supernumerary rays.

67. Anal-fin spine. Presence of a strong spine (unsegmented ray) preceding the anal fin is a plesiomorphic condition found in atherinomorph outgroups. Cyprinodontea, bedotiines, and some pseudomugilins of the Pseudomugil signifer species group (Saeed et al., 1989) share the derived absence of an anal-fin spine (Fig. 23B); the remaining atheriniforms have a flexible anal-fin spine (Fig. 23A; Ivantsoff et al., 1987: figs 4, 5). $(0=$ anal-fin spine present, $1=$ anal-fin spine absent; $0.50,0.67)$

68. Interdorsal bones (Ivantsoff et al., 1987). Pterygiophores without associated fin rays between the dorsal fins (interdorsals) are found in mugilids (Parenti, 1993: fig. 8A), and in most atheriniforms except for Iso, some atherinopsids (e.g. Atherinella eriarcha Jordan \& Gilbert), pseudomugilins (Said, 1983; Saeed et al., 1989), and Craterocephalus marjoriae. In atheriniforms, interdorsals resemble a basal pterygiophore in that they have a ventral shaft (Ivantsoff et al., 1987 fig. 5A; Parenti, 1993: fig. 8B). Interdorsals lacking a ventral shaft is a derived feature of atherinopsids (Parenti, 1993: fig. 8C), Dentatherina (Ivantsoff et al., 1987: fig. 5B), and Telmatherina; the telmatherin Kalyptatherina helodes has the plesiomorphic interdorsal with a ventral shaft (Saeed \& Ivantsoff, 1991). Another derived condition is found in phallostethines in which a single spine-like element of the first dorsal pterygiophore is in place of interdorsals (Ivantsoff et al., 1987: fig. 5G). Whether the phallostethine interdorsals are actually fused into this spine-like element or are absent altogether could not be determined in this study. $(0=$ interdorsals with ventral shaft, $1=$ interdorsals lacking a ventral shaft, 2 = interdorsals absent, $3=$ interdorsals fused into spine-like element, $-=$ non-applicable; $0.67,0.60 ;$ n-add) 
A derived condition is found in Rheocles lateralis Stiassny \& Reinthal, in which the interdorsals are broad and plate-like (Stiassny \& Reinthal, 1992: fig. 6A). Allen (1980) considered the reduced number of interdorsal elements $(2-3)$ to be a derived feature diagnostic of melanotaeniines. Though not coded by us because of variability and overlap of ranges, the generalized condition for atheriniforms seems to be five or more interdorsals. Such is the case in atherinopsids, Atherion, Dentatherina, atherinines, Craterocephalus honoriae (Ogilby), Allanetta, and Stenatherina. Bedotiines and most craterocephalines have four or five elements, atherinomorines other than Stenatherina have five or fewer, telmatherins and melanotaeniines have two or three, and pseudomugilins, phallostethines, and Iso have none.

\section{Caudal fin and axial skeleton}

69. Pleural ribs posterior to anal-fin origin. The plesiomorphic condition found in most atherinomorphs is for the posterior pleural rib to be anterior to the anal-fin origin (Schultz, 1948: fig. 1A). In atheriniforms, atherinopsids and melanotaeniids have three or more pleural ribs posterior to the anal-fin origin (Fig. 23B, C, D), together with posterior projection of the coelomic cavity. Within atherinoideins, melanotaeniines have roughly 10 to 12 ribs posterior to the anal-fin origin, bedotiines have six to eight, and telmatherins and pseudomugilins have three to five. In atherinopsids, three to ten ribs are posterior to the anal-spine origin except for Membras, Melanorhinus, and species of Odontesthes (Dyer, 1993). ( $0=$ no pleural ribs posterior to anal-fin origin, $1=$ three or more pleural ribs posterior to anal-fin origin; 0.50 , 0.88 )

70. Ventral interhaemal cartilage PU2vt. Presence of a cartilage between the distal ends of the PU2 and PU3 haemal spines is widespread throughout acanthomorphs (Stiassny, 1990). Ossification of the cartilage is a derived feature shared by psuedomugilins, telmatherins and Alepidomus. (0 = PU2vt cartilaginous, $1=$ PU2vt ossified; 0.50)

\section{External features}

71. Sensory canals of the head. The plesiomorphic condition as found in mugilids and exocoetoids (Astakhov, 1980), is for the sensory canals of the head, except the preopercular canal, to be fully enclosed by bone. Atherinopsids have all head sensory canals enclosed, including the preopercular canal which is partially or fully enclosed by bone (Chernoff, 1986b; Dyer, 1993, in press). A derived condition is present in adrianichthyoids (e.g. Oryzias, Horaichthys), cyprinodontiforms, and atherinodeins, in which the sensory canals of the head are in an open canal or trough, rather than in a tube fully enclosed by bone (Fig. 8A). Bedotiines and atherinids, with the exceptions of Alepidomus and Atherinomorus stipes Müller \& Troschel, share a derived condition in which only the mandibular canal is enclosed by bone (Figs 14, 16). ( 0 = head sensory canals enclosed by bone, except for preopercular canal, $1=$ all head sensory canals open, 2 = head sensory canals open, except for mandibular canal; $0.50,0.80$ )

A derived condition is found in Craterocephalus kailolae in which the anterior infraorbital, frontal, nasal, and posttemporal sensory canals are enclosed (Crowley, 1990a; Crowley \& Ivantsoff, 1992).

72. Odontodes. The plesiomorphic condition is for teeth to be attached only to the oral and pharyngeal jaws. Teeth attached to other dermal bones of the head (e.g. frontal, 
infraorbitals, preopercular, etc.) or odontodes, are a derived feature of Notocheirus and Atherion (Figs 8, 9; Ivantsoff, 1978; Patten, 1978; Said, 1983). Notocheirus has head odontodes attached either to dermal bones or restricted to scales as in the rest of the body. $(0=$ teeth attached only to jaws, $1=$ teeth attached to jaws and other head bones; $0.50,0.0)$

73. Body size (as Standard Length: SL) of adult atheriniforms, mugilids, cyprinodontiforms, and beloniforms is variable. A derived condition for atheriniform fishes is the small adult size of phallostethids, with a maximum recorded size of $37 \mathrm{~mm}$ SL in Gulaphallus eximius Herre (Parenti, 1989). This is about one-and-a-half times the maximum size of minature fishes, as defined by Weitzman \& Vari (1988). $(0=\geq 50 \mathrm{~mm}$ SL adult size, $1=\leq 40 \mathrm{~mm}$ SL adult size; 1.00$)$

The only atheriniform species that clearly qualifies as a miniature is the pseudomuguilin Scaturiginichthys vermeilipinnis Ivantsoff et al. (1991), though some species of Pseudomugil are possible candidates (Saeed et al., 1989). The maximum size recorded for any atheriniform is $520 \mathrm{~mm}$ SL (Odontesthes bonariensis, MNHM-N 199), or about $600 \mathrm{~mm}$ Total Length.

74. Body depth. Mugilids, adrianichthyoids and cyprinodontiforms usually have body depths over $25 \%$ of Standard Length (SL), with some exceptions (Parenti, 1981; Kottelat, 1990b). The body form typical of exocoetoids and atheriniforms is elongate and fusiform, with body depth at the anal fin origin less than $20 \%$ of SL. Within atheriniforms, melanotaeniids and Quirichthys share the primitive condition of body depths more than $20 \%$ of SL. ( $0=$ body deep, depth at anal fin origin more than $20 \% \mathrm{SL}, 1$ = body elongate, depth at anal fin origin less than $20 \% \mathrm{SL} ; 0.50$, 0.80 )

Notocheirus also has a deep body at the anal fin origin, but this is considered independently derived as a result of the great body depth at the pectoral fin origin and the anterior position of anal fin origin ( $\mathrm{Ch} .80)$.

75. Lateral band. Lack of a lateral band, as in mugilids and cyprinodontiforms, is considered the plesiomorphic condition for atherinomorphs. A broad lateral silvery band that is characteristic of exocoetoids and accounts for the vernacular name of atheriniforms in North America (silversides), is reduced or absent in adrianichthyoids, melanotaeniids, and Quirichthys. $(0=$ no lateral band or greatly reduced, 1 = lateral band present; $0.50,0.80$ )

76. Sexual dimorphism. The plesiomorphic atherinomorph condition, as seen in exocoetoids and most atheriniforms, is no pronounced sexual dimorphism. Sexual dimorphism in body and fin coloration, dorsal fin position, and anal fin-ray modifications is considered a derived feature in cyprinodontiforms and adrianichthyoids (Parenti, 1981; Kottelat, 1990 b,c). Atheriniforms are mostly monomorphic except for melanotaeniids and Quirichthys, which are sexually dimorphic in body and fin coloration, and median fin-ray extensions (Allen \& Cross, 1982). ( $0=$ sexually monomorphic, 1 = sexually dimorphic, bright coloration and median fin elongation in males; $0.50,0.75$ )

77. Characters of Phallosthethinae. Phallostethines are strongly sexual dimorphic in having a subcephalic copulatory organ, the priapium, modified from the pelvic girdle and fin, and parts of the pectoral girdle and fin (Parenti, 1984, 1989). Five features were extracted from Parenti (1989) as diagnostic of phallostethines: (1) sexually 
dimorphic characters associated with the priapium, and bilateral asymmetry of the anus and urogenital pores; (2) dorsal hypohyal absent; (3) first dorsal fin reduced or absent (similar in Notocheirus); (4) postcleithra reduced to bony slivers or absent; and (5) presence of a fleshy keel from urogenital opening to anal fin (a reduced membrane is also present in $I s o$ ). These characters were used to provide $\mathrm{Ch}$. 77 with a weight of five in the analysis (1.00)

78. Larval melanophores in a single mid-dorsal row (White et al., 1984). The larval pigmentation pattern of atheriniform outgroups is of two or more rows of melanophores arranged along the dorsal mid-line, or no observable pattern. Atheriniform larvae have the derived condition of a single row of melanophores arranged along the dorsal mid-line (White et al., 1984: fig. 189A). The same pigmentation pattern is found, however, in some adrianichthyoids (White et al., 1984: 359; Parenti, 1993). ( $0=$ two or more mid-dorsal rows of melanophores, $1=$ one mid-dorsal row of melanophores; 1.00)

79. Preanal length in hatchling-flexion period (White et al., 1984). The preanal length of larvae through flexion in atheriniform outgroups is greater than $40 \%$ of body length. Atheriniform larvae have a short preanal length in the hatchling-flexion period, of about $33 \%$ of body length at the time of flexion (White et al., 1984: fig. 188). This feature, among acanthomorphs, is also found in gadids and has been considered potentially homologous by Parenti (1993), or independently derived by White et al. (1984) and Johnson \& Patterson (1993). (0 = preanal length greater than $40 \%$ of body length, $1=$ preanal length less than $40 \% ; 1.00)$

80. Characters of Notocheiridae (Rosen, 1964). Of the ten features listed by Rosen (1964: 227) for the diagnosis of Notocheiridae, five are unique to Notocheirus and only five are characteristic of the family: "scapula and coracoid entirely above midlateral line; cleithrum a long strut extending from above scapula to midventral line where it joins fellow; postcleithrum almost as long as cleithrum, its ventral tip expanded and dentate where it joins fellow at midventral line somewhat posterior to cleithral symphysis; pelvic bone with lateral spur extending upward between pleural ribs nearly to ventral column; last few caudal vertebrae, neural and hemal spines bunched together". Schultz (1948) first diagnosed the family with, among other characters: "the greatest depth of the body occurring near the rear of the head and then the body tapering to the least depth at the caudal peduncle and compressed throughout, with the ventral edge of the belly of almost paper thinness". Because of the overlap of features described above, the following is a summary diagnosis for the group involving the pectoral and pelvic girdles: (1) body depth greatest at pectoral fin origin, with greatly elongated cleithra and postcleithra; (2) ventral abdominal edge in a sharp keel, with ventral expansions of the cleithra and postcleithra contacting at the mid-line; (3) pectoral fin and scapula above mid-lateral band; (4) pelvic bones greatly modified to form a sharp ventral keel, a foramen apparently formed by the fusion of the antero-medial spine to the medial plate (Fig. 21A), and a long dorsolateral process of the pelvic bone attached to the pleural rib via a broad ligament (Ch. 60). The above-listed characters were used to provide $\mathrm{Ch}$. 80 with a weight of four in the analysis (1.00)

81. Characters of Atherinomorpha Stiassny, 1990, 1993; Parenti, 1993). Of a list of 18 characters compiled from Parenti (1993) and Stiassny (1993), we conservatively selected five unique features to diagnose atherinomorphs: (1) spermatogonia 
restricted to distal end of testicular tubules; (2) pelvic girdles lacking median suture and dorsolateral processes associated with pleural ribs; (3) supracleithrum reduced and saddled on cleithral dorsal enclosure rather than laterally; (4) enlarged fourth epibranchial and fourth pharyngobranchial; and (5) olfactory sensory epithelium arranged in sensory islets. The above-listed characters were used to provide Ch. 81 with a weight of five in the analysis. (1.00)

82. Characters of Atherinposidae (White, 1985; Chernoff, 1986; Dyer, in press). The following characters are diagnostic of atherinopsids: (1) sphenotic postorbital process wide; (2) dermosphenotic not articulated to postorbital process and (3) with sensory canal enclosed; (4) presence of pterotic wing and (5) exoccipital wing; (6) posttemporal with anterior process; (7) premaxilla with narrow anterior joint; (8) premaxillary alveolar arm greatly expanded; (9) premaxilla-dentary coronoid ligament very short; (10) presence of a maxilla-anguloarticular ligament; (11) premaxilla-maxilla ligament long; (12) ethmomaxillary ligament with palatine attachment; (13) vertical shaft of preopercular canal enclosed; (14) dorsal border of opercle displaced medially from dorsal process; (15) Baudelot's ligament posteriorly attached to cleithrum, parapophysis and epineural of first vertebra; (16) presence of pectoral struts in cleithral dorsal enclosure; (17) pectoral-fin spur fused to second ray; (18) ventral postcleithrum between pleural ribs one and two; (19) interdorsals without a ventral shaft; (20) pleural ribs posterior to first anal-fin pterygiophore. The abovelisted characters $1,5,7,8,9$, and 15 are unique features of Atherinopsidae and were used to provide Ch. 82 with a weight of six in the analysis (1.00)

83. Characters of Phallostethini (Parenti, 1989). The Phallostethini (= 'Phallostethini + Neostethini' of Parenti, 1989:fig. 7) is diagnosed by four unique features (Parenti, 1989:256), as follows: (1) second ctenactinium present; (2) shieldlike pulvinus present and outer pulvinular bone robust; (3) highly protrusible oral jaws; and (4) reduction of hyobranchial apparatus. The above-listed characters were used to provide Ch. 83 with a weight of four in the analysis. (1.00)

\section{Phylogenetic relationships}

Claims of monophyly are supported solely by diagnostic features, i.e. characters that are unambiguously derived at that node (whether unique or homoplasious) in the context of the proposed hypothesis of phylogenetic relationships. Most nodes have an additional suite of characters that are ambiguously optimized at that node but are, nevertheless, deemed informative of the group's historical identity.

\section{Ambiguous characters}

Ambiguity due to alternative equally parsimonious reconstructions of a character's evolution may lead to loss of diagnostic information if only the unique and unambiguous traits are considered as informative of relationships. Some of this phylogenetic information can be retrieved, in the form of additional supporting characters, by identifying the type of ambiguity affecting each character.

Three classes of character ambiguities were identified in this study that allow, given the assumptions, for the recovery of characters as evidence of monophyly:

(1) character is ambiguous because the relatively primitive state is present in a highly derived sister taxon to one of two ingroup sister taxa (Fig. 24A). Examples 
such as Chs 20, 26, 57 (Appendix 2: Atherinoidei, except in Notocheirus), Ch. 14 (Appendix 2: Node F, except in phallostethines), and Ch. 71 (Appendix 2: Atherinidae, except in Alepidomus) are otherwise unique or clearly derived characters and are deemed as informative of relationships at those nodes. The auxiliary assumption is that the ingroup sister-taxon in particular (e.g. Notocheirus, Alepidomus) is highly derived by some mode of paedomorphic development; (2) despite presence of the derived character state in the ingroup, that character state is ambiguous because of other character-state polymorphism, absence of data, or both, in one or more outgroups (Fig. 24B) (Appendix 2: Atherinopsidae, Chs 32, 61; Atherinoidei, Ch. 71). The auxiliary assumption is the pleisomorphic condition is present at the outgroup nodes; and (3) a non-additive multistate character is ambiguous because the character states present in each of two ingroup sister taxa are different and derived
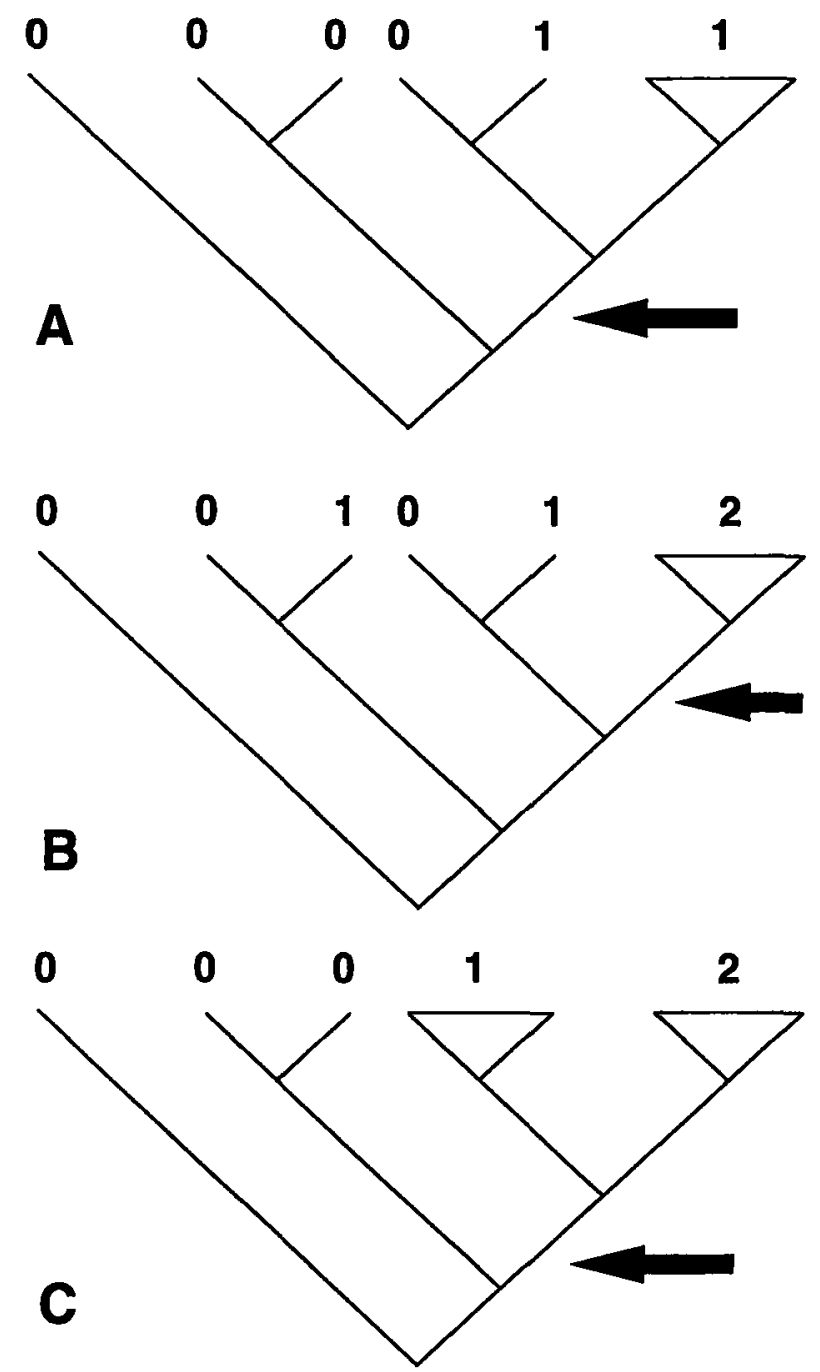

Figure 24. Three classes of character state distributions that result in ambiguous optimizations when mapped on a cladogram; A, Type 1 ambiguity; B, Type 2 ambiguity; C, Type 3 ambiguity. See text for explanation under Relationships section. Arrows indicate node of a posterion suggested optimization. 
relative to the plesiomorphic state present in outgroups. Examples such as Ch. 2 (Appendix 2: Atherininae \& Craterocephalinae), Ch. 68 (Appendix 2: Phallostethinae \& Dentatherininae) are otherwise diagnostic of the clades in which they are present. The auxiliary assumption is that both states are derived independently from the primitive condition present in their common ancestor.

Different modes of optimization are chosen for each individual character according to the type of ambiguity identified after the phylogenetic analysis. Rather than choosing a single optimization criterion for all characters prior to the analysis, we chose an a posteriori approach as a more appropriate method for additionalcharacter support of monophyly. In the first and second types of ambiguity, characters are optimized to the node of greater generality with subsequent reversals (ACGTRAN in PAUP), whereas in the third type of ambiguity the derived character states are optimized to nodes of lesser generality by assuming the primitive state at the preceding node (DELTRAN in PAUP). The number of ad hoc assumptions decreases when suites of characters of the same class of ambiguity are present at one node (Appendix 2: Atherinoidei). In this manner a total of 30 character states were 'recovered' and 'allocated' to particular nodes as additional support to the diagnosis of a group.

\section{Monophyly of Atheriniformes}

Adult morphology of the vomer (Ch. 1), jaw musculature (Ch. 31), number of infraorbital bones (Ch. 37), pelvic girdle (Chs 58, 60), second dorsal-fin spine (Ch. 66), body depth (Ch. 74), and lateral band (Ch. 75) corroborate the monophyly of Atheriniformes proposed by White et al. (1984) based on larval characters alone (Chs $78,79)$. The scarcity of larval material in collections raises some concern about the universality of the larval characters. Nonetheless, the larval pigmentation pattern (Ch. 78) and preanal length at flexion (Ch. 79) continue to be robust hypotheses of homology supporting a monophyletic assemblage, each feature challenged by only one other independent occurrence in different taxa within beloniforms (White et al., 1984; Parenti, 1993).

Stiassny (1990: fig. 2) explicitly proposed atheriniforms as a paraphyletic assemblage by placing bedotiines and melanotaeniines as sequential outgroups to the remaining 'atherinoids' and Cyprinodontea. Based on the characters presented herein (Table 2), Stiassny's hypothesis requires at least 30 additional steps relative to the hypothesis presented by us (Fig. 3). More recently, Saeed et al. (1994) also proposed a paraphyletic Atheriniformes with atherinopsids and notocheirids as sister to Cyprinodontea and Atherines. Based on the characters of Table 2, which includes most of Saeed et als (1994) features, their hypothesis is 29 steps longer than that of Figure 3.

\section{Monophyly of Atherinopsidae}

Atherinopsidae, comprised of the New World silversides Menidiinae and Atherinopsinae, is the sister group to other atheriniforms (Fig. 3). Twenty diagnostic characters support the monophyly of this group (Dyer, 1993, in press). Character 82 represents six unique features that diagnose atherinopsids (Appendix 2; see Characters section) taken from the works of Patten (1978), White (1985), Chernoff (1986), and Dyer (1993, in press). The following eight characters are also diagnostic features of Atherinopsidae: ethmomaxillary ligament attached to palatine (Ch. 2); presence of posttemporal canal (Ch. 14); pectoral-fin spur absent (Ch. 49); ventral 
postcliethrum laminar (Ch. 53; also in Dentatherina and atherinids), with dorsal and anterior rami of about equal size (Ch. 54), and between first and second pleural ribs (Ch. 55; also in atherinids); interdorsals without a ventral shaft (Ch. 68; also in Dentatherina); and three to ten ribs posterior to anal-fin origin (Ch. 69). Additional support is the Al maxillary tendon attached to the distal half of maxilla (Ch. 32) and the posterior position of the pelvic girdle (Ch. 61).

The New World silversides were first proposed as a monophyletic group by Patten (1978), and this was later confirmed by White (1985) and Chernoff (1986). Saeed \& Ivantsoff (1991) discussed the difference between New and Old World silversides, and grouped the Old World silversides with melanotaeniids and phallostethines. Saeed et al. (1994) proposed the New World silversides as a separate family, Atherinopsidae, diagnosed by eleven characters extracted from Patten (1978), White (1985), and Chernoff (1986).

\section{Monophyly of Atherinoidei}

Atherinoidei is a monophyletic group which includes notocheirids, melanotaeniids, Atherion, phallostethids and atherinids. This group is diagnosed by three features: lack of epioccipital wings (Ch. 12; also in Chirostoma), the basisphenoid articulated with the prootic only (Ch. 18; also in beloniforms), and lack of a palatine dorsal process (Ch. 35). The derived nature of Notochirus and Iso, in combination with their phylogenetic position (Fig. 3: Notocheiridae), resulted in the ambiguous optimization (type 1, see above) of four characters (Chs 17, 20, 26, 57) that would otherwise have diagnosed Atherinoidei. Two of these additional-support characters are the otherwise unique presence of a parasphenoid fossa (Ch. 20) and presence of a maxillary posterodorsal spine (Ch. 26), both of which are absent in Notocheinus. Open sensory canals of the head (Ch. 71 ) is a feature also found in cyprinodontiforms and adrianichthyoids, and presents an example of ambiguity type 3 .

Patten (1978) proposed these taxa as a clade, with the exception of phallostethids which were omitted from the analysis, but his characters are not diagnostic at this level in our hypothesis of relationships.

\section{Monophyly of Notocheiridae}

Notocheiridae, comprised of Notocheirus and Iso, is the sister group to the other lineages within Atherinoidei (Fig. 3). Rosen (1964: 227) listed ten features in his diagnosis of the family, but only five characters are actually diagnostic of Notocheiridae. The notocheirid traits listed by Rosen are reanalyzed and summarized in the data matrix as Character 80 (Table 2, Appendix 2; For a discussion of features see Ch. 80 in Gharacters section). Other diagnostic features of notocheirids are an elongated pelvic-pleural rib ligament (Ch. 60) and absence of a supracleithrum (Ch. 47), the latter feature not mentioned by Rosen (1964) despite it being listed for Oryziidae.

Notocheirus and Iso were first proposed as close relatives by Schultz (1948), based mainly on body shape. The subfamily name was later corrected from Tropidostethinae to Notocheirinae, and Notocheirus was explicitly nominated as type genus (Schultz, 1950). Rosen (1964) called this same group of fishes Isonidae with a diagnosis based mainly on unique osteological modifications of the head, pectoral, and pelvic girdles. Notocheiridae of Schultz (1950), has precedence over Isonidae of Rosen (1964). Saeed et al. (1994) placed each genus in a separate family, but with no justification beyond citing unpublished work by Saeed \& Ivantsoff we find no reason to follow that proposition. Saeed et al. (1994) also proposed this group as a sister to 
atherinopsids and named that assemblage 'Atherinopsoidea', based solely on the spine-like dorsolateral process of the pelvic girdle (Ch. $59\{1\}$ ).

From Rosen's (1964: 227) list of characters, the first four and the tenth are diagnostic of Notocheirus: teeth restricted to external surface of a laminar and convex premaxillary head (Ch. 29), palatine minute, vomer absent, large antero-ventral process of parasphenoid, and epurals absent. Saeed et al. (1994) diagnosed Notocheirus with seven features of which two are derived and not previously mentioned by Rosen: first dorsal fin absent and body scales elongated with teeth. Five other diagnostic features (Chs 19, 36, 49, 64) result from this study, of which one is unique in atheriniforms and independently derived in Cyprinotontea: the posterior pterygiophore of the anal and dorsal fins is well developed, not sharing a basal plate with the penultimate pterygiophore, and hence, the posterior two rays do not form a couplet (Ch. 64). Additional-support characters are absence of mesethmoid (Ch. 3) and reduced dorsal enclosure of cleithrum (Ch. 48; also in pseudomugilins).

Diagnostic features of Iso from Said (1983) and Saeed et al. (1994) are: a small fleshly keel behind the genital opening; absence of scales on anterior regions of the body and head (also in Atherinella lisa Meek); parietals small, not in posttemporal fossa; interhyal long; an enlarged postero-medial spine of the pelvic girdle (Fig. 21A); and an exoccipital process (Fig. 13A). Of four additional-support characters (Chs 3, $37,48,68$ ) for this group, one is the unique shape of the mesethmoid (Ch. 3; Fig. 8E) which is not diagnostic because of ambiguity (type 3 ).

\section{Monophyly of Atherines, new infraorder (Fig. 3, Node C)}

This clade is comprised of melanotaeniids, Atherion, phallostethids, and atherinids. Eight characters are diagnostic of this group: presence of a rostral fossa depression (Gh. 4); nasal bone participating in the orbital rim (Ch. 6); presence of a nasal ventromedial ligament to lateral ethmoid (Ch. 7); absence of parietals (Ch. 10; also in Oryzias); presence of intercalars (Ch. 11); distal radials of pectoral girdle ossified (Ch. 50); scapular foramen shared with coracoid (Ch. 56); and the posterior basal pterygiophore of the anal fin and second dorsal fin cartilaginous or ossified with medial plate (Ch. 64; Fig. 22 B,C). Characters of additional support are an isolated mesethmoid (Ch. 3); pterotic and posttemporal canals disconnected (Ch. 16); and the dorsolateral process of pelvic girdle short and directed anteriorly (Ch. 59).

Saeed \& Ivantsoff (1991: 229) agreed with Parenti (1984) on the non-monophyly of Division I (Atherininiformes, Table 1), but regarded “...Melanotaeniidae, Old World Atherinidae (but not the New World Atherinidae), Dentatherinidae, Telmatherinidae, Phallostethidae and Pseudomugilidae" as a monophyletic group. Although Saeed \& Ivantsoff (1991) distinguished a portion of this clade from Atherinopsidae by four features (Chs $4,10,59,64$ ), notocheirids were not included in their comparative analysis. Saeed et al. (1994) included bedotiines in the above list of families and named it 'Atherinoidea', which is equivalent to Atherines of this study.

\section{Monophyly of Melanotaeniidae}

A monophyletic Melanotaeniidae (Fig. 5) is proposed as the oldest available family-level name for an assemblage of four groups of freshwater fishes known as Madagascar rainbows (bedotiines), rainbowfishes (melanotaeniines), blue-eyes (pseudomugilins), and sailfin silversides (telmatherins).

Melanotaeniidae is diagnosed by six features: posterior myodome restricted to the 
prootics (Ch. 22), absence of a second dorsal-fin spine (Ch. 66), three or more pleural ribs posterior to first anal pterygiophore (Ch. 69; also in atherinopsids), greater body depth (Ch. 74), reduction or loss of the silvery lateral band (Ch. 75), and sexual dimorphism in body colour and median-fin ray elongation (Ch. 76). Characters 74-76 are also present in cyprinodontiforms, adrianchthyoids, and the craterocephaline Quirichthys, but are considered as independently derived in this hypothesis of relationships.

Saeed et al. (1994) proposed bedotiines and melanotaeniines as sister taxa, but considered telmatherins and pseudomugilins to be more closely related to phallostethines. The relationship among bedotiines, pseudomugilines, and melanotaeniines is weak (Fig. 5: Node E1). Furthermore, the addition of new characters and especially the addition of taxa lacking in this analysis (e.g. Rhadinocentrus, Caimsichthys, Kiunga, Kalyptatherina, Tominanga, Paratherina, etc.) may shift the level of generality at which some of these characters are diagnostic. The results of this study provide us with strong support for each of the subfamilies and a fully resolved, though weakly supported set of melanotaeniid interrelationships (Fig. 5) which is, nevertheless, shorter than Saeed et als (1994) hypothesis and deserves some discussion.

Melanotaeniinae is tentatively considered to be the sister group to Pseudomugilinae (Pseudomugilini-Telmatherinini clade) as supported by presence of enlarged distal premaxillary teeth (Ch. 28; also in phallostethines and Oryzias). Additional support is presence of external premaxillary teeth (Ch. 29) and Al muscle manibular tendon (Ch. 31). Taxa of Node El (Fig. 5) are in freshwater systems east of Wallace's Line, whereas its sister group, Bedotiinae, is a strictly freshwater group endemic to Madagascar.

Bedotiinae is comprised of Bedotia and Rheocles. Four features diagnose this group: absence of pterotic canal (Ch. 13), a posterior extension of the parasphenoid ridge (Ch. 19), absence of an anal-fin spine (Ch. 67), and enclosed mandibular sensory canals (Ch. 7l). Character 67 is unique within Atheriniformes, but is also a feature of Cyprinodontea. Stiassny (1990) diagnosed Bedotiinae with three characters: assymetric medial processes of the pelvic bones, thickening of the posterior vertebrae, and two anterior infraorbitals (Ch. 37). In this analysis, the latter trait is ambiguously optimized at this node because two bones are also present in Glossolepis, Cairmsichthys, and Iriatherina (Ivantsoff et al., 1987).

Rheocles is diagnosed by absence of urohyal posterodorsal processes (Ch. 45) and with cartilaginous pectoral distal radials (Ch. 50). Fused ventral elements of the caudal skeleton was the only diagnostic feature of Rheocles proposed by Stiassny (1990). That feature, however, is also present in most melanotaeniines (Allen, 1980) and pseudomugilins (Saeed et al., 1989). Bedotia is diagnosed by presence of a parasphenoid ventral fenestra (Ch. 21) and an enlarged mesethemoid (Ch. 3; also in Melanotaenia and Chilatherina). Stiassny (1990) diagnosed Bedotia with the following features: a premaxillary notch, a paired tooth patch on basibranchial three, absence of pelvic anteromedial spines, and reduction of pelvic posteromedial spines. We tentatively accept these features as diagnostic because we lack the appropriate comparative material and the features are present in some other melanotaeniid taxa (De Beaufort, 1922; Allen, 1980: figs 6, 10; Saeed et al., 1989). Confirmation of these characters as diagnostic features can only come from a complete revision of the melanotaeniid group.

Melanotaeniinae sensu stricto (Melanotaenia. Chilatherina, Glossolepis, ?Iriatherina) is diagnosed by presence of a posttemporal canal (Ch. 14), and strong or stout spines 
of the median fins (Ch. 66). Additional support is presence of the pelvic-fin ray-tobody membrane (Ch. 62). Characters shared by Melanotaenia and Chilatherina are presence of three anterior infraorbitals (Ch. 37) and a connection between the preopercular and anterior infraorbital sensory canals (Ch. 40); additional support is the enlarged mesethmoid (Ch. 3; also in Bedotia). The interrelations of melanotaeniine genera are not addressed in this study because we are unable to include Iriatherina, Caimsichthys and Rhadinocentrus in the analysis of all characters. Allen (1980) and Allen \& Cross (1982) suggested these three monotypic genera are melanotaeniines. The combination of characters used by these authors, however, suggest these genera could be either related with melanotaeniines (Allen, 1980; Allen \& Cross, 1982) or with other melanotaeniid subfamilies.

Pseudomugilinae is comprised of pseudomugilins and telmatherins (Fig. 5), a clade diagnosed by seven derived features: nasal ventromedial ligament attached to palatine (Ch. 7); an enlarged submaxillary meniscus (Ch. 23) with a hyaline-cartilage core (Ch. 24), maxillary shaft wide proximally (Ch. 27), $\mathrm{Al}$ maxillary tendon to distal half of maxilla (Ch. 32), presence of anal plate (Ch. 65), and an ossified PU2vt cartilage (Ch. 70). The proposed relationship between these two groups is not new, though usually they have been lumped together with melanotaeniines, with phallostethids, or with both (Patten, 1978; Parenti, 1984; Saeed \& Ivantsoff, 1991). Characters presented by Patten (1978: 96, 97) and Saeed \& Ivantsoff (1991: table 1) in support of this sister-group relationship are plesiomorphic and uninformative about relationships. Saeed et al. (1994) consider pseudomugilins more closely related to phallostethids.

Psuedomugilini was revised by Saeed et al. (1989) to include 13 species of Pseudomugil and the monotypic Kiunga Allen, 1983. Recently, Ivantsoff et al. (1991) described a new pseudomugilin genus Scaturiginichthys. Pseudomugilini has been diagnosed with six characters (Saeed et al., 1989; Saeed \& Ivantsoff, 1991: 230): absence of a mesethmoid (Ch. 3; also in Notocheirus, Craterocephalus, Quirichthys, and Odontesthes), a single anterior infraorbital or lacrimal (Ch. 37; also in Cyprinodontea), supracleithrum small and disk-like (Ch. 47; also in phallostethines), interdorsals absent (Ch. 68; also in Iso and some Atherinella), coronoid processes of articular and dentary of equal height (also in Basilichthys), and interhyal reduced or unossified. Another six diagnostic features resulted from this study: pterotic canal absent (Ch. 13), anterior palatine process directed dorsally ( $\mathrm{Ch}$. 33), anterior palatine ligament to nasal bone (Ch. 34), palatine ventral process reduced or absent (Ch. 36), cleithrum dorsal enclosure reduced (Ch. 48), and dorsal postcleithrum absent (Ch. 51). Allen (1980) presented the pelvic-fin ray-to-body membrane (Ch. 62) as evidence of a sister-group relationship between melanotaeniines and Pseudomugil. This membrane is also present in Kiunga (Allen, 1983), but was not mentioned by Ivantsoff $e t$ al. (1991) in the description of Scaturiginichthys, nor was it discussed by Saeed et al. (1989) or Saeed \& Ivantsoff (1991). Hence, this pelvic-fin membrane is an ambiguous feature, yet treated in this study as additional support for melanotaeniines and pseudomugilins.

Telmatherinini was recently revised by Kottelat (1990a, 1991) who recognized ten species of Telmatherina, four species of Paratherina, and two new species of Tominanga. Saeed \& Ivantsoff (1991) added the monotypic Kalyptatherina helodes (Ivantsoff \& Allen) to this group, a species described in Pseudomugil. Kottelat (1990a: 228) listed seven characters in his diagnosis of Telmatherinini and Saeed \& Ivantsoff (1991) presented at least three characters as apomorphic, none of which we have been able to support 
in this study. A feature we were unable to confirm in our specimens of Telmatherina, but is potentially of diagnostic value is 'presence of a spine in pectoral' (Kottelat, 1990a: 228). Telmatherinini is diagnosed solely by presence of three anterior infraorbitals (Ch. 37). A feature possibly diagnostic of Telmatherina is absence of the ventral interdorsal stays (Ch. 68), but the stays are present in Kalyptatherina (Saeed \& Ivantsoff, 1991) and the states in other telmatherin groups is unknown to us.

Rosen \& Parenti (1981) superficially discussed some features shared by bedotiines and melanotaeniines they considered plesiomorphic to all atherinomorphs, and which separated them from the remaining 'atherinoids'. Parenti (1984) was more specific, and proposed the reduction of the articular process of the premaxilla and the partial decoupling of the rostral cartilage from the ascending processes of the premaxillae as evidence of their percoid-like features and 'primitive' status relative to other atherinomorphs. The morphological trends assumed by Rosen \& Parenti are reversed in the phylogenetic hypothesis presented herein.

\section{Atherionidae-Atherinoidea clade}

This group is comprised of Atherionidae, Phallostethidae, and Atherinidae, diagnosed by three characters: a hyaline-cartilage submaxillary meniscus (Ch. 24), three anterior infraorbitals (Ch. 37), and posterodorsal border of opercle above articulation axis of suspensorium (Ch. 4l). Additional-support characters are the posterolateral border of the nasal bone straight (Ch. 5), and a bony contact between the frontal and lateral ethmoids (Ch. 9).

Patten (1978) proposed a close relationship between melanotaeniids and atherinids, but he did not include phallostethids in his analysis, and supported this assemblage with two plesiomorphic features. Saeed et al. (1994) include Atherion in their 'Atherinidae' and phallostethines as sister group to pseudomugilins.

\section{Monophyly of Atherionidae}

Atherionidae is comprised by the single genus Atherion and is diagnosed by three characters: parasphenoid ventral ridge extended posteriorly (Ch. 19), Al muscle mandibular tendon (Ch. 31), and presence of odontodes (Ch. 72; also in Notocheirus). Additional-support characters include presence of external premaxillary teeth (Ch. 29), preopercular-anterior infraorbital canal connected semi-continuous (Ch. 40), and absence of the dorsal cleithrum enclosure (Ch. 48; also in Notocheirus and phallostethids).

Atherion was placed in a monotypic atherine subfamily by Schultz (1948:24) because it "...appears to be intermediate between the Taeniomembrasinae \{Old World Atherinidae in part $\}$ and Menidiinae". Patten (1978: fig. 19A) proposed Atherioninae as sister to melanotaeniids plus atherinids, and Saeed \& Ivantsoff (1991) considered Atherion as distinct from other 'Old World atherinids', or as a subfamily of 'Atherinidae' (Saeed et al., 1994).

\section{Monophyly of Atherinoidea (Fig. 3, Node F)}

This clade is formed by phallostethids and atherinids as sister groups (Fig. 3), a novel hypothesis diagnosed by seven characters: absence of the palatine ventral process (Ch. 36); absence of a notch or process on the dorsal border of the interopercle (Ch. 44); absence of urohyal posterodorsal processes (Ch. 45); ventral postcleithrum laminar (Ch. 53) and with dorsal ramus (Ch. 54); pelvic medial plate extended to anterior end (Ch. 58), and presence of anal plate (Ch. 65). Two 
characters are ambiguously optimized at this node (type 1) and are of additional support to this clade: presence of a posttemporal sensory canal (Ch. 14; absent in phallostethines) and enlarged submaxillary meniscus (Ch. 23: small in atherinomorines).

\section{Monophyly of Phallostethidae}

We have expanded the family to include the genus Dentatherina (Fig. 6) and, thus, have made Phallostethoidea of Parenti (1984) synonymous with Phallostethidae (Fig. 1). Parenti (1984, 1989) discussed some characters shared by Dentatherina and phallostethines which unambiguously place them as sister taxa. Together they form a clade diagnosed by five characters: absence of parasphenoid fossa (Ch. 20), posterior myodome restricted to prootics (Ch. 22), presence of paradentaries (Ch. 25), absence of an uncinate process on epibranchial one (Ch. 46), and small sized adults (Ch. 73). Additional support is absence of the dorsal enclosure of the cliethrum (Ch. 48; also in Iso and Atherion). The first sentence to Parenti's (1989: 266) diagnosis of the family still stands for this expanded Phallostethidae: "Small to minute, laterally compressed, nearly transparent, atherinomorph fishes, largest size recorded $37 \mathrm{~mm}$ SL.".

Phallostethinae is monophyletic (Fig. 6) diagnosed by a suite of characters detailed in Parenti (1989) and Saeed \& Ivantsoff (1991), the most obvious of which are summarized in Character 77: sexually dimorphic males with priapium, and asymmetric position of anus and urogenital pore; dorsal hypohyal absent; first dorsal fin reduced or absent (also absent in Notocheirus); and presence of a fleshy keel from urogenital opening to anal fin (a reduced membrane in Iso). Another seven diagnostic features resulted from this study all of which involve reductions, reversals, or absences in different parts of the body: absence of an intercalar (Ch. 11), lack of pterotic canal (Ch. 13), posterior myodome absent (Ch. 22), two anterior infraorbital bones (Ch. 37), posterodorsal border of opercle below articulation axis of suspensorium (Ch. 41), supracleithrum disk-like (Ch. 47), and second dorsal-fin spine absent (Ch. 66). Additional support is an ossified hyaline-cartilage submaxillary meniscus (Ch. 24), premaxillary distal teeth enlarged (Ch. 28), and lack or fusion of interdorsals (Ch. 68). Parenti (1989) evidenced a phallosthethin-neostethin sistergroup relationship (Fig. 6: Phallostethini) with a suite of priapial characters summarized as Character 83 in the data matrix (Table 2).

Of the 15 characters used by Patten \& Ivantsoff (1983) to diagnose Dentatherina, ten survive as derived features in our hypothesis of relationships: large lateral wings of the parasphenoid, frontals narrow anteriorly, spatulate process of the maxilla, ventral excavation of dentary near the symphysis, metapterygoid and symplectic bones fused, ectopterygoid and quadrate bones fused, five branchiostegal rays, a sphenotic component of the temporal sensory canal, hypural five fused to uroneurals and ural centrum, and parhypural spine directed anteriorly. Two more diagnostic characters were found in this study, both of which are reversals: nasal not reaching orbit rim (Ch. 6) and distal radials of pectoral girdle cartilaginous (Ch. 50). Four additionalsupport characters are: preopercular sensory canal connected to dermosphenotic canal (Ch. 17), calcified hyaline-cartilage submaxillary meniscus (Ch. 24), pelvic dorsolateral process directed posteriorly (Ch. 59), and interdorsals without ventral shafts (Ch. 68). 


\section{Monophyly of Atherinidae}

This restricted version of Atherinidae includes the subfamilies Atherinomorinae, Atherininae, and Craterocephalinae (Fig. 4). Atherinidae is diagnosed by three characters: presence of a lacrimal notch (Ch. 38), ventral postcleithrum between first and second pleural ribs (Ch. 55), and a ventral pelvic spine (Ch. 63). Characters 38 and 63 are unique in atheriniforms. Additional-support characters are the preopercular and anterior infraorbital canals fully connected (Ch. 40; ambiguity type 2) and the mandibular sensory canal enclosed by bone (Ch. 71; absent in Alepidomus, ambiguity type 1).

Atherinidae sensu stricto corresponds to 'Atherininae' of Patten (1978) and Saeed $e t$ al. (1994), and the 'Old World Atherinidae' of Saeed \& Ivantsoff (1991). Patten (1978: fig. 19B) diagnosed three tribes that correspond to our subfamilies Atherinomorinae (= Pranesini), Atherininae (= Atherinini), and Craterocephalinae (= Craterocephalini), but left the relationships among them unresolved. In this study we have demonstrated the monophyly of the subfamilies and we have also found some evidence to suggest that atherinines and craterocephalines are sister groups (Fig. 4: Chs 7, 24). We consider the following phylogenetic hypotheses within each of the subfamilies as preliminary. The survey of characters and taxa within these groups is not extensive and the results are presented as a working hypothesis to stimulate further research in this group.

\section{Monophyly of Atherinomorinae, new subfamily}

Type Genus: Atherinomorus Fowler, 1903

Atherinomorinae is comprised of Atherinomorus, Hypoatherina, Stenatherina, Teramulus, and Alepidomus. This taxon is diagnosed by four characters: posttemporal sensory canal oriented along dorsal arm of posttemporal bone (Ch. 15), parasphenoid fossa with ventral fenestra (Ch. 21), fibrocartilage submaxillary meniscus (Ch. 24), and presence of a hyomandibular nerve foramen (Ch. 42).

Alepidomus evermanni Eigenmann, is the monotypic sister taxon to the remaining atherinomorines and is diagnosed by three characters: presence of the palatine ventral process (Ch. 36), presence of dorsal process of interopercle (Ch. 44), and an ossified PU2vt (Ch. 70). The remaining atherinomorines form a clade (Fig. 4: Node H1A) diagnosed by three features the first two of which are unique: a large notch in the canal bone of infraorbital two (Ch. 39), a preopercular notch (Ch. 43), and an elongated dorsal postcleithrum (Ch. 52). Relationships among genera of this clade (Atherinomorus, Hypoatherina, Stenatherina and Teramulus) are tenuously supported in this study. Despite important regional treatments of these groups by Ivantsoff (1978), Patten (1978), Ivantsoff \& Kottelat (1988), and Ivantsoff \& Crowley (1991), systematic revisions of entire groups are still wanting and only preliminary diagnoses are at hand. In this study we used the following species to represent the morphologies of their respective genera: Atherinomorus stipes, Hypoatherina harringtonensis and Stenatherina ovalaua. Stenatherina is distinguished from the other taxa by an enlarged submaxillary meniscus (Ch. 23: correlated with long premaxillary ascending processes and upper jaw protrusion) and a posteromedial extension of the vomerine tooth patch (Patten, 1978). Atherinomorus is distinguished by a pointed posterior edge of the dentary coronoid process (Patten, 1978; Whitehead \& Ivantsoff, 1983; Ivantsoff \& Crowley, 1991). The limits and species composition of Hypoatherina are most problematic, as it seems to have a morphology intermediate between that of 
Atherinomorus and Stenatherina (Ivantsoff \& Kottelat, 1988). Atherinomous and Hypoatherina have premaxillae with relatively short and wide ascending processes, relatively reduced protrusion, and a patch of villiform teeth extended on to the lateral surface of the jaws (Chs 29, 30). Stenatherina and Hypoatherina, however, lack the laterodorsal process of the pelvic bone (Ch. 59). Though material of Teramulus was not available for examination, this taxon was placed in this group of four genera because the preopercular notch (Ch. 43) is mentioned and figured in the original description (Smith, 1965).

Atherininae-Craterocephalinae clade (Fig. 4, Node H2)

The sister-group relationship between atherinines and craterocephalines is diagnosed by two features: a nasal ventromedial ligament to the palatine (Ch. 7; also in pseudomugilines) and the anterior palatine process directed dorsally (Ch. 33). Additional support is the enlarged size of the submaxillary meniscus (Ch. 23; also present in Stenatherina and phallostethids).

\section{Monophyly of Atherininae}

Atherininae is monophyletic, comprised of Atherina, Atherinason, Atherinosoma, Kestratherina, and Leptatherina. This groups is diagnosed by presence of the A1 muscle mandibular tendon (Ch. 31) and the posterior position of the pelvic girdle (Ch. 61; also in atherinopsids). Two characters are of additional support at this node: a thin ethmomaxillary ligament to the posterodorsal region of the lateral ethmoid (Ch. 2; Fig 8D) and anterior palatine ligament to nasal (Ch. 34). Both characters are ambiguous (Ch. 2: type 3; Ch. 34: type 2), though Character 2 is otherwise unique in atheriniforms.

Atherinosoma is the sister group to other atherinines (Fig. 4: H3A) a group diagnosed by the unique shape of the nasal (Ch. 6; Fig. 8D). Other results, though preliminary, support Kestratherina and Atherina as sister taxa (Chs 40, 59; Fig. 4), and form a trichotomy with Atherinason and Leptatherina, the resolution of which is beyond the scope of this study.

Monophyly of Craterocephalinae, new subfamily.

Type Genus: Craterocephalus McCulloch, 1912

Craterocephalinae includes the nominal genera Allanetta, Craterocephalus, and Quirichthys, and is diagnosed by six characters: presence of a nasal ventral process (Ch. 8), parasphenoid ventral ridge extended posteriorly (Ch. 19), absence of a parasphenoid fossa (Ch. 20), maxillary shaft wide proximally (Ch. 27), absence of the anterior palatine process (Ch. 33), and absence of the pelvic dorsolateral process ( $\mathrm{Ch}$. 59). Additional support is the absence of an ethmomaxillary ligament (Ch. 2) that is ambiguously optimized (type 3) at this node but otherwise unique in atheriniforms.

The monotypic Quirichthys stramineus Whitley, and Allanetta mugiloides McCulloch, are regarded as junior synonyms of Craterocephalus by Patten (1978), Crowley \& Ivantsoff (1988, 1992), and Crowley (1990a). In this study, Quirichthys is diagnosed by four characters: presence of premaxillary teeth on external surface (Ch. 29), body deep (Ch. 74), lateral band reduced to absent (Ch. 75), and sexually dimorphic (Ch. 76). Quirichthys is more closely related to Craterocephalus than either is to Allanetta (Fig. 4) based upon the posterodorsal end of the opercle below the articulation axis of the suspensorium to neurocranium (Ch. 4l). Additional support is the lack of a 
mesethmoid (Ch. 3), ambiguously optimized (type 2) because of the polymorphic state in Allanetta.

We refer to these taxa by their generic names pending a cladistic analysis of the group. In Patten's (1978) statements of craterocephaline relationships Allenetta is sister to other craterocephalines, but Quirichthys was not included in the analysis. Inclusion of Quirichthys in Craterocephalus was first suggested by Ivantsoff et al. (1987), stated with some reservations by Crowley \& Ivantsoff (1988: 165), and finally adopted by Crowley (1990a) and Crowley \& Ivantsoff (1992). In the cladistic analysis section of Crowley's (1990a: appendix 5) revision of Craterocephalus, Quirichthys is the sister group to other craterocephalines, and Allanetta, together with $C$. honoriae, is sister to the remaining craterocephalines. Crowley \& Ivantsoff (1988) and Crowley (1990b), however, have only published results of cluster analyses which include Allanetta, but exclude Quirichthys from the analysis. Crowley \& Ivantsoff (1992), in their final revision of the group, placed $C$. stramineus in the Craterocephalus stercusmuscarum species group. The results presented by us are far from conclusive about relationships within Craterocephalinae. Our results, however, corroborate Crowley \& Ivantsoff's (1992) placement of Quirichthys as a craterocephaline and not as a melanotaeniid (Whitley, 1951: 63), a telmatherine (Munro, 1958: 98), or as a monotypic atherinid genus with unknown relationships (Lake, 1971; Allen, 1980; Merrick \& Schmida, 1984).

\section{DISCUSSION}

The evolution of several characters deserve discussion in the context of the phylogenetic hypothesis (Figs 3-6).

The posttemporal sensory canal (Ch. 14) is plesiomorphically lacking in atheriniforms and appears to have been derived independently at least three times according to this phylogenetic hypothesis: in atherinopsids, melanotaeniines, Dentatherina, and atherinids. This is the case if the posttemporal canal is considered separately from the pterotic canal (Ch. 13). One pattern that has emerged is that all atherinomorph taxa lacking a pterotic sensory canal also lack a posttemporal canal. The latter situation is observed in Cyprinodontea, bedotiines, pseudomugilins and phallostethines. This association of characters could be the expression of a progenetic truncation of an ontogenetic sequence in which the development of the pterotic canal precedes that of the posttemporal canal. If true, absence of the posttemporal canal in Pseudomugil and Telmatherina would be due to different paedomorphic events in the ontogeny of the sensory canals of the temporal region. In Pseudomugil, absence of a posttemporal canal would be due to a pre-pterotic canal truncation and in Telmatherina a post-pterotic truncation of development. In the context of these phylogenetic and ontogenetic hypotheses, absence of a posttemporal canal and presence of pterotic canal is the plesiomorphic condition of atherinomorphs, a condition found only in notocheirids, Atherion, and telmatherins. These hypotheses may be addressed with appropriate tests from ontogenetic studies, but until results of those studies are made available, we consider presence of the posttemporal canal to be diagnostic of atherinopsids (Fig. 3), melanotaeniines (Fig. 5), and to provide additional support for atherinoideans (Appendix 2: F). Presence or absence of the pterotic canal also affects the historical interpretation of the connectivity between the pterotic and posttemporal sensory canals (Ch. 15) as it does with the connectivity between the pterotic and preopercular canals (Ch. 17). 
The Al lacrimal tendon was considered a diagnostic feature of Atherinomorpha by Stiassny (1990). Parenti (1993) agreed with Stiassny's hypothesis despite absence of this feature in cyprinodontiforms. One problem with this hypothesis is that exocoetoids have a lacrimal ligament instead of a tendon and an Al lacrimal tendon is present in some cyprinodontiforms. In all exocoetoids examined, a strong ligament connects the mandible and the ventromedial end of the lacrimal (Fig. 25A), a condition that is questionably homologous to the atheriniform Al lacrimal tendon. A lacrimal ligament is lacking in Oryzias and Horaichthys. Exocoetoids have a reduced Al muscle, attached directly to the lacrimal (e.g. Cololabis, Fodiator) or not, or with a maxillary tendon (e.g. Arrhamphus, Hyporhamphus) or without. The plesiomorphic condition for beloniforms and the homology of the lacrimal ligament is unclear at this time. Cyprinodontiforms and atheriniforms, however, share the presence of an Al lacrimal tendon. Most cyprinodontiforms have a short tendon from the distal end
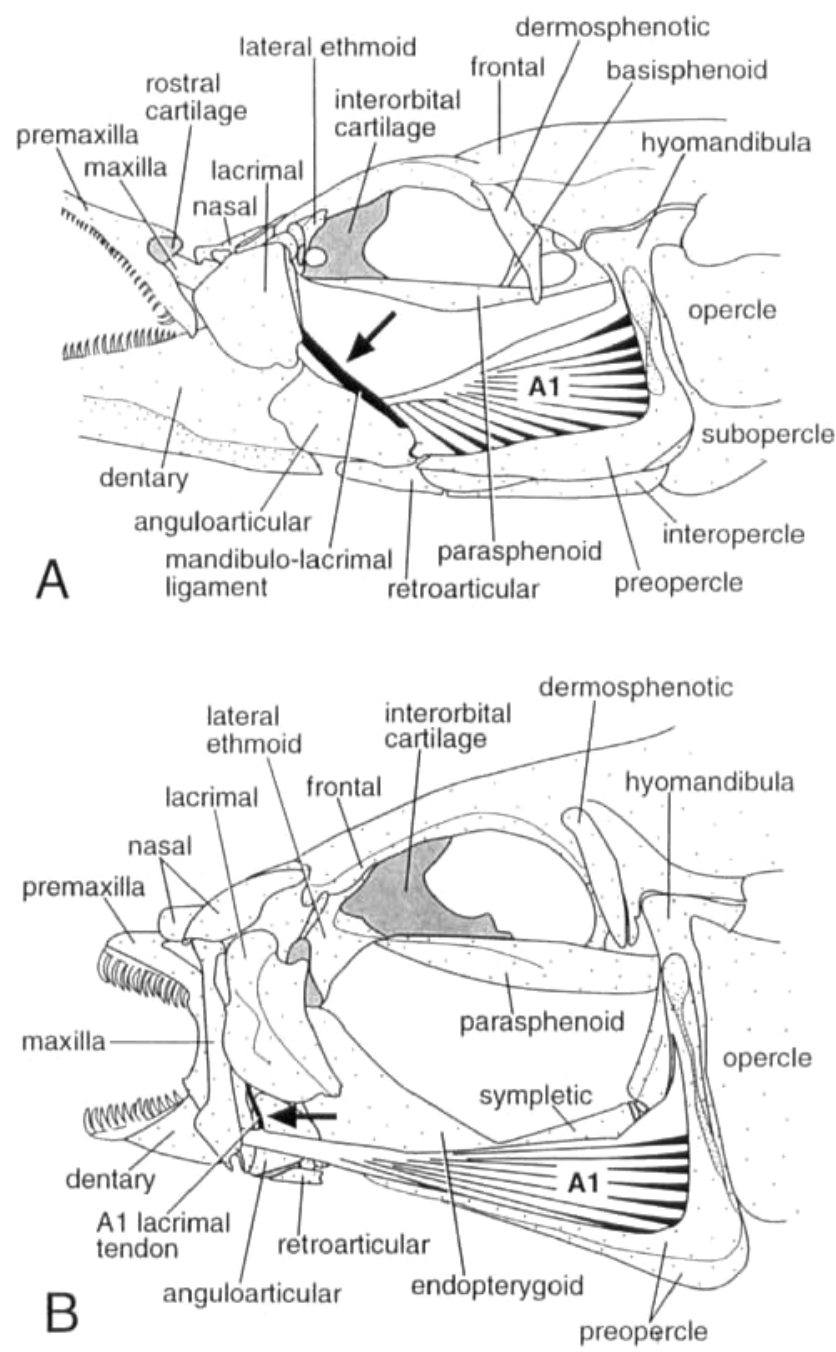

Figure 25. Schematic view of left side of head: A, Demogenys pusilla (UMMZ 195917); B, Epiplatys spilauchen (UMMZ 187902). Arrows indicate potentially homologous lacrimal ligament (A) and Al lacrimal tendon (B). 
of the Al maxillary tendon to the medial face of the lacrimal's anteroventral region (Fig. 25B), despite Stiassny (1993) and Parenti's (1993) claim otherwise. This connection is absent in Profundulus, Chapalichthys, and other genera. The Al muscle attaches directly to the maxilla with no tendon in fundulines (Alexander, 1967b: fig. 4A). The Al mandibular tendon characteristic of some atheriniforms is not present in cyprinodontiforms. The articular-maxilla ligament of atheriniforms is clearly separated from the $\mathrm{Al}$ muscle tendons, unlike that found in atherinomorph outgroups. Hence, the primitive condition clearly seems to be absence of a lacrimal connection of the $\mathrm{Al}$ muscle, but the homologies between the lacrimal tendons of atheriniforms and cyprinodontiforms, and the lacrimal ligament of exocoetoids remains to be tested.

The number of anterior infraorbital bones (Ch. 37) considered plesiomorphic for atheriniforms in this analysis was five or more. Chernoff (1986: 198) discussed the distribution of infraorbital numbers and concluded that three anterior infraorbitals is the plesiomorphic condition for atheriniforms. He reasoned that six or more bones is primitive for atherinomorphs with a derived trend of reduction in numbers. Results from this study, however, do not support that hypothesis and indicate instead that two anterior infraorbitals is the plesiomorphic condition for atherinomorphs with an increase and decrease in numbers of bones. The evolution of this character as derived from the cladogram indicates an increase in the number of anterior infraorbitals from $1 \leftarrow 2 \rightarrow 3$ with some reversals and independent derivations. In this hypothesis of relationships (Figs 3, 5,6), three anterior infraorbitals is a derived feature diagnosing the atherionid-atherinoidea clade, Iso, melanotaeniines, and telmatherins. Concomitantly with number of elements, however, is the discontinuity of the infraorbital sensory system into anterior and posterior canals, a gap found also in mugilids and other atherinomorph outgroups such as Elassoma and most gasterosteiforms (Johnson \& Patterson, 1993: 581). In addition to the structural and phylogenetic patterns there is the ontogeny of the infraorbital canals. In centrarchids, the developmental pattern of appearance of the infraorbital bones is from first to last: lacrimal $\rightarrow$ dermosphenotic $\rightarrow$ infraorbitals $6 \rightarrow 2$ (Mabee, 1993: 263). A similar pattern is found in other percoids, anabantids (Mabee, pers. comm.), channids and silurids (Kapoor, 1961), suggesting an ontogenetic pattern of greater generality. If the above structural, ontogenetic, and phylogenetic patterns are integrated into the hypothesis that the plesiomorphic condition for atherinomorphs is a single anterior infraorbital (the lacrimal), then infraorbitals two and three of atheriniforms are not homologous to infraorbitals two and three of mugilids and outgroups. Hence, if one anterior infraorbital is considered as the plesiomorphic condition for atheriniforms (present in mugilids and Cyprinodontea) and an increase in anterior infraorbital bone numbers as relatively derived conditions, then one anterior infraorbital is the plesiomorphic condition for atherinomorphs and two anterior infraorbitals is unambiguously diagnostic of atheriniforms. The latter hypothesis is two steps shorter than that which considers four or more bones as the plesiomorphic condition.

The position of the pelvic girdle (Ch. 61) in atheriniforms was determined by the pleural rib to which the pelvic dorsolateral process is attached (Ch. 60). The position that is plesiomorphic of Cyprinodontea and atherinopsids is ambiguous. Assuming the condition present in mugilids, percoids and other acanthomorphs is plesiomorphic, the posterior displacement of the pelvic girdle to a position beyond the sixth pleural rib has evolved at least three times in Atherinomorpha: in exocoetids, in atherinopsines, and in atherinines. Allen (1980) proposed that attachment of the 
pelvic girdle to pleural ribs two or three is diagnostic of melanotaeniines. Even though bedotiines and pseudomugilines have the pelvic bone connected to pleural ribs four or five, Allen's hypothesis may not stand in a future revision of melanotaeniids because the closely related outgroups Atherion and Iso have the pelvic process attached to pleural rib three.

Presence of a greatly modified anal pterygiophore (Ch. 65) into a roughly triangular plate and the anterior displacement of the anus may be unique in teleosts. In this hypothesis, however, the anal plate is independently derived in pseudomugilines and atherinoideans. Should future evidence support melanotaeniines and bedotiines as sister groups, the statement of non-homology presented by this hypothesis would not be refuted.

Presence of strong stout spines (Ch. 66) in the median fins of Melanotaenia, an enlarged mesethmoid (Ch. 3) present in Melanotaenia and Bedotia, as well as deep bodies (Ch. 74) and premaxillae closely attached to the rostral cartilage, were the key percoid-like characters used by Jordan \& Hubbs (1919), Rosen (1964), Rosen \& Parenti (1981), Ghernoff (1986) and Stiassny (1990) to regard them as 'primitive atherinoids'. All these characters, however, are clearly derived features within the Melanotaeniidae and represent independent derivations of these conditions relative to other percomorphs.

\section{CONCLUSIONS}

This study has corroborated the monophyly of Atheriniformes proposed by White et al. (1984) and its sister-group relationship to Cyprinodontea, the Cyprinodontiformes - Beloniformes clade. The traditional assemblage of 'atherinid' taxa is confirmed as paraphyletic. Atherinidae (sensu stricto) is a subset of the 'Old World atherinid' genera of Saeed \& Ivantsoff (1991), which includes atherinomorines, craterocephalines and atherinines. Of the taxa formerly placed in Atherinidae, Atherion is in a monotypic family, Menidiinae and Atherinopsinae constitute Atherinopsidae, and Dentatherina is included in an expanded Phallostethidae. Atherinopsidae is the sister group to other atheriniforms, or Atherinoidei. Notocheiridae is the sister taxon to Atherines. The latter group comprises melanotaeniids, atherionids, phallostethids, and atherinids. Atherinids and phallostethids constitute the Atherinoidea clade which is the sister taxon to Atherionidae.

Bedotiines and melanotaeniines have been traditionally assumed to be 'primitive atherinoids'. These taxa have been used by systematists as 'representative atherinomorphs' in their choice of outgroups for systematic revisions of acanthomorph fishes, and also as the 'primitive atherinoids' in revisions of atheriniform families. Bedotiines are by no means generalized atherinomorphs in the present hypothesis but are, instead, part of an expanded Melanotaeniidae that includes pseudomugilins and telmatherins. Relationships among melanotaeniids are only tentative, but, they do indicate that pseudomugilins and telmatherins are sister groups. The relevance of this phylogenetic hypothesis to the biogeographic history of the Indo-West Pacific region is significant because Melanotaeniidae is a monophyletic group of primarily freshwater fishes.

The placement of Dentatherina with respect to atherinids or phallostethids has been discussed many times in the literature (Patten \& Ivantsoff, 1983; Parenti, 1984; Ivantsoff et al., 1987; Parenti, 1989) and was a point of contention in this analysis. 
Ultimately, we conclude with Parenti (1984) that Dentatherina is the sister group to phallostethines. The alternative hypothesis of Dentatherina as sister group to atherinids requires four additional steps and is supported by a smaller suite of diagnostic features. The nature of these latter characters is not sufficiently compelling to prefer them over the most parsimonious solution.

Relationships within Atherinidae sensu stricto are resolved into three large clades, with atherinines and craterocephalines most closely related. Alepidomus is the sister species of a monophyletic Atherinomorinae, and Quirichthys is part of a monophyletic Craterocephalinae. Alepidomus evermanni, Atherinomorus stipes, and Hypoatherina harringtonesis, each of which live in the West Indies, are part of Indo-West Pacific atherinomorine lineages that extend into the Atlantic Ocean Basin.

An interesting case emerges from our phylogenetic results (Fig. 3). There are two instances in which groups with many, notable morphological specializations (notocheirids and phallostethids) are the sister groups to large clades with less obvious specializations (e.g. Atherines and Atherinidae, respectively). We caution systematists on the use of single taxa as plesiomorphic representatives of clades in their choice of outgroups, especially when the relationships within that clade are unknown or poorly supported. The example of bedotiines, mentioned above, demonstrates how choices of a single taxon assumed to be generalized can mislead the results of a systematic study.

\section{ACKNOWLEDGEMENTS}

We wish to thank the following individuals for their loan of specimens: William F. Smith-Vaniz and Willaim G. Saul (Academy of Natural Sciences of Philadelphia), Melanie Stiassny and Michael L. Smith (American Museum of Natural History), William Eschmeyer (California Academy of Sciences), Atila Gosztonyi (Centro Nacional Patagónico), Peter Reinthal (Eastern Michigan University), Carter Gilbert and George Burgess (Florida State Museum), Stuart Poss (Gulf Coast Research Laboratory), Walter Ivantsoff (Macquarie University), Victor Hugo Ruiz (Universidad de Concepción), Victor G. Springer and Susan Jewett (United States National Museum). We are sincerely grateful to Jon Moore, Darrel Siebert, Mario de Pinna, and an anonymous reviewer for their detailed comments and suggestions on the manuscript. We wish to express our gratitude to James Albert, Reeve M. Bailey, Douglas Begle, Paulo A. Buckup, William L. Fink, Sara V. Fink, Lance Grande, William A. Gosline, Brian Hall, Julian M. Humphries, Walter Ivantsoff, Arnold Kluge, John G. Lundberg, Robert R. Miller, Gerald R. Smith, William F. SmithVaniz and Mark Westneat for helpful discussions during the development of this study. We also wish to thank Christine Johnson for the beautiful computer-generated figures. BD gratefully acknowledges the Armour Fellowship of the Field Museum of Natural History and a Jessup Fellowship from the Academy of Natural Sciences of Philadelphia. BC is grateful to Bruce and Sarah Collette for all their hospitality during a visit to the USNM. BC extends his thanks to the Zoology Department of Duke University for all of their hospitality during his sabbatical leave. Finally, we thank sincerely all of the help of Douglas W. Nelson, Mary Anne Rogers, Kevin Swagel, and Dan Miller on many logistical fronts. 


\section{REFERENCES}

Alexander RMcN. 1967a. The functions and mechanisms of the protrusible upper jaws of some acanthopterygian fish. Foumal of Zoology, London 151(1): 43-64.

Alexander RMcN. 1967b. Mechanisms of the jaws of some atheriniform fish. Joumal of Zoology, London 151(2): 233-255.

Allen GR. 1980. A generic classification of the rainbowfishes (Family Melanotaeniidae). Records of the Westem Australian Museum 8(3): 449-490.

Allen GR. 1983. Kiunga ballochi, a new genus and species of rainbowfish (Melanotaeniidae) from Papua New Guinea. Tropical Fish Hobbyist 32(2): 72-77.

Allen GR, Cross NJ. 1982. Rainboufishes of Australia and Papua New Guinea. T.F.H. Publications.

Astakhov DA. 1980. Cranial lateral-line canals of the Beloniform fishes (Beloniformes, Osteichthyes). Transaction of the P.P. Shirsov Institute of Oceanology 97: 174-211.

Chedhomme J, Gaudant J. 1984. Sur une nouvelle espèce du genre †Palaeoatherina Gaudant (Poissons Téléostéens, Atherinomorpha) découverte dans l'Eocène supérieur continental des environs d'Orgnac-L'Aven (Ardèche). Géologie Méditerranéenne 6(4): 303-319.

Chernofr B. 1986. Phylogenetic relationships and reclassification of menidiine silverside fishes with emphasis on the tribe Membradini. Proceedings of the Academy of Natural Sciences, Philadelphia 138(1): 189-249.

Clark C, Curran DJ. 1986. Outgroup analysis, homoplasy, and global parsimony: a response to Maddison, Donoghue, and Maddison. Systematic Zoology 35(3): 422-426

Crowley LELM. 1990a. Biogeography and the systematics of the endemic freshwater fish genus Craterocephalus (Family: Atherinidae). Unpublished Ph.D. Thesis, Macquarie University, Sydney, Australia, 333pp.

Crowley LELM. 1990b. Biogeography of the endemic freshwater fish Craterocephalus (Family Atherinidae). Memoirs of the Queensland Museum 28(1): 89-98.

Crowley LELM, Ivantsoff W. 1988. A new species of Australian Craterocephalus (Pisces: Atherinidac) and redescription of four other species. Records of the Western Australian Museum 14(2): 151-169.

Crowley LELM, IvantsoffW. 1989. An historical overview of the genus Craterocephalus with special reference to the hardyheads from Dalhousie Springs. In: Ziedler W, Ponder WF, eds. Natural History of Dalhousie Springs. Publication of the South Australian Museum, 113-118.

Growley LEIM, Ivantsoff W. 1990a. A second hardyhead, Cratcrocephalus gloveri (Pisces: Atherinidae), from Dalhousie Springs, central Australia. Ichthyological Exploration of Freshwaters 1(2): 113-122.

Crowley LELM, Ivantsoff W. 1990b. A review of species previously identified as Craterocephalus eyresii (Pisces: Atherinidae). Proceedings of the Linnean Society of New South Wales 112(2): 87-103.

Crowley LELM, Ivantsoff W. 1992. Redefinition of the freshwater fish genus Craterocephalus (Teleostei: Atherinidae) of Australia and New Guinea with an analysis of three species. Ichthyological Exploration of Freshwaters 3(3): 273-287.

Crowley LEIM, IvantsoffW, Allen GR. 1991. Freshwater fishes of the genus Craterocephalus (Atherinidae) from the southern drainages of Papua New Guinea and Irian Jaya with reference to C.s. stercusmuscarum from Australia. Records of the Westem Australian Museum 15(1): 33-52.

De Beaufort LF. 1922. Some remarks on the anatomy of the Melanotaeniinae. Bïdragen tot de dierkunde 1922: 259-263.

De la Hoz E, Tosti-Croce E. 1981. Osteologia de Basilichthys australis Eigenmann (Teleostei - Atherinidae). Anales del Museo de Historia Natural de Valparaiso 14: 229-245.

De la Hoz E, Vial J. 1988. Potencialidades mecánicas del sistema de protacción premaxilar de Austromenidia regia (Teleostei - Atherinidae). Revista Chilena de Historia Natural 61, 163-176.

Dyer BS. 1993. A phylogenetic study of atheriniform fishes with a systematic revision of the South American silversides (Atherinomorpha, Atherinopsinae, Sorgentinini). Unpublished Ph.D. thesis, University of Michigan, Ann Arbor.

Dyer B.S. in press. Phylogenetic revision of Atherinopsinae (Teleostei, Atheriniformes, Atherinopsidae), with comments on the systematics of the South American freshwater genus Basilichthys Girard, 1854. Misc. Publ. Univ. Michigan, Ann Arbor. 92pp, 45 figs.

Eschmeyer W. 1990. Catalog of the Genera of Recent Fishes. San Francisco: Califormia Academy of Sciences, Special Publication No.1.

Farris JS. 1972. Estimating phylogenetic trees from distance matrices. American Naturalist 106: 645-668.

Farris JS. 1982. Outgroups and parsimony. Systematic Zoology 31(3): 328-334.

Farris JS. 1988. Hennig86, Version 1.5. A PC-DOS program for phylogenetic analysis.

Ferrandini M, Ferrandini J, Gaudant J. 1976. Découverte d'une nouveau gisement d'athérines (poissons Téléostéens, Atherinomorpha) dans le Paléogène de Mormoiron (Vaucluse). Géologie Méditerranéenne 3(2): $115-126$.

Gaudant J. 1989. L'ichthyofaune stampienne des environs de Chartres-de-Bretagne, prés de Rennes (Ille-etVilaine): un réexamen. Géologie de la France 1-2: 41-54.

Greenwood PH, Rowen DR, Weitzman SH, Myers GS. 1966. Phyletic studies of teleostean fishes, with a provisional classification of living forms. Bulletin of the American Museum of Natural History 131(4): 339-456. 
Ivantsoff $W$. 1978. Taxonomic and systematic review of the Australian fish species of the family Atherinidae with references to related species of the Old World. Unpublished Ph.D. Thesis, Macquarie University, Sydney, Australia, 70lpp.

Ivantsoff W, Crowley LELM. 1991. Review of the Australian fishes of the genus Atherinomonus (Atherinidae). Australian Joumal of Marine and Freshwater Research 42: 479-505.

Ivantsoff W, Crowley LELM, Allen GR. 1987. Description of a new species of freshwater Hardyhead Craterocephalus kailolae (Pisces: Atherinidae) from Safia, northeastern Papua New Guinea. Proceedings of the Linnean Society of New South Wales 109(4): 331-337.

Ivantsoff W, Kottelat M. 1988. Redescription of Hypoatherina valenciennei and its relationships to other species of Atherinidae in the Pacific and Indian Oceans. Japanese Joumal of lchthyology 35(2): 142-149.

Ivantsoff W, Said B, Williams A. 1987. Systematic position of the family Dentatherinidae in relationship to Phallostethidae and Atherinidae. Copeia, 1987: 649-658.

Ivantsoff W, Unmack P, Saeed B, Crowley LELM. 1991. A redfinned blue-eye, a new species and genus of the family Pseudomugilidae from central western Queensland. Fishes of Sahul 6(4): 277-282.

Johnson GD, Patterson C. 1993. Percomorph phylogeny: a survey of acanthomorphs and a new proposal. Bulletin of Marine Srience 52(1): 554-626.

Jordan DS, Hubbs CL. 1919. Studies in Ichthyology. A monographic review of the family of Atherinidae or silversides. Leland Stanford funior University Rublications, University Series 40: 1-87.

Kapoor AS. 1961. The time and order of formation of sensory canals in the fishes Ophicephalus punctatus (Ophicephalidae) and Wallago attu (Siluridae). Copeia, 1961: 176-181.

Kottelat M. 1990a. Sailfin silversides (Pisces: Telmatherinidae) of lakes Towuti, Mahalona and Wawontoa (Sulawesi, Indonesia) with descriptions of two new genera and two new species. Ichthyological Exploration of Freshwaters 1(3): 35-54.

Kottelat M. 1990b. Synopsis of the endangered Buntingi (Osteichthyes: Adrianichthyidae and Oryziidae) of Lake Poso, Central Sulawesi, Indonesia, with a new reproductive guild and descriptions of three new species. Ichthyological Explorations of Freshwaters 1(1): 49-67.

Kottelat M. 1990c. The ricefishes (Oryziidae) of the Malili Lakes, Sulawesi, Indonesia, with description of a new species. Ichthyological Explorations of Freshwaters 1(2): 151-166.

Kottelat M. 1991. Sailfin silversides (Pisces: Telmatherinidae) of Lake Matano, Sulawesi, Indonesia, with descriptions of six new species. Ichthyological Exploration of Freshwaters 1(4): 321-344.

Lake JS. 1971. Freshwater Fishes and Rivers of Australia. Sydney: Thomas Nelson (Australia).

Leviton AE, Gibbs Jr RH, Heal E, Dawson CE. 1985. Standards in Herpetology and Ichthyology: Part I. Standard symbolic codes for institutional resource collections in Herpetology and Ichthyology. Copeia, 1985: 802-832.

Lipscomb DL. 1992. Parsimony, homology and the analysis of multistate characters. Cladistics 8(1): 45-65.

Maddison WP, Donoghue MJ, Maddison DR. 1984. Outgroup analysis and parsimony. Systematic Zoology 33(1): 83-103.

Maddison WP, Maddison DR. MacClade. Analysis of Phylogeny and Character Evolution. Version 3. Sinauer Associates, Inc., 398pp.

Melinkat R, Zeiske E. 1979. Functional morphology of ventilation of the olfactory organ in Bedotia geayi Pellegrin 1909 (Teleostei, Atherinidae). Zoologischer Anzeiger, Jena 203(5/6): 354-368.

Merrick JR, Schmida GE. 1984. Australian freshwater fishes. Biology and management. South Australia: Griffin Press.

Munro ISR. 1958. Handbook of Australian Fishes. Fisheries Newsletter 17(6): 17-20.

Munro ISR. 1967. The Fishes of New Guinea. Department of Agriculture, Stock and Fisheries: Port Moresby, New Guinea. $651 \mathrm{pp}$.

Nelson JS. 1984. Fishes of the World. 2nd ed. New York: John Wiley \& Sons.

Nelson JS. 1994. Fishes of the World. 3rd ed. New York: John Wiley \& Sons.

Parenti LR. 1981. A phylogenetic and biogeographic analysis of cyprinodontiform fishes (Teleostei, Atherinomorpha). Bulletin of the American Museum of Natural History 168(4): 335-557.

Parenti LR. 1984. On the relationships of phallostethid fishes (Atherinomorpha), with notes on the anatomy of Phallostethus dunckeri Regan, 1913. American Museum Novitates 2779: 1-12.

Parenti LR. 1986. The phylogenetic significance of bone types in euteleost fishes. Zoological Foumal of the Linnean Society 87: $37-51$.

Parenti LR. 1987. Phylogenetic aspects of tooth and jaw structure of the Medaka, Oryzias latipes, and other beloniform fishes. Joumal of Zoology, London 211: 561-572.

Parenti LR. 1989. A phylogenetic revision of the phallostethid fishes (Atherinomorpha, Phallostethidae). Proceedings of the Califomia Academy of Sciences 46(11): 243-277.

Parenti LR. 1993. Relationships of Atherinomorph fishes (Teleostei). Bulletin of Marine Science 52(1): 170-196.

Patten JM. 1978. Osteology, relationships and classification of hardyheads of the subfamily Atherininae (Pisces: Atherinidae). Unpublished Master's thesis, Macquarie University, 169pp.

Patten JM, Ivantsoff W. 1983. A new genus of atherinid fish, Dentatherina merceri from the western Pacific. Japanese Foumal of Ichthyology 29(4): 329-338.

Patterson C. 1982. Morphological characters and homology. In: Joysey KA, Friday AE, eds. Aroblems of Phylogenetic Reconstruction. Systematics Association Special Volume No. 21, New York: Academic Press, 21-74. 
Pattermon C. 1992. Supernumerary median fin-rays in teleostean fishes. Zoological Joumal of the Linnean Society $106(2): 147-161$.

Pavlov A, Ivantwoff W, Lagt PR, Crowley LELM. 1988. Kestratherina brevirostris, a new genus and species of silverside (Pisces: Atherinidae) with a review of atherinid marine and estuarine genera of southern Australia Austratian Joumal of Marine and Freshwater Research 39: 385-397.

Pletsch TW. 1984. Enlarged cartilages in the protrusible upper jaws of teleost fishes: phylogenetic and functional implications Copeia, 1984: 1011-1015.

Roberts TR. 1971. Osteology of the Malaysian phallostethid fish Ceratostethus bicomis, with a discussion of the evolution of remarkable structural novelties in its jaws and external genitalia. Bulletin of the Museum of Comparatize Zoology 12(4): 393-418.

Rosen DE. 1964. The relationships and taxonomic position of the halfbeaks, killifishes, silversides, and their relatives. Bulletin of the American Muserm of Natural History 127(5): 217-268.

Rosen DE. 1973. Interrelationships of higher euteleostean fishes. In: Greenwood PH, Miles RS, Patterson C, eds. Interrelationships of Fishes. London: Supplement 1, Zoological Journal Linnean Society, 397-513.

Rosen DE, Parenti LR. 1981. Relationships of Onzzias, and the groups of Atherinomorph fishes. American Museum Novitates 2719: 1-25.

Saeed B, Ivantwoff W. 1991. Kalyptatherina, the first telmatherinid genus known outside of Sulawesi. Ichthyological Exploration of Freshwaters 2(3): 227-238.

Saeed B, Ivantsoff W, Allen GR. 1989. Taxonomic revision of the family Pseudomugilidae (Order Atheriniformes). Australian Joumal of Marine and Freshwater Research 40: 719-787.

Saeed B, Ivantsoff W, Crowley LELM. 1994. Systematic relationships of atheriniform families within Division I of the Series Atherinomorpha (Acanthopterygii) with relevant historical perspectives. Voprosi Ikhtiologii 34(4): 1-32.

Said BM. 1983. Revision of the fish genus ISO. Unpublished Master's Thesis, Macquarie University, 177pp.

Schultz LP. 1948. A revision of six subfamilies of atherine fishes, with descriptions of new genera and species. Proceedings of the United States National Museum 98(3220): 1-48.

Schultz LP. 1950. Correction for "A revision of six subfamilies of atherine fishes, with descriptions of new genera and species". Copeia, 1950: 150.

Smith JLB. 1965. Fishes of the family Atherinidae of the Red Sea and the Western Indian Ocean with a new freshwater genus and species from Madagascar. Ichthyological Bulletin of Rhodes University, Grahamstown 31: 601-632.

Starks EC. 1899. The osteological characters of the fishes of the suborder Percesoces. Proceedings of the United States National Museum 22(1179): 1-10.

Stiasany MIJ. 1990. Notes on the anatomy and relationships of the bedotiid fishes of Madagascar, with a taxonomic revision of the genus Rheocles (Atherinomorpha: Bedotiidae). American Museum Noritates 2979: 1-33.

Stiassny MПJ. 1993. What are grey mullets? Bulletin of Marine Science 52(1): 197-219.

Stiassny MI, Moore JA. 1992. A review of the pelvic girdle of acanthomorph fishes, with comments on hypotheses of acanthomorph intrarelationships. Zoological Joumal of the Linnean Society 104(3): 209-242.

Stiaseny MIJ, Reinthal PN. 1992. Description of a new species of Rheocles (Atherinomorpha, Bedotiidae) from the Nosivolo tributary of the Mangoro River, eastern Malagasy Republic. American Museum Novitates 3031: 1-8.

Swofford DL. 1993. PAUP: Phylogenetic Analysis Using Parsimony, Version 3.1. Computer program distributed by the Illinois Natural History Survey. Champaign, Illinois.

Taylor WR, Van Dyke GC. 1985. Revised procedures for staining and clearing small fishes and ather vertebrates for bone and cartilage study. Cybium 9(2): 107-119.

Tigano G, Parenti LR. 1988. Homology of the median ethmoid ossifications of Aphanius fasciatus and other atherinomorph fishes. Copeia, 1988: 866-870.

Weitaman SH. 1974. Osteology and evolutionary relationships of the Sternoptychidae, with a new classification for stomiatoid families. Bulletin American Museum of Natural History 153: 329478.

Weitzman SH, Vari RP. 1988. Miniaturization in South American freshwater fishes; an overview and discussion. Proceedings of the Biological Sociaty of Washington 101(2): 444-465.

White BN. 1985. Evolutionary relationships of the Atherinopsinae (Pisces: Atherinidae). Contributions in Science, Natural History Museum of Los Angeles County 368: 1-20.

White BN, Lavenberg RJ, McGowen GE. 1984. Atheriniformes: Development and relationships. In: Moser HG, Richards WJ, Cohen DM, Fahay MP, Kendall Jr AW, Richardson SL, eds. Ontogeny and Systematics of Fishes. Special Publication No.1, American Society of Ichthyologists and Herpetologists, 355-362.

Whitehead PJP, IvantsofirW. 1983. Atherina lacunosa and the fishes described by J. R. Forster. Japanese Joumal of Ichthyology 29(4): 355-364.

Whitley GP. 1951. New fish names and records. Proceedings of the Royal Society of New South Wales 1949-50: $61-68$. 


\title{
APPENDIX 1
}

\author{
Material examined
}

Institutional abbreviations follow Leviton et al. (1985), and the number of cleared-and-stained specimens examined are in parentheses. Genera and species are listed alphabetically within each major grouping.

Percopsiformes: Aphredoderus sayanus FMNH 7282(5), ANSP 116656(5); Percopsis omiscomaycus UMMZ 146339(3).

'Percoids': Elassoma pulchellum UMMZ 133263(10); Elassoma zonatum UMMZ 18047(1); Lepomis megalotis UMMZ 60240(2); Perca flavescens UMMZ 210284(1); Polydactylus approximans UMMZ 190261(4).

Mugilidae: Agonostomus monticola UMMZ 178460(5), UMMZ 199463(3), ANSP 122356(2), FMNH 4623; Crenimugil crenilabis ANSP 114275(1); Joturus pichardi ANSP 99859(1); Liza argentea ANSP 135485(4); Mugil curema UMMZ 209709(3), ANSP 128030(3); Mugil dussumieri ANSP 61891-93(1); Mugil trichodon ANSP 145654(5).

Adrianichthyoidei: Horaichthys setnai UMMZ 201181(1), UMMZ 213443(3), ANSP 157315(4); Oryzias javanicus UMMZ 146566(10), FMNH 68669(5); Oryzias latipes UMMZ 146592(10), UMMZ 218498, FMNH 58732(5); Oryzias melastigma UMMZ uncat(3).

Exocoetoidei: Arrhamphus brevis FMNH 47553, UMMZ 100333; Chriodorus atherinoides UMMZ 143079(4), UMMZ 102192; Cololabis saira FMNH 63758(1), ANSP 88978(1), UMMZ 7.1135; Cypselurus hetesurus ANSP 50519-33(3); Cypselurus starski UMMZ 212929(1); Dermogenys pusilla UMMZ 195917(4); Dermogenys viviparus ANSP 48843-48852(2); Fodiator acutus ANSP 88928(1), UMMZ 190985; Hemirhamphus balao ANSP 111444(1); Hinundichthys affinis ANSP 14973(1); Hyporhamphus unifasciatus ANSP 118641(5), UMMZ 158837(1); Parexocoetus brachypterus ANSP 144887(1); Scomberesox saurus FMNH 48552(2); Strongylura marina ANSP 1 16170(5); Strongylura notata UMMZ 174356(1); Xenentodon cancila ANSP 123993(2); Xenentodon sp. UMMZ 218510(2); Zenarchopterus dispar ANSP 79674(2).

Cyprinodontiformes: Adinia xenica UMMZ 158860(5); Alfaro cultratus ANSP 104371(4); Anableps dowi ANSP 91678(2); Aphyosemion australe ANSP 141548(4); Aphyosemion gulare ANSP 141552(5); Aplocheilichthys spilauchena ANSP 38679-88(2); Chapalichthys pardalis UMMZ 202427(4); Lucania goodei ANSP 140561(5); Cyprinodon variegatus ANSP 95086(5); Epiplatys spilauchen UMMZ 187902(2); Fundulus diaphanus ANSP 90980(4); Fundulus heteroclitus ANSP 116576(5); Fundulus notatus UMMZ 209055(5); Orestias agassii FMNH 77376(2); Profundulus guatemalensis UMMZ 218513(2); Profundulus labialis ANSP 64747-64779(4); Profundulus hildebrandi UMMZ 157634(5); Pterolebias sp. ANSP 141546(4); Rivulus agile FMNH 85368(5); Rivulus bondi UMMZ 141915(10); Rivulus deltaphilus FMNH 70375(4); Rivulus harti FMNH 50098(2); Rivulus hildebrandi ANSP 151286(3); Rivulus marmoratus ANSP 103453(2); Rizulus tenuis FMNH 82194(4); Valencia letoumeuxi UMMZ 213902(3).

Atherinopsinae: Atherinops affinis UMMZ 72212(2); Atherinopsis califomiensis UMMZ 190946(1), UMMZ 68147(3); Odontesthes regia 215521(1), UMMZ 218455(1), UMMZ 215530(1), SU 37431(1); Odontesthes smitti UMMZ 218448(1); Basilichthys sp. UMMZ 215515(1), UMMZ 215520(4), UMMZ 215505(3), UMMZ 218074(3), CAS 42587(3); Colpichthys regis UMMZ 190400(1); Leuresthes tenuis UMMZ 65910(1); Odontesthes hatcheri UMMZ 218450(2); Odontesthes incisa UMMZ 95499(1); Odontesthes penugiae UMMZ 221328(1), UMMZ uncat(1); Odontesthes retropinnis 218796(2).

Menidiinae: Atherinella alvarezi UMMZ 196439(6); Atherinella argentea UMMZ 202408(4); Atherinella crystallina UMMZ 171990(3); Atherinella guatemalensis UMMZ 173523(5); Atherinella sallei UMMZ 184767(3); Chirostoma arge UMMZ 197622(6); Chirostoma chapalae UMMZ 197612(4); Chirostoma estor UMMZ 197650(2); Chirostoma humboldtianum UMMZ 97663(1); Chirostoma jordani UMMZ 197602(5); Chirostoma labarcae UMMZ 193463(3); Chirostoma mezquital UMMZ 211095(3); Chirostoma promelas UMMZ 193465(1); Chirostoma sphyraena UMMZ 186203(1); Labidesthes sicculus UMMZ 222857(3); UMMZ uncat(1); Melanorhinus microps UMMZ 198779(1); Membras sp. UMMZ 202405(1); Membras martinica UMMZ 199183(1); Menidia menidia UMMZ 136589(3); Menidia colei UMMZ 196562(5); Poblana alchichica UMMZ $192371(7)$

Notocheiridae: Notocheirus hubbsi UMMZ uncat(3), IZUC 18406, IZUC 22479; Iso rhothophilus UMMZ 217631(1), UMMZ 212579(2); Iso natalensis USNM uncat(2).

Atherionidae: Atherion elymus UMMZ 204128(1); Atherion sp. USNM 231354(3).

Bedotiinae: Bedotia geayi UMMZ 217630(3), UMMZ 218508(4); Bedotia sp. AMNH 88011(1), UMMZ 218515(2), FMNH 99280(3); Rheocles alaotrensis UMMZ 217679(1), FMNH 99281(1), AMNH 88171(1).

Melanotaeniinae: Chilatherina crassispinosa FMNH 97767(3); Glossolepis multisquamata FMNH 97766(2); Melanotaenia maccullochi UMMZ 218504; Melanotaenia nigrans UMMZ 203847(3); Melanotaenia rubrostriata UMMZ 203849(3); Melanotaenia solata UMMZ 203850(3); Melanotaenia trifasciata UMMZ 218505, UMMZ 218506(2).

Pseudomugilini: Pseudomugil signifer UMMZ 217684(1), ANSP 135502(5), I-081(3); Pseudomugil tenellus UMMZ 203852.

Telmatherinini: Telmatherina ladigesi FMNH 152041(2).

Phallostethidae: Dentatherina merceri UMMZ 217685, FMNH 99632(3); Gulaphallus mirabilis UMMZ 211664(3), ANSP 91045(2); Neostethus sp. UMMZ 211666(3); Ceratostethus bicomis FMNH 51726(10).

Atherinidae: Alepidomus evermanni UMMZ 64226, UMMZ 103358, S90-39(6), MCZ 36165(4); Allanetta mugiloides UMMZ 212569(1), UMMZ 212571(2); Atherina boyeri UMMZ 185092(1); Atherina hepsetus UMMZ 1851 16; Atherina sp. FMNH 77485(2); Atherina mochon FMNH 62520(2); Atherinason hepsetoides UMMZ 212576; Atherinomonus duodecimalis UMMZ 204125(2); Atherinomorus endrachtensis UMMZ 196221, UMMZ 203854(3); Atherinomorus lacunosus FMNH 21107(1), FMNH 21126(1), FMNH 63916(2), FMNH 21206(1), FMNH 21209(1); Atherinomorus insularum FMNH 55704(1); Atherinomorus lineatus FMNH 40800(2); Atherinomorus ogilbyi UMMZ 212573(3); Atherinomorus stipes UMMZ 199482, UMMZ 174207(2), FMNH G72-22(1); Atherinosoma elongata UMMZ 212566(3); Atherinosoma micrastoma 
UMMZ 212562(3), UMMZ 212581; Craterocephalus honoriae UMMZ uncat(5); Craterocephalus gyresi UMMZ 212564(2); Craterocephalus pauciradiatus UMMZ 214554; Hypoatherina bleekeri FMNH 52131(1), FMNH 57459(1); Hypoatherina harringtonensis UMMZ 175987, UMMZ 175992(2), FMNH G74-18(4); Hypoatherina valenciennei UMMZ 191279(3); Kestratherina esox UMMZ 212580, UMMZ 21584(1); Loptatherina presbyteroides UMMZ 212568(5); Leptatherina wallacei UMMZ 209402-(4); Quirichthys stramineus FMNH uncat. (4); Stenatherina hepsetus FMNH 46092(2); Stenatherina ovalaua UMMZ 212578(1); Stenatherina panatela UMMZ 198330; Stenatherina regina FMNH 40475(1), FMNH 40476(1), FMNH 23506(1), FMNH 23507(1); Stenatherina temmincki FMNH 44136(2); Sienatherina sp. FMNH 77487(4), FMNH 84703(4), FMNH 90685(4).

\section{APPENDIX 2}

\section{List of synapomorphies}

Characters preceded by a dash $(-)$ are diagnostic, and those preceded by an asterisk $\left(^{*}\right)$ are additional support to that clade (ambiguously polarized features).

A-----ATHERINIFORMES

-Ch. 1: ventral face of vomer concave.

-Ch. 31: Al lacrimal tendon long, to sub-nasal shelf.

-Ch. 37: two anterior infraorbital bones.

-Ch. 58: pelvic medial plate not extended to anterior tip.

-Ch. 60: pelvic-rib ligament present.

-Ch. 66: second dorsal-fin spine flexible.

-Ch. 74: body depth less than $20 \% \mathrm{SL}$.

-Ch. 75: lateral band present.

-Ch. 78: larval pigmentation pattern.

-Ch. 79: larval preanal length.

-A-ATHERINOPSIDAE

-Ch. 2: ethmomaxillary ligament attached to palatine.

-Ch. 14: posttemporal canal present.

-Ch. 49: absence of pectoral-fin spur (also in Notocheinus).

-Ch. 53: ventral postcleithrum laminar.

-Ch. 54: ventral postcleithrum with two dorsal rami of about equal size.

-Ch. 55: ventral postcleithrum between first and second pleural ribs.

-Ch. 68: interdorsals without ventral shaft.

-Ch. 69: $\geq 3$ pleural ribs posterior to first anal pterygiophore.

-Ch. 82: premaxilla with narrow anterior joint; premaxillary alveolar arm expanded distally; premaxillacoronoid ligament very short and premaxilla-maxilla ligament long; postorbital sphenotic process wide; exoccipital with wing processes; pectoral struts present.

*Ch. 32: Al maxillary tendon to distal half of maxilla.

*Ch. 61: pelvic girdle attached to pleural rib $\geq 6$.

B----ATHERINOIDEI

-Ch. 12: epioccipital wings absent.

-Ch. 18: basisphenoid articulated with prootic only.

-Ch. 35: palatine dorsal process absent

*Ch. 17: pterotic-preopercular sensory canals disconnected (connected in Iso).

*Ch. 20: presence of a parasphenoid fossa (absent in Notocheirus).

*Ch. 26: maxillary posterodorsal spine (absent in Notocheirus).

*Ch. 57: distal end of coracoid wide (narrow in Notocheirus).

*Ch. 71: all sensory canals of the head open.

\section{--NOTOCHEIRIDAE}

-Ch. 47: absence of the supracleithrum.

-Ch. 60: pelvic-rib ligament elongated.

-Ch. 80: pectoral fin and scapula entirely above mid-lateral line; pelvic bone short and flat, with foramen; cleithrum and coracoid elongated, to give greatest body depth at pectoral origin; cleithrum and ventral postcleithrum adjoining fellow at mid-ventral line, expanded ventrally to form abdominal keel with pelvic bones. 
C-----ATHERINES

-Ch. 4: ethmoid cartilage concave medially (rostrum depression).

-Ch. 6: nasal bone in orbit rim, posterior wider than middle.

-Ch. 7: nasal ventromedial ligament to lateral ethmoid.

-Ch. 10: parietals absent

-Ch. 11: presence of intercalars.

-Ch. 50: distal radials of pectoral girdle ossified.

-Ch. 56: scapular foramen shared with coracoid.

-Ch. 64: posterior basal pterygiophores cartilaginous or ossified with medial plate.

*Ch. 3: mesethmoid isolated.

*Ch. 16: pterotic and posttemporal canals disconnected.

*Ch. 59: dorsolateral process of pelvic bone short and stubby, directed anteriorly.

E---MELIANOTAENIIDAE

-Ch. 22: posterior myodome restricted to prootic.

-Ch. 66: absence of second dorsal-fin spine.

-Ch. 69: $\geq 3$ pleural ribs posterior to first anal pterygiophore.

-Ch. 74: body depth greater than $20 \%$ SL.

-Ch. 75: lateral band reduced or absent.

-Ch. 76: sexual dimorphism in body coloration and median fin development.

-BEDOTIINAE

-Ch. 13: pterotic canal absent.

-Ch. 19: parasphenoid ventral ridge extended posteriorly.

-Ch. 67: absence of anal-fin spine (also in Cyprinodontea).

-Ch. 71: mandibular sensory canals enclosed.

E1---MELANOTAENIINAE-PSEUDOMUGLINAE CLADE

-Ch. 28: distal premaxillary teeth enlarged.

*Ch. 29: teeth on external surface of premaxilla.

*Ch. 31: Al mandibular tendon present.

---MELANOTAENIINAE

-Ch. 14: posttemporal canal present.

-Ch. 66: strong or stout second dorsal-fin spine (absent in Rhadinocentrus, Caimsichthys).

*Ch. 62: presence of membrane connecting fifth pelvic-fin ray and body wall (also in pseudomugilins).

-----MELANOTAENIA ( + ) CHILATHERINA

-Ch. 37: three anterior infraorbitals.

-Ch. 40: preopercular-anterior infraorbital canals connected, semi-continuous.

*Ch. 3: enlarged mesethmoid.

---PSEUDOMUGILINAE

-Ch. 7: nasal ventromedial ligament attached to palatine.

-Ch. 23: enlarged submaxillary meniscus.

-Ch. 24: submaxillary meniscus with hyaline-cartilage core.

-Ch. 27: maxillary shaft wide proximally.

-Ch. 32: Al maxillary tendon to distal half of maxilla.

-Ch. 65: anal plate present.

-Ch. 70: ossified PU2vt cartilage.

-PSEUDOMUGILIN

-Ch. 3: absence of a mesethmoid.

-Ch. 13: pterotic canal absent.

-Ch. 33: anterior palatine process directed dorsally.

-Ch. 34: anterior palatine ligament to nasal bone.

-Ch. 36: palatine ventral process reduced or absent.

-Ch. 37: one anterior infraorbital bone (lacrimal).

-Ch. 47: supracleithrum disk-like.

-Ch. 48: cleithrum dorsal enclosure reduced.

-Ch. 51: dorsal postcleithrum absent.

-Ch. 68: interdorsals absent.

*Ch. 62: presence of membrane connecting fifth pelvic-fin ray and body wall. 
--_--TELMATHERININI

-Ch. 37: three anterior infraorbitals

D----ATHERIONIDAE-ATHERINOIDEA CLADE

-Ch. 24: hyaline-cartilage submaxillary meniscus.

-Ch. 37: three anterior infraorbital bones.

-Ch. 41: posterodorsal border of opercle above articulation axis of suspensorium.

*Ch. 5: posterolateral border of the nasal bone straight, posterior naris lateral.

*Ch. 9: bony contact between frontal and lateral ethmoid.

---ATHERIONIDAE

-Ch. 19: parasphenoid ventral ridge extended posteriorly.

-Ch. 31: Al mandibular tendon present.

-Ch. 72: presence of odontodes.

*Ch. 29: teeth on external surface of premaxilla.

*Ch. 40: preopercular-anterior infraorbital canal connected, semi-continuous.

*Ch. 48: absence of cleithrum dorsal enclosure.

\section{F--ATHERINOIDEA}

-Ch. 36: palatine ventral process absent.

-Ch. 44: absence of interopercle dorsal process.

-Ch. 45: absence of urohyal posterodorsal processes.

-Ch. 53: ventral postcleithrum laminar.

-Ch. 54: ventral postcleithrum with dorsal ramus.

-Ch. 58: pelvic medial plate extended to anterior end.

-Ch. 65: presence of anal plate.

*Ch. 14: posttemporal canal present.

*Ch. 23: submaxillary meniscus enlarged.

\section{G----PHALLOSTETHIDAE.}

-Ch. 20: parasphenoid fossa absent.

-Ch. 22: posterior myodome restricted to prootic.

-Ch. 25: presence of paradentary cartilage.

-Ch. 46: uncinate process of first epibranchial absent.

-Ch. 73: small sized adults (s $40 \mathrm{~mm}$ SL).

*Ch. 48: absence of cleithrum dorsal enclosure.

\section{G1---PHALLOSTETHINAE}

-Ch. 11: intercalar absent.

-Ch. 13: pterotic canal absent.

-Ch. 22: posterior myodome absent.

-Ch. 37: two anterior infraorbital bones.

-Ch. 41: posterodorsal border of opercle below articulation axis of suspensorium.

-Ch. 47: supracleithrum disk-like.

-Ch. 66: second dorsal-fin spine absent.

-Ch. 77: priapium; asymmetric males; dorsal hypohyal absent; first dorsal reduced or absent; ventral keel (also in Iso \& Kiunga).

*Ch. 24: hyaline-cartilage submaxillary meniscus ossified.

*Ch. 28: premaxillary distal teeth enlarged.

*Ch. 68: interdorsals absent or fused.

---PHALLOSTETHINI

-Ch. 83: phallostethin priapial characters (Parenti, 1989)

--GULAPHALIINI

-Ch. 49: pectoral-fin spur absent.

\section{--DENTATHERININA}

-Ch. 6: nasal not reaching orbit rim, middle of bone wider.

-Ch. 50: distal radials of pectoral girdle cartilaginous.

*Ch. 17: preopercular-dermosphenotic sensory canals connected.

*Ch. 24: hyaline-cartilage submaxillary meniscus calcified.

*Ch. 59: pelvic dorsolateral process directed posteriorly.

*Ch. 68: interdorsals without ventral shaft. 
H---ATHERINIDAE

-Ch. 38: lacrimal notch present.

-Ch. 55: ventral postcleithrum between first and second pleural ribs.

-Ch. 63: pelvic ventral spine present.

*Ch. 40: preopercular-anterior infraorbital canals connected, fully continuous.

*Ch. 71: mandibular sensory canals enclosed (except in Alepidomus).

H1---ATHERINOMORINAE

-Ch. 15: posttemporal canal oriented along dorsal arm of posttemporal bone.

-Ch. 21: parasphenoid fossa with ventral fenestra.

-Ch. 24: fibrocartilage submaxillary meniscus.

-Ch. 42: hyomandibular foramen present.

---ALEPIDOMUS

-Ch. 36: palatine ventral process present.

-Ch. 44: dorsal process of interopercle present.

-Ch. 70: ossified PU2vt (also in pseudomugilines).

HIA--ATHERINOMORINAE (-) ALEPIDOMUS CLADE

-Ch. 39: infraorbital two with notch in sensory canal.

-Ch. 43: preopercular notch of sensory canal present.

-Ch. 52: dorsal postcleithrum elongated.

---ATHERINOMORUS (+) HYPOATHERINA

-Ch. 29: teeth on external surface of premaxilla.

-Ch. 30: villiform patch of teeth on jaws.

H2----ATHERININAE-CRATEROCEPHALINE CLADE

-Ch. 7: nasal ventromedial ligament to palatine.

-Ch. 33: anterior palatine process directed dorsally.

*Ch. 23: submaxillary meniscus enlarged, barrel-like.

H3---ATHERININAE

-Ch. 31: Al mandibular tendon present.

-Ch. 61: pelvic process attached to pleural rib six to eight.

*Ch. 2: thin ethmomaxillary ligament to posterodorsal region of lateral ethmoid.

*Ch. 34: anterior palatine ligament to nasal.

H3A--ATHERININAE (-) ATHERINOSOMA CLADE

-Ch. 6: nasal not in orbit rim, middle as narrow as posterior border.

----ATHERINA $(+)$ KESTRATHERINA

-Ch. 40: preopercular-anterior infraorbital connection absent.

-Ch. 59: pelvic dorsolateral process oriented posterodorsally.

H4---CRATEROCEPHALINAE

-Ch. 8: nasal ventral process present.

-Ch. 19: parasphenoid ventral ridge extended posteriorly.

-Ch. 20: parasphenoid fossa absent.

-Ch. 27: maxillary shaft wide proximally.

-Ch. 33: anterior palatine process and ligament absent.

-Ch. 59: pelvic dorsolateral process absent.

*Ch. 2: ethmomaxillary ligament absent.

---CRATEROCEPHALUS ( + ) QUIRICHTHYS

-Ch. 41: posterodorsal border of opercle below articulation axis of suspensorium with neurocranium.

*Ch. 3: mesethmoid absent. 